\title{
A production-tagged aerosol module for Earth system models, OsloAero5.3 - extensions and updates for CAM5.3-Oslo
}

\author{
Alf Kirkevåg ${ }^{1}$, Alf Grini ${ }^{1}$, Dirk Olivié ${ }^{1}$, Øyvind Seland ${ }^{1}$, Kari Alterskjær ${ }^{2,3}$, Matthias Hummel $^{3}$, Inger H. H. Karset ${ }^{3}$, \\ Anna Lewinschal ${ }^{4}$, Xiaohong Liu ${ }^{5}$, Risto Makkonen ${ }^{6,7}$, Ingo Bethke ${ }^{8}$, Jan Griesfeller ${ }^{1}$, Michael Schulz ${ }^{1}$, and \\ Trond Iversen ${ }^{1,2}$ \\ ${ }^{1}$ Norwegian Meteorological Institute, P.O. Box 43, Blindern, 0313 Oslo, Norway \\ ${ }^{2}$ CICERO Center for International Climate Research, 0349 Oslo, Norway \\ ${ }^{3}$ Department of Geosciences, Section for Meteorology and Oceanography, University of Oslo, 1022 Oslo, Norway \\ ${ }^{4}$ Department of Meteorology, Stockholm University, 10691 Stockholm, Sweden \\ ${ }^{5}$ Department of Atmospheric Science, University of Wyoming, Laramie, Wyoming 82071, USA \\ ${ }^{6}$ Institute for Atmospheric and Earth System Research/Physics, Faculty of Science, P.O. Box 64, 00014, \\ University of Helsinki, Helsinki, Finland \\ ${ }^{7}$ Climate System Research, Finnish Meteorological Institute, P.O. Box 503, 00101, Helsinki, Finland \\ ${ }^{8}$ Uni Research Climate, Bjerknes Centre for Climate Research, P.O. Box 7810, 5020 Bergen, Norway
}

Correspondence: Alf Kirkevåg (alfk@met.no)

Received: 19 February 2018 - Discussion started: 31 May 2018

Revised: 28 August 2018 - Accepted: 30 August 2018 - Published: 1 October 2018

\begin{abstract}
We document model updates and present and discuss modeling and validation results from a further developed production-tagged aerosol module, OsloAero5.3, for use in Earth system models. The aerosol module has in this study been implemented and applied in CAM5.3-Oslo. This model is based on CAM5.3-CESM1.2 and its own predecessor model version CAM4-Oslo. OsloAero5.3 has improved treatment of emissions, aerosol chemistry, particle life cycle, and aerosol-cloud interactions compared to its predecessor OsloAero4.0 in CAM4-Oslo. The main new features consist of improved aerosol sources; the module now explicitly accounts for aerosol particle nucleation and secondary organic aerosol production, with new emissions schemes also for sea salt, dimethyl sulfide (DMS), and marine primary organics. Mineral dust emissions are updated as well, adopting the formulation of CESM1.2. The improved model representation of aerosol-cloud interactions now resolves heterogeneous ice nucleation based on black carbon (BC) and mineral dust calculated by the model and treats the activation of cloud condensation nuclei $(\mathrm{CCN})$ as in CAM5.3. Compared to OsloAero4.0 in CAM4-Oslo, the black carbon (BC) mass concentrations are less excessive aloft, with a better fit to observations. Near-surface mass concentrations of BC and
\end{abstract}

sea salt aerosols are also less biased, while sulfate and mineral dust are slightly more biased. Although appearing quite similar for CAM5.3-Oslo and CAM4-Oslo, the validation results for organic matter (OM) are inconclusive, since both of the respective versions of OsloAero are equipped with a limited number of OM tracers for the sake of computational efficiency. Any information about the assumed mass ratios of OM to organic carbon (OC) for different types of OM sources is lost in the transport module. Assuming that observed OC concentrations scaled by 1.4 are representative for the modeled OM concentrations, CAM5.3-Oslo with OsloAero5.3 is slightly inferior for the very sparsely available observation data. Comparing clear-sky column-integrated optical properties with data from ground-based remote sensing, we find a negative bias in optical depth globally; however, it is not as strong as in CAM4-Oslo, but has positive biases in some areas typically dominated by mineral dust emissions. Aerosol absorption has a larger negative bias than the optical depth globally. This is reflected in a lower positive bias in areas where mineral dust is the main contributor to absorption. Globally, the low bias in absorption is smaller than in CAM4-Oslo. The Ångström parameter exhibits small biases both globally and regionally, suggesting that the aerosol par- 
ticle sizes are reasonably well represented. Cloud-top droplet number concentrations over oceans are generally underestimated compared to satellite retrievals, but seem to be overestimated downwind of major emissions of dust and biomass burning sources. Finally, we find small changes in direct radiative forcing at the top of the atmosphere, while the cloud radiative forcing due to anthropogenic aerosols is now more negative than in CAM4-Oslo, being on the strong side compared to the multi-model estimate in IPCC AR5. Although not all validation results in this study show improvement for the present CAM5.3-Oslo version, the extended and updated aerosol module OsloAero5.3 is more advanced and applicable than its predecessor OsloAero4.0, as it includes new parameterizations that more readily facilitate sensitivity and process studies and use in climate and Earth system model studies in general.

\section{Introduction}

Humans influence the production of aerosols (microscopic solid and liquid particles suspended in air) in various ways, giving rise to local and regional air pollution. Furthermore, Earth's climate can be influenced by aerosols, either directly through changes to the scattering and absorption of solar radiation or more indirectly through the effects these particles have on cloud properties and precipitation. Numerical modeling of Earth's climate therefore requires a description of aerosols in which mass and number concentrations and chemical composition as a function of size are important properties.

Even without going all the way in calculating how aerosols impact climate by including slow responses and feedbacks through atmospheric and ocean-atmosphere interactions that can be simulated in fully coupled climate models or Earth system models (ESMs), one may quantify a first-order effect on Earth's radiative budget in partly uncoupled model configurations through estimates of the so-called aerosol radiative forcing. It is common to distinguish between the traditional concepts of radiative forcing (RF) and the effective radiative forcing (ERF), which includes rapid adjustments that modify the radiative budget through fast atmospheric and surface changes (IPCC AR5: Boucher et al., 2013; Myhre et al., 2013). ERF from aerosols can furthermore be decomposed into a forcing term due to aerosol-radiation interactions (ERFari), which includes the traditional direct effect and semi-direct effects (as rapid adjustments to atmospheric heating by absorbing aerosols), and an aerosol-cloud interaction term (ERFaci) (Boucher et al., 2013), which includes the cloud albedo effect (Twomey, 1977) and associated adjustments in the form of lifetime effects (e.g., Albrecht, 1989). In this study we follow the method outlined by Ghan (2013) for calculating the effective radiative forcing of aerosols, which is decomposed into a direct radiative forcing, a cloud radia- tive forcing, and a surface albedo forcing term. In contrast to the terminology used in IPCC AR5, the semi-direct effect is integrated into the cloud radiative forcing term here.

Traditionally, mainly two methods have been used to calculate aerosol size and chemical composition. Modal approaches (e.g., Binkowski and Shankar, 1995) approximate the aerosol size distribution as lognormal distributions. Sectional methods (e.g., Bergman et al., 2012) discretize the size distribution into fixed size intervals that have constant properties. In a sectional aerosol module the size distribution does not have to be lognormal or of any other specified shape and is generally considered to be closer to "first principles".

An alternative "production-tagged" aerosol module is used in the atmospheric component (CAM-Oslo) of the Norwegian Earth System Model (NorESM) and in various predecessor model versions. This aerosol module has been documented in Kirkevåg et al. (2013) for CAM4-Oslo (NorESM1) and in earlier studies (Kirkevåg et al., 1999, 2005, 2008; Kirkevåg and Iversen, 2002; Iversen and Seland, 2002, 2003; Seland et al., 2008). The productiontagged method describes a number of "background" lognormal modes. These modes can change their size distribution due to condensation, coagulation, and cloud processing. The corresponding aerosol microphysical calculations are performed in a detailed size-resolving model and run offline. A selection of results in terms of bulk properties from these aerosol microphysics calculations are stored in lookup tables, which during the NorESM model simulation provide information about aerosol optical parameters as well as size and composition where needed (for details, see Sect. 2.1 in Kirkevåg et al., 2013). Production-tagged refers to the fact that the tracers which change the aerosol size distribution represent their production pathway (e.g., condensation, coagulation, and cloud processing). We will refer to the online aerosol module as OsloAero and to the offline sizeresolving model that produces the lookup tables as AeroTab. Although the aerosol module has been developed over many years and already been used in numerous model versions, it has previously not been given any name or version number. For the purpose of simplicity and clarity in the intercomparison of the respective module versions, we hereafter denote the OsloAero module described and used by Kirkevåg et al. (2013) as OsloAero4.0 and the present version as OsloAero5.3. We similarly denote the respective versions of the offline size-resolving lookup table model as AeroTab4.0 (Kirkevåg et al., 2013) and AeroTab5.3.

In this work we have ported OsloAero to the Community Atmospheric Model version CAM5.3 (Neale et al., 2012; Liu et al., 2016) so that it exists as an option alongside the CAM modal aerosol modules (MAM3 and MAM7). We hereafter refer to the atmospheric model including OsloAero5.3 and the AeroTab5.3-produced lookup tables as CAM5.3-Oslo. CAM5.3 is part of the Community Earth System Model version 1.2, CESM1.2 (http://www. cesm.ucar.edu/models/cesm1.2, last access: 24 September 
2018). The Norwegian Earth System Model version based on CESM1.2, which we name NorESM1.2, uses CAM5.3Oslo instead of CAM5.3 and an updated MICOM version based on NorESM1 (Bentsen et al., 2013) instead of POP2 as the ocean model, while the land model CLM4.5, the sea ice model CICE4, and the coupler CPL7 are all as in CESM1.2. In this study we do not make use of the fully coupled model system, but prescribe sea surface temperatures and sea ice fractions (i.e., an AMIP setup). In the following discussions we therefore just refer to the model as CAM5.3-Oslo.

CAM5.3-Oslo is after some final updates and tuning planned to be merged with the atmospheric component, CAM6, from the upcoming release of the NCAR/DOE Community Earth System Model, CESM2 (http://www. cesm.ucar.edu/working_groups/Atmosphere/, last access: 24 September 2018). This merged version is expected to be the atmospheric component of NorESM2. NorESM2 is planned to participate in the Coupled Model Intercomparison Project 6 (CMIP6). NorESM1.2 (using a further adapted and tuned version of CAM5.3-Oslo) is at present a fallback version and may be used in the early phases of CMIP6 if NorESM2 is not finalized in time. Two versions of NorESM1, NorESM1M (Bentsen et al., 2013; Iversen et al., 2013; Kirkevåg et al., 2013) and NorESM1-ME (Tjiputra et al., 2013), contributed with results for CMIP5 and were analyzed together with the other CMIP5-contributing models in IPCC AR5 (Myhre et al., 2013).

The main purpose of this study is to document the changes in the treatment of aerosols and aerosol-cloud interactions since the predecessor model version CAM4-Oslo, as well as to summarize the main principles behind the aerosol schemes applied in earlier and the present model versions. We then evaluate CAM5.3-Oslo's performance with respect to various aerosol and cloud droplet properties and present and discuss new estimates of effective radiative forcing, both for comparison with results from CAM4-Oslo and other CMIP5 models.

The article is organized as follows: Sect. 2 describes the model components that have changed since Kirkevåg et al. (2013), with an emphasis on the aerosol module. Section 3 describes the model configurations used in this study. Section 4 compares the aerosol and cloud droplet concentrations and optical properties to observations and remote retrievals, as well as to previous studies wherever feasible. Section 5 puts the results into a climate context by discussing the effective radiative forcing due to aerosol-radiation and aerosolcloud interactions, before presenting the summary and conclusions in Sect. 6.

\section{Aerosol model description}

OsloAero5.3, as it is implemented in CAM5.3, applies the same method of aerosol activation (Abdul-Razzak and Ghan, 2000), transport, and transition between aerosols in the inter- stitial and cloud phase as in Liu et al. (2012), with the simplifications proposed by Ghan and Easter (2006) that cloudborne aerosols are not advected, except by vertical turbulent mixing. An important feature of CAM5.3 is that it includes a general chemical solver (CAM-Chem) as well as a standardized chemical code preprocessor (MOZART; Emmons et al., 2010), which OsloAero5.3 (unlike earlier versions) makes use of. The sulfur chemistry is now also as in Liu et al. (2012), except for the DMS + OH addition reaction in which $75 \%$ of the reaction product is $\mathrm{SO}_{2}$ (as in Pozzoli et al., 2008) compared to $50 \%$ in Liu et al. (2012). However, the treatments of nucleation and secondary organic aerosols differ, as in many other processes that are specific to CAM5.3Oslo, i.e., to OsloAero5.3 and AeroTab5.3.

Since Kirkevåg et al. (2013) (CAM4-Oslo), several improvements have been made to OsloAero and AeroTab. These updates will be described in detail in this section, but may be briefly summarized as follows. Aerosol nucleation and secondary organic aerosols have been taken explicitly into account based on Makkonen et al. (2014), with some extensions. Sea salt emissions and emission sizes have been changed to those of Salter et al. (2015). Dimethyl sulfide (DMS) and oceanic primary organics are now emitted from concentration- and wind-driven parameterizations (Nightingale et al., 2000; Vignati et al., 2010), and dust emissions are calculated online based on Zender et al. (2003). Aerosol hygroscopicity and a few other microphysical properties have also been changed since CAM4-Oslo. Finally, heterogeneous ice nucleation is implemented based on Wang et al. (2014), which was based on a modified version of the scheme in CAM3-Oslo (Hoose et al., 2010).

\subsection{The production-tagged aerosol module}

The production-tagged aerosol module has been used previously in many studies. The life-cycling component of the online aerosol module we now call OsloAero was first developed and described by Seland and Iversen (1999) and Iversen and Seland (2002, 2003). The offline size-resolving aerosol model we call AeroTab, including table lookups and interpolations with respect to aerosol-radiation and aerosol-cloud interaction calculations in OsloAero, was first developed and described by Kirkevåg et al. (1999) and Kirkevåg and Iversen (2002), with some updates by Kirkevåg et al. (2005). Later versions of both components of the production-tagged aerosol module as a whole are described by Seland et al. (2008) and Kirkevåg et al. (2008), and Kirkevåg et al. (2013), hereafter referred to as K13. The essential difference to other aerosol module treatments is the division of tracers into "background" and "process" tracers. Background tracers, which are mainly primary emitted particles (nucleation being the exception), form lognormal modes and contribute to the aerosol number concentration. The process tracers change the shape and chemical composition of the initially lognormal background modes. Examples of pro- 
Table 1. Transported aerosol tracers included in OsloAero5.3. The aerosol precursor and oxidant gas tracers transported by the model are $\mathrm{SO}_{2}, \mathrm{H}_{2} \mathrm{SO}_{4}$, DMS, isoprene, monoterpene, SOAG_LV, SOAG_SV, and $\mathrm{H}_{2} \mathrm{O}_{2}$.

\begin{tabular}{|c|c|c|}
\hline Tracer variable ID & $\begin{array}{l}\text { Meaning } \\
\text { S4: } \mathrm{SO}_{4} \text { (particulate sulfate); SOA: secondary organic aerosol; } \\
\text { BC: black carbon; OM: primary organic matter; SS: sea salt; } \\
\text { DU: DST (mineral dust) }\end{array}$ & Notation in Fig. 1 \\
\hline SO4_NA & $\mathrm{SO}_{4}$ formed by co-nucleation with SOA & $\mathrm{S} 4(\mathrm{n})$ \\
\hline SO4_A1 & $\mathrm{SO}_{4}$ condensate on existing particles from $\mathrm{H}_{2} \mathrm{SO}_{4}$ (gas) & S4 (yellow) \\
\hline SO4_A2 & $\mathrm{SO}_{4}$ formed from aqueous-phase chemistry & S4 \\
\hline SO4_AC & $\mathrm{SO}_{4}$ particles coagulated with other particles & $\mathrm{S} 4(\mathrm{ac}), \mathrm{S} 4(\mathrm{c})$ \\
\hline SO4_PR & $\mathrm{SO}_{4}$ primary emissions, emitted as particles & $\mathrm{S} 4(\mathrm{ac})$ \\
\hline SOA_NA & SOA formed by co-nucleation with $\mathrm{SO}_{4}$ & $\operatorname{SOA}(\mathrm{a})$ \\
\hline SOA_A1 & SOA condensate on existing particles from $\mathrm{SOAG}_{\mathrm{SV}}$ (gas) & SOA (yellow) \\
\hline BC_N & BC emitted externally mixed as nucleation sized mode & $\mathrm{BC}(\mathrm{n})$ \\
\hline BC_AX & BC emitted externally mixed as fractal accumulation mode & $\mathrm{BC}(\mathrm{ac})$ \\
\hline BC_NI & BC emitted internally mixed with OM, Aitken mode & $\mathrm{OM} / \mathrm{BC}(\mathrm{a})$ \\
\hline BC_A & BC coated with water-solubles, Aitken mode & $\mathrm{OM} / \mathrm{BC}(\mathrm{a})$ \\
\hline BC_AI & BC coexisting with $\mathrm{OM}$ and coated Aitken mode & $\mathrm{OM} / \mathrm{BC}(\mathrm{a}), \mathrm{BC}(\mathrm{a})$ \\
\hline BC_AC & $\mathrm{BC}$ particles coagulated with other aerosols (coagulate) & $\mathrm{BC}(\mathrm{ac}), \mathrm{BC}(\mathrm{c})$ \\
\hline OM_NI & OM emitted internally mixed with $\mathrm{BC}$, Aitken mode & $\mathrm{OM} / \mathrm{BC}(\mathrm{a})$ \\
\hline OM_AI & OM coexisting with $\mathrm{BC}$ and coated, Aitken mode & $\mathrm{OM} / \mathrm{BC}(\mathrm{a})$ \\
\hline OM_AC & $\begin{array}{l}\text { OM and SOA particles coagulated with other aerosols } \\
\text { (coagulate) }\end{array}$ & $\begin{array}{l}\mathrm{OM}(\mathrm{ac}), \mathrm{OM}(\mathrm{c}) \\
\mathrm{SOA}(\mathrm{ac}), \mathrm{SOA}(\mathrm{c})\end{array}$ \\
\hline DST_A2 & Mineral dust, accumulation mode & $\mathrm{DU}(\mathrm{ac})$ \\
\hline DST_A3 & Mineral dust, coarse mode & $\mathrm{DU}(\mathrm{c})$ \\
\hline SS_A1 & Sea salt aerosol, Aitken mode & SS(a) \\
\hline SS_A2 & Sea salt aerosol, accumulation mode & $\mathrm{SS}(\mathrm{ac})$ \\
\hline SS_A3 & Sea salt aerosol, coarse mode & $\mathrm{SS}(\mathrm{c})$ \\
\hline
\end{tabular}

cess tracers are sulfate condensate, sulfate coagulate, sulfate from cloud processing (aqueous-phase chemistry in cloud droplets, followed by evaporation), and secondary organic aerosol (SOA) condensate. All tracers that are calculated explicitly are listed in Table 1 .

For gas-phase and aqueous aerosol chemistry, concentrations of $\mathrm{OH}, \mathrm{NO}_{3}, \mathrm{O}_{3}$, and $\mathrm{HO}_{2}$ are prescribed (see also Karset et al., 2018) as time-varying climatological 3D monthly mean fields from simulations with the global stratosphere-troposphere chemistry model CAM-chem v3.5 in the study of Lamarque et al. (2010), representative for conditions in the year $2000 . \mathrm{H}_{2} \mathrm{O}_{2}$ is calculated as in Liu et al. (2012) and depends on the prescribed (monthly averaged) $\mathrm{HO}_{2}$ concentrations.

As soon as the aerosol background modes have changed composition and shape, we refer to them as "mixtures". Because the resulting size-distribution from AeroTab is no longer lognormal and "modes" are traditionally used for aerosol size distributions that are lognormal, the term mixture is used in order to avoid confusion. The resulting mixtures, which the lookup tables are based on, are given in Table 2. The table shows which tracers are assumed to be background tracers (lognormally distributed at the point of emission or production) and which tracers are purely size and composition modifying. OsloAero calculates how much of each "modifying" tracer should be distributed onto each of the background modes (thus forming mixtures of mass from the various tracers) within a time step. When that fraction is known, interpolations in the lookup tables (generated by AeroTab) return the optical properties or the best lognormal fit (in terms of modal median radius and standard deviation) of the final dry size distribution of that mode after growth. The assumed standard deviation of the initially lognormal size distributions and the accommodation coefficients for each of the mixtures are still as in Table 1 in K13.

Concerning the basic principles behind the productiontagged aerosol module (see K13 and references therein), we may look at it as a three-stage process over a time step in the model. First, during atmospheric transport the background aerosol tracers are assigned typical tropospheric dry sizes (i.e., the sizes at the point of emission, augmented to take into account atmospheric growth for the finest particles; mixture nos. 1-4 in Table 2). The size-modifying aerosol tracers are also assigned prescribed sizes (see Table 2). Their respective sizes after hygroscopic growth, calculated as in OsloAero4.0 (K13), are eventually used for the calculation of dry deposition, in which both types of aerosol tracers are treated as if they were separate particles. Secondly, when the size distribution resulting from aerosol microphysics is needed, the mass of the size-modifying tracers is distributed onto the dif- 
Table 2. Distribution of aerosol tracers in the particle mixtures treated in the model. Tracer names in bold and italic fonts are background tracers, while the others are tracers that modify the size distribution. The initial number median dry radius (NMR) and standard deviation (SIGMA) of each background mode are listed in the second and third column. Also listed (with numbers in brackets) are the prescribed dry NMR values assumed during transport (including atmospheric growth) for the finest particle mixtures (nos. 1, 2, and 4). For other mixtures, the dry sizes of transported tracers are assumed to be identical to the initial sizes. Note that for historical reasons, particle mixture numbers 3,11 , and 13 do not exist in the present model version. For the sake of consistency and transparency, the numbering is the same as in the model code. Assumed dry size parameters for the size-modifying tracers during transport: NMR =0.04 $\mu$ m and SIGMA = 1.8 for SO4_A1; $\mathrm{NMR}=0.1 \mu \mathrm{m}$ and SIGMA $=1.59$ for SO4_A2, SO4_AC,OM_AC, BC_AC, and SOA_A1.

\begin{tabular}{|c|c|c|c|c|c|c|c|c|c|c|}
\hline $\begin{array}{l}\text { Particle } \\
\text { mixture no. }\end{array}$ & NMR & $(\mu \mathrm{m})$ & SIGMA & Aerosol tra & cers (cf. Tab & 1) contribu & ing to the $p$ & ticle mixture & & \\
\hline 0 & 0.0626 & & 1.6 & $B C \_A X$ & & & & & & \\
\hline 1 & 0.0118 & $(0.025)$ & 1.8 & SO4_NA & SOA_NA & SO4_A1 & SOA_A1 & & & \\
\hline 2 & 0.024 & $(0.025)$ & 1.8 & $B C \_A$ & SO4_A1 & SOA_A1 & & & & \\
\hline 4 & 0.04 & $(0.06)$ & 1.8 & $O M_{-} A I$ & BC_AI & SO4_A1 & SO4_A2 & SOA_A1 & & \\
\hline 5 & 0.075 & & 1.59 & SO4_PR & BC_AC & OM_AC & SO4_A1 & SO4_AC & SO4_A2 & SOA_A1 \\
\hline 6 & 0.22 & & 1.59 & $D S T \_A 2$ & BC_AC & OM_AC & SO4_A1 & SO4_AC & SO4_A2 & SOA_A1 \\
\hline 7 & 0.63 & & 2.0 & $D S T \_A 3$ & BC_AC & OM_AC & SO4_A1 & SO4_AC & SO4_A2 & SOA_A1 \\
\hline 8 & 0.0475 & & 2.1 & $S S \_A 1$ & BC_AC & OM_AC & SO4_A1 & SO4_AC & SO4_A2 & SOA_A1 \\
\hline 9 & 0.3 & & 1.72 & $S S \_A 2$ & BC_AC & OM_AC & SO4_A1 & SO4_AC & SO4_A2 & SOA_A1 \\
\hline 10 & 0.750 & & 1.6 & $S S \_A 3$ & BC_AC & OM_AC & SO4_A1 & SO4_AC & SO4_A2 & SOA_A1 \\
\hline 12 & 0.024 & & 1.8 & $B C_{-} N$ & & & & & & \\
\hline 14 & 0.04 & & 1.8 & $O M_{-} N I$ & BC_NI & & & & & \\
\hline
\end{tabular}

ferent background size modes according to how large the sink is for the tracer in question, estimated online following Kirkevåg et al. (1999). For example, the amount of condensate added to a background mode is proportional to the background mode's condensation sink (prior to growth). Finally, the mass of these mixture-apportioned tracers is fed into the interpolation code connected to the lookup tables, giving us estimated sizes and optical properties. The lookup tables have been calculated offline by using AeroTab5.3 based on the fully size-resolved (with 44 size bins) solution to the continuity equations for particle number and mass concentrations (Kirkevåg et al., 1999) after aerosol growth. Note that the full size distribution (i.e., number concentration for each size bin) is not stored in these lookup tables, but rather the subsequent bulk (i.e., size-integrated) parameters that are required by the atmospheric model, such as single scattering albedo, asymmetry factor, and mass specific extinction, in addition to lognormal fits to the dry size distributions after growth. Tabulated aerosol optical parameters include the effect of humidity swelling.

Using this technique, we lose information about which sizes were modified by which tracer in the past, since the detailed size information is lumped back into a limited number of tracers before atmospheric transport. However, we gain computational efficiency since the technique requires fewer transported tracers. The size of the aerosol mixtures, i.e., of background tracers including growth by process tracers, could in principle be estimated by using the tabulated size parameters for the particle mixtures in the previous time step. Such a link has not yet been implemented in the model, but is something that should be investigated and tested in future model versions.

The total number of transported aerosol and gas tracers in OsloAero5.3 is 29 (21 aerosol and 8 gas tracers; see Table 1) compared to 20 (15 and 5) in MAM3 and 37 (31 and 6) in MAM7. Comparing CAM5.3-Oslo simulations using OsloAero5.3 with MAM3, we find a ca. $49 \%$ increase in model cost (50\% for the atmosphere module alone). Much of the relatively large increase in model cost compared to MAM3 is due to the multidimensional table lookups and interpolation calculations for aerosol optical properties and sizes in OsloAero5.3. For comparison, according to Liu et al. (2012), CAM5.1 set up with MAM7 runs about $30 \%$ slower than with MAM3.

\subsection{Secondary organic aerosols and nucleation}

The treatment of secondary organic aerosol (SOA) and nucleation has been much improved since K13, for which SOA was simply prescribed as a monthly surface source, and nucleation (sulfate only) was implicitly determined by the amount of available $\mathrm{H}_{2} \mathrm{SO}_{4}$ left after condensation during a model time step. The treatment is now based on Makkonen et al. (2014), hereafter referred to as M14, who implemented emissions of monoterpene and isoprene in a research version of NorESM1-M (see also Boy et al., 2018). These SOA precursors are oxidized by $\mathrm{OH}, \mathrm{O}_{3}$, and $\mathrm{NO}_{3}$.

The chemical reactions and assumed yields ( 0.15 and 0.05 ) are given below, with reaction rates (not shown) taken from IUPAC (Atkinson et al., 2004, 2006). These yields are similar to values used in other studies (e.g., Mann et al., 2010; 


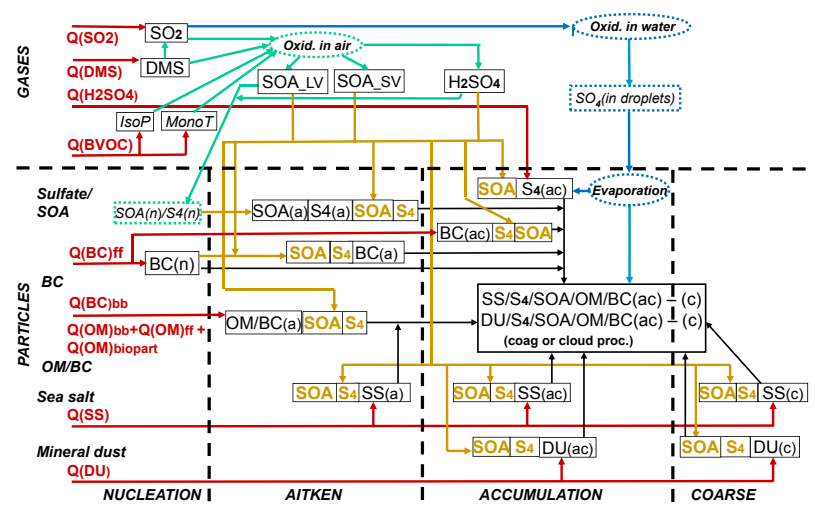

Figure 1. Flow diagram of processes in the aerosol module OsloAero5.3. The source terms to the left, labeled $Q(X) y$, where $X$ is the constituent name and $y$ is the source type, can be primary emissions or secondary production. The source labels $y=b b$, ff, or biopart indicate biomass burning, fossil fuel or biofuel combustion, and biogenic particle sources. Primary particles are emitted (red arrows) as accumulation-mode sulfate (S4(ac)), nucleationand accumulation-mode black carbon $(\mathrm{BC}(\mathrm{n}), \mathrm{BC}(\mathrm{ac}))$, Aitkenmode $\mathrm{BC}(\mathrm{BC}(\mathrm{a}))$, internally mixed Aitken-mode organic matter and black carbon (OM/BC(a)), Aitken-, accumulation-, and coarse-mode sea salt (SS(a), SS(ac), SS(c)), and accumulationand coarse-mode mineral dust (DU(ac), DU(c)). Model-calculated gas-phase components are DMS, $\mathrm{SO}_{2}$, isoprene (IsoP), monoterpene (MonoT), $\mathrm{H}_{2} \mathrm{SO}_{4}$, and gaseous secondary organics $\left(\mathrm{SOAG}_{\mathrm{LV}}\right.$ and $\mathrm{SOAG}_{\mathrm{SV}}$ ). $\mathrm{SOAG}_{\mathrm{LV}}$ partly co-nucleates with nucleation-mode sulfate (S4(n), SOA(n), turquoise arrows) and partly condensates (yellow arrows) on existing particle surfaces, while $\mathrm{SOAG}_{\mathrm{SV}}$ only forms SOA through condensation. Sulfate produced in cloud water droplets (SO4(in droplets), blue arrow) is partly added to S4(ac) and partly to a broad internal mixture of accumulation- and coarse-mode particles coagulated with either mineral dust or sea salt. Black arrows represent coagulation that contributes to the latter two particle types. Components in dashed boxes are not explicitly calculated.

Tsigaridis et al., 2014).

$$
\begin{aligned}
& \text { monoterpene }+\mathrm{O}_{3} \rightarrow 0.15 \cdot \mathrm{SOAG}_{\mathrm{LV}} \\
& \text { monoterpene }+\mathrm{OH} \rightarrow 0.15 \cdot \mathrm{SOAG}_{\mathrm{SV}} \\
& \text { monoterpene }+\mathrm{NO}_{3} \rightarrow 0.15 \cdot \mathrm{SOAG}_{\mathrm{SV}} \\
& \text { isoprene }+\mathrm{OH} \rightarrow 0.05 \cdot \mathrm{SOAG} \\
& \text { isoprene }+\mathrm{O}_{3} \rightarrow 0.05 \cdot \mathrm{SOAG}_{\mathrm{SV}} \\
& \text { isoprene }+\mathrm{NO}_{3} \rightarrow 0.05 \cdot \mathrm{SOAG}_{\mathrm{SV}}
\end{aligned}
$$

The idea of separating $\mathrm{SOAG}_{\mathrm{SV}}$ and $\mathrm{SOAG}_{\mathrm{LV}}$ is that the SOA gas (SOAG) tracer labeled "SV" is assumed to be semi-volatile, with an equilibrium vapor pressure too high to contribute to new particle formation but instead goes to condensation. In addition to contributing to condensation, the tracer labeled "LV" is assumed to be low volatile enough to also contribute to particle nucleation and subsequent aerosol growth below the number median radius of the SO4_N/SOA_N mixture (mixture no. 1 in Table 2). Only low-volatile products are assumed to take part in new particle formation as described by Kulmala et al. (2004). In M14, low-volatile products are only assumed to form in the reaction between monoterpene and $\mathrm{O}_{3}$. This choice is supported by an observed correlation between growth rates of 7-20 nm (in diameter) aerosol and monoterpene ozonolysis (Yli-Juuti et al., 2011), as well as the relatively higher yield of extremely low-volatility organic compounds (ELVOCs) from $\mathrm{O}_{3}$ compared to $\mathrm{OH}$ reaction with monoterpenes (Jokinen et al., 2015). The fractions of monoterpene and isoprene that do not react to form SOA gas in Reactions (R1)-(R6) are not taken into account, assuming that they form other gas or aerosol products that we do not track in the model. This approach is a good way to resolve oxidant-mediated variations in SOA production and is suitable for global aerosol models with simplified aerosol precursor chemistry schemes (e.g., Spracklen et al., 2008). We also note that, since the model uses the "offline oxidant approach", Reactions (R1) to (R6) need only resolve one product, meaning that the products of the second reactants (the oxidants) do not need to be included on the right-hand side of the chemical equations. While methanesulfonic acid (MSA) in K13 was emitted directly into the OM_NI tracer as primary OM, we now also treat MSA as a biogenic VOC that may form SOA, assuming that $20 \%$ and $80 \%$ of the mass is added to the $\mathrm{SOAG}_{\mathrm{LV}}$ and $\mathrm{SOAG}_{\mathrm{SV}}$ tracers, respectively (see Fig. 1). The exact LV-to$\mathrm{SV}$ ratio is unknown, but some of the MSA is of low enough volatility to contribute to nucleation and subsequent growth (Chen et al., 2017; Willis et al., 2016).

The concentrations of the condensable gases $\mathrm{H}_{2} \mathrm{SO}_{4}$, $\mathrm{SOAG}_{\mathrm{LV}}$, and $\mathrm{SOAG}_{\mathrm{SV}}$ are calculated based on the production rates from the gas-phase chemistry solver MOZART (Horowitz et al., 2003). The solver is configured to use the chemical mechanism used in K13 with the additional reactions for SOA. The chemical mechanisms in OsloAero5.3, for sulfur and oxidant chemistry as well as the SOA chemistry in Reactions (R1)-(R6), have been described in more detail by Karset et al. (2018, Sect. 2). For an overview of the chemical reactions and the respective reaction rate coefficients, see Table 2 in Karset et al. (2018).

Furthermore, only a fraction of the $\mathrm{SOAG}_{\mathrm{LV}}$ oxidation products $(50 \%$, as in M14) is assumed to be low volatile enough to nucleate or condense onto nucleation-sized particles, while the remaining fraction and the semi-volatile tracer is allowed to condense on preexisting particles. $\mathrm{Bi}$ nary nucleation of $\mathrm{H}_{2} \mathrm{SO}_{4}$ vapor is based on Vehkamäki et al. (2002). Boundary layer nucleation is implemented according to several semi-empirical parameterizations from Paasonen et al. (2010). For the present model version and the simulations in this study we have used Eq. (18) in Paasonen et al. (2010).

After nucleation, particles grow further by condensation of sulfuric acid and organic vapors. Growth of nucleated clusters to the particle size of the corresponding mixture treated in the model (see Table 2) is based on Lehtinen et al. (2007). 
The organic vapors available for this transition have been found to be very important for the growth of atmospheric particles (Riipinen et al., 2011; Keskinen et al., 2013).

The condensation sink is known from the surface area of the background aerosols. After the gas-phase chemistry is treated in the model, the concentrations of the condensable gases are set back to their value from the start of the time step, and the following equation is solved to obtain concentrations at the end of the time step:

$\frac{\mathrm{d} C_{\mathrm{gas}}}{\mathrm{d} t}=P_{\mathrm{gas}}+L_{\mathrm{cond}} \cdot C_{\mathrm{gas}}-L_{\mathrm{nuc}} \cdot C_{\mathrm{gas}}$,

where $L_{\text {cond }}$ is the loss rate $\left(\mathrm{s}^{-1}\right)$ for condensation and $L_{\text {nuc }}$ is the loss rate $\left(\mathrm{s}^{-1}\right)$ due to nucleation for the condensing gas. Since $L_{\text {nuc }}$ is dependent on the concentration we perform one iteration before the equation is solved with an Euler backwards method to obtain the concentration at the end of the time step $C_{\text {gas,new. }}$ In the first iteration, $L_{\text {nuc }}$ is zero. The resulting gas-phase concentration from the first iteration is used to calculate the nucleation rate. When the concentration at the end of the time step has been found with the Euler backwards method, the tendency is calculated as

$\frac{\mathrm{d} C_{\text {gas }}}{\mathrm{d} t}=\left(C_{\text {gas,new }}-C_{\text {gas,old }}\right) / \mathrm{d} t$.

Nucleated particles from $\mathrm{SOAG}_{\mathrm{LV}}$ and $\mathrm{H}_{2} \mathrm{SO}_{4}$ have much smaller diameters $\left(d_{\text {nuc }} \sim 1-3 \mathrm{~nm}\right)$ than the respective aerosol mixture in CAM5.3-Oslo (mixture no. 1 in Table 2), which has a median modal diameter $\left(d_{x}\right)$ of $23.6 \mathrm{~nm}$. The smallest particles can either coagulate with the background particles or grow by condensation of $\mathrm{SOAG}_{\mathrm{LV}}$ and $\mathrm{H}_{2} \mathrm{SO}_{4}$ until they reach sizes that have a longer lifetime with respect to coagulation. The following formula (Eq. 7 in Lehtinen et al., 2007; see also M14) gives the rate $J_{x}$ at which particles of size $d_{x}$ form, growing from nucleation size to that of the corresponding mixture (no. 1) in the model:

$$
\begin{aligned}
J_{x} & =J_{\mathrm{nuc}} \cdot \exp \left(-\gamma \cdot d_{\mathrm{nuc}} \frac{\operatorname{CoagS}\left(d_{\mathrm{nuc}}\right)}{\mathrm{GR}}\right) \\
\gamma & =\frac{1}{m+1}\left[\left(\frac{d_{x}}{d_{\mathrm{nuc}}}\right)^{m+1}-1\right]
\end{aligned}
$$

Here $J_{\text {nuc }}$ is the nucleation rate of $d_{\text {nuc }}$ sized particles, CoagS is the coagulation sink, and GR is the rate of particle growth due to condensation. The factor $\gamma$ is expressed as a function of $d_{\text {nuc }}$ and $d_{x}$, as well as a background sizedependent exponent $m$. Here we simply let $m=-1.6$ (as in M14), which is a typical value for atmospheric conditions (Lehtinen et al., 2007). The formation rate is in other words determined by the concentration of sulfuric acid and organic vapors available for condensational growth and by the coagulation sink of the newly formed particles onto preexisting aerosols.

There are four important differences in the SOA treatment compared to M14.
1. We close the mass balance both for $\mathrm{H}_{2} \mathrm{SO}_{4}$ and for organic vapors, while M14 put nucleated mass into the model as $\mathrm{H}_{2} \mathrm{SO}_{4}$, thus allowing sulfur mass to be produced by organic vapors. Unlike the M14 study, which focused on changes in aerosol life cycling but not on the radiative effects of SOA, the lookup tables for optics and sizes with respect to aerosol-radiation and aerosolcloud interactions are now also taking into account SOA.

2. We add the non-nucleated vapor as condensate. The condensate is only added through condensation on preexisting particles and does not produce new particles. In M14, non-nucleated vapor was added to the tracer representing primary organics. Since primary organics is a background tracer in OsloAero5.3, increasing primary organic mass also increases aerosol number concentration. In the updated treatment condensate does not increase particle number concentrations (unless it leads to increased nucleation rates).

3. M14 assumed secondary organic aerosol formation only from monoterpenes. In this work both monoterpenes and isoprene are assumed to produce SOA mass. Still only monoterpene ozonolysis products are allowed to produce new particles by nucleation (via $\mathrm{SOAG}_{\mathrm{LV}}$ ).

4. We now also make use of interactive emissions of SOA precursors from CLM4.5 using the MEGAN v2.1 (Guenther et al., 2012) algorithm instead of reading them in from file. This allows us to study the effects of a changing climate on SOA formation and facilitates feedback studies. We lump 21 monoterpene species (myrcene, sabinene, limonene, 3-carene, $\mathrm{t}$ - $\beta$-ocimene, $\beta$-pinene, $\alpha$-pinene, dimethyl styrene, p-cymene, o-cymene, $\alpha$-phellandrene, $\alpha$-thujene, $\alpha$ terpinene, $\gamma$-terpinene, terpinolene, $\beta$-phellandrene, camphene, bornene, $\alpha$-fenchene, allo-ocimene, and cis$\beta$-ocimene) into one atmospheric monoterpene tracer.

The main advantages of the new treatment of SOA in this study compared to M14 are that the atmospheric composition influences the aerosol size distribution and particle number, as well as its optical properties, that SOA is allowed to form outside the boundary layer, and that the use of interactive biogenic volatile organic compound (BVOC) emissions, including MSA from the ocean surface, facilitates studies of the effects of climate change on SOA formation, as well as on subsequent feedbacks.

\subsection{Aerosol microphysics}

Diffusion coefficients for condensable gases have been calculated based on Eqs. (11)-(4.4) and Table 11-1 in Poling et al. (2001). For SOA, which was not explicitly treated in the predecessor model CAM4-Oslo (K13), we use a molecular weight of $168.2\left(\mathrm{~g} \mathrm{~mol}^{-1}\right)$, corresponding to $\mathrm{C}_{10} \mathrm{H}_{16} \mathrm{O}_{2}$ as 
our assumed representative SOA molecule. Due to a lack of exact information about the large range of possible organic compounds we call SOA, for simplicity and computational efficiency we assume SOA to have the same microphysical properties (mass density, hygroscopicity, refractive index) as OM in the model, i.e., both in AeroTab5.3 and OsloAero5.3. A bug in the life cycle scheme (OsloAero4.0; K13) that produced too-slow growth by condensation has also been found and rectified in OsloAero5.3. The effect of this is discussed to some degree by Iversen et al. (2017).

Mass densities and refractive indices are unchanged from K13, except for $\mathrm{BC}$ and mineral dust. For BC we have adopted the recommendations by Bond and Bergström (2006) of using a monomer mass density of $1800 \mathrm{~kg} \mathrm{~m}^{-3}$ and a refractive index of $m=1.95-0.79 i$ (assumed to be wavelength independent). The refractive index for mineral dust has also been modified. This now follows Hess et al. (1998) for all wavelengths, which gives somewhat more light absorption by dust than in K13.

Modal number median radii and standard deviations for background tracers at the point of emissions (Table 2) are as in CAM4-Oslo, except for BC and sea salt (SS_A1, SS_A2, and SS_A3). Sea salt particle sizes have been changed to fit the new emission parameterization by Salter et al. (2015).

NMR for mixture nos. 2 and 12 (BC_A and BC_N from fossil fuel combustion) has been ca. doubled (to $24 \mathrm{~nm}$ ) compared to CAM4-Oslo $(11.8 \mathrm{~nm})$ in order to account for some growth from the $\mathrm{BC}$ monomer size near the emission source to a more representative model grid mean value. This NMR is consistent with observations of somewhat aged $\mathrm{BC}$ mass size distributions of diesel exhaust and urban aerosol (Ning et al., 2013) and has also been shown to give more realistic aerosol number concentrations in a version of CAM4-Oslo with improved nucleation parameterization (M14). The new NMR is also more in line with the Aitken-mode fossil fuel carbonaceous particle size assumptions applied by the participating models in the multi-model AeroCom aerosol microphysics model intercomparison study (Mann et al., 2014), which were in the range $15-40 \mathrm{~nm}$. We note, however, that most of those models emitted particles as mixed BC-POM particles, so the size for a pure $\mathrm{BC}$ emission mode is not exactly comparable.

The externally mixed BC_AX mixture is a "fluffy" fractalstructured agglomerate consisting of $\mathrm{BC} \_\mathrm{N}$ particles assumed to be formed by rapid self-coagulation in exhaust from fossil fuel combustion. We keep the standard deviation $($ SIGMA $=1.6)$ as in K13, but have reduced NMR from 0.1 to $0.0626 \mu \mathrm{m}$ in order to conserve number concentrations as BC_AX gets coated and ages into BC_AI. We keep the assumed fractal dimension $D$ (Ström et al., 1992) as in CAM4Oslo; i.e., $D=2.5$.

One aerosol tracer has been removed compared to CAM4Oslo, namely the nucleation-mode sulfate (SO4_N, originally mixture no. 11 in Table 2). This was done in order to save computational cost and has been found to affect

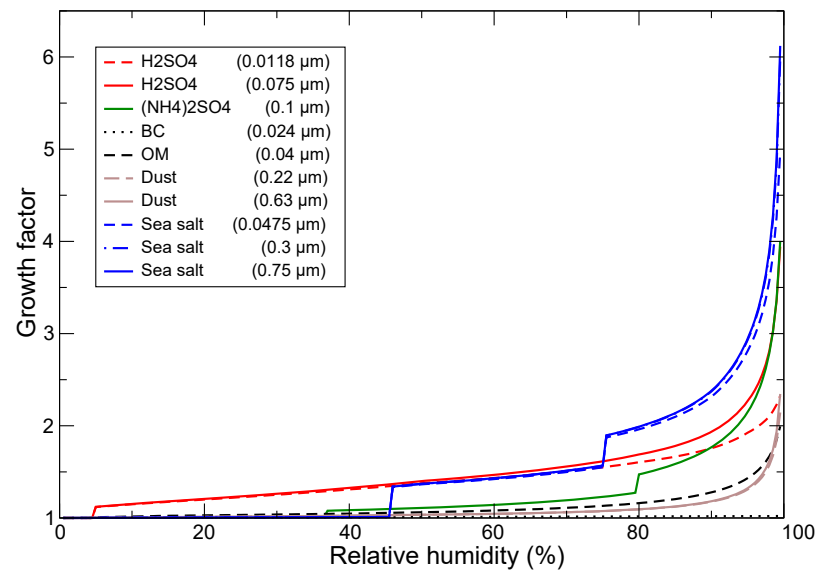

Figure 2. Hygroscopic growth factors (wet-ambient radius divided by dry radius) for aerosol components at some typical dry radii and for relative humidities up to $\mathrm{RH}_{\max }=99.5 \%$, as treated in AeroTab5.3 and the optics lookup tables. Note that the growth factor curve for sea salt at dry radius $0.3 \mu \mathrm{m}$ is not visible due to overlap with that for $0.75 \mu \mathrm{m}$. To relate this figure to the nomenclature in Table 2, $\mathrm{H}_{2} \mathrm{SO}_{4}$ (sulfuric acid) may come as SO4_NA, SO4_PR, or SO4_A1, $\left(\mathrm{NH}_{4}\right)_{2} \mathrm{SO}_{4}$ (ammonium sulfate) as SO4_A2, BC as BC_AX, BC_N, BC_NI, or BC_A, OM as OM_NI, OM_AI, SOA_NI, or SOA_A1, mineral dust as DST_A2 or DST_A3, and sea salt as SS_A1, SS_A2, or SS_A3.

the overall life-cycling properties with respect to, e.g., sulfate concentrations and atmospheric residence times negligibly. This tracer was originally introduced to help mimic the growth in time from freshly nucleated sulfate particles (with a fixed size and composition) to aged particles. Since the assumed chemical composition (with respect to life cycling in OsloAero) in effect is quite similar to those of the aged particles, the division between those two aerosol tracers, despite their somewhat different sizes, has been found unnecessary in OsloAero5.3.

Although the aerosol scheme is different from that of Liu et al. (2012), we use the same method for calculating the aging of externally mixed $\mathrm{BC}$ and organic aerosols. The layer thickness of SOA and sulfate condensate collected by the externally mixed species BC_N and BC_AX must exceed three monolayers (sulfate equivalent) before transitioning to the respective coated or aged particle mixtures is allowed. In K13 the BC_AX mixture was assumed to be large enough so that aging by condensation could be ignored, an assumption that was based on near-surface measurements of $\mathrm{BC}$ in the remote Arctic. However, the extreme conditions in Arctic winter are not representative of conditions elsewhere, and this assumption contributed to the somewhat exaggerated upper troposphere mass concentrations of $\mathrm{BC}$ that were modeled in CAM4-Oslo.

Hygroscopicities have also been modified somewhat, both with respect to internal consistency and simplicity. The new treatment ensures that the hygroscopicity of an aerosol 
mixture for humidity swelling (for use with the offline optics calculations in AeroTab5.3) at slight sub-saturation $(\mathrm{RH}=99.5 \%)$ is the same as the value used for calculating activation to cloud droplets at supersaturated conditions (online in OsloAero5.3). These two cases were treated independently and could be slightly different in OsloAero4.0. The new growth factors (i.e., wet radius divided by dry radius) for RH values up to the cutoff value of $99.5 \%$, hereafter referred to as $\mathrm{RH}_{\max }$, are shown in Fig. 2.

For BC we now assume a very low hygroscopicity of $B=5.0 \times 10^{-7}$ (Ghan et al., 2001) for all relative humidities. In CAM4-Oslo BC was assumed to be entirely hydrophobic $(B=0)$ in calculations of hygroscopic swelling, but $B=8.9 \times 10^{-7}$ with respect to $\mathrm{CCN}$ activation. Although the hygroscopicity for $\mathrm{CCN}$ activation is nearly halved since CAM4-Oslo, the values are already so small that the effect of this on cloud droplet production is probably negligible.

For ammonium sulfate we assume that $B=0.507$ (Ghan et al., 2001) at $\mathrm{RH}_{\max }$ and at supersaturated conditions. This value is the same as in CAM4-Oslo with respect to CCN activation, but larger than what was used for hygroscopic growth at $\mathrm{RH}_{\max }(0.434)$. Instead of imposing a linear growth in the hysteresis domain, i.e., for RH $=37-80 \%$ (Tang and Munkelwitz, 1994; Tang, 1996) as in CAM4-Oslo, we simply assume here that $B$ is reduced to the half $(B=0.2535)$ between the points of crystallization and deliquescence. Below the point of crystallization, the hygroscopicity is assumed to be the same as for $\mathrm{BC}$ (i.e., very low) compared to 0 in CAM4-Oslo.

While sulfate in OsloAero5.3 is consistently treated as ammonium sulfate, just as in CAM5.3 (Liu et al., 2012), in AeroTab5.3 we still (as in AeroTab4.0) treat both nucleated sulfate particles and condensate (SO4_NA and SO4_A1, respectively) as sulfuric acid with respect to hygroscopicity. This hygroscopicity is now parameterized to vary with $\mathrm{RH}$ in such a way that the growth factor equals that of $\mathrm{H}_{2} \mathrm{SO}_{4}$ (for a range of RH values from $50 \%$ to $99 \%$ ) in Table 2 in Köpke et al. (1997). By solving the Köhler equation, $B$ is then estimated to be 0.534 at $\mathrm{RH}=99 \%$ (and assumed to be the same at $\mathrm{RH}_{\max }$ ) compared to 0.646 in CAM4-Oslo.

For sea salt we have inferred the $B$ values from Köpke et al. (1997) and then reduced the values by $50 \%$ in the hysteresis domain, i.e., for $\mathrm{RH}=46-75 \%$ (Tang and Munkelwitz, 1994; Tang, 1996). This gives $B=1.20$ at $\mathrm{RH}_{\max }$, which is slightly larger than the CAM4-Oslo $B$ values of 1.15 at $\mathrm{RH}_{\max }$ and 1.16 for CCN activation (as in Ghan et al., 2001).

The OM hygroscopicity is assumed to be 0.14 (Ghan et al., 2001) for all RH values, slightly below the $B$ value of 0.158 at $\mathrm{RH}_{\max }$ but the same $B$ value with respect to $\mathrm{CCN}$ activation as in CAM4-Oslo.

For mineral dust a $B$ value of 0.069 has been chosen, consistent with a ca. $10 \%$ soluble mass fraction of dust. This is a high-range value of the "less-hygroscopic" dust category in Koehler et al. (2009). In CAM4-Oslo much lower values were assumed: $B=4.8 \times 10^{-5}$ at $\mathrm{RH}_{\max }$ and $B=0.015$ with respect to $\mathrm{CCN}$ activation. However, the new $B$ value is still low compared to the value 0.14 assumed by Ghan et al. (2001).

In this model version, as in CAM4-Oslo, hygroscopicity with respect to $\mathrm{CCN}$ activation is not calculated within AeroTab. AeroTab instead provides lookup tables of aerosol size parameters for each mixture, which in addition to $B$ is used as input to the activation code (Abdul-Razzak and Ghan, 2000). The hygroscopicity is calculated as a mass-weighted $B$ for mixtures that are uncoated or have a thin coating of soluble components (i.e., sulfate, OM, and/or sea salt) and as a mass-weighted $B$ of the coating itself when the coating is sufficiently thick. This threshold coating thickness is assumed to be $2 \mathrm{~nm}$, as in K13.

\subsection{Emission fluxes}

DMS and biogenic OM emissions from the ocean have been updated to be wind driven. In K13 DMS emissions were taken from Dentener et al. (2006) and given as daily averages. Biogenic OM was assumed to have the same spatial distribution as the fine mode of sea salt emissions given in Dentener et al. (2006) and scaled to the global number in Spracklen et al. (2008). The DMS emissions are now instead given as the product of the transfer velocity and the ocean DMS molar concentration:

$F_{\mathrm{DMS}}=C \cdot k_{600} \cdot M_{\mathrm{DMS}} \cdot C_{\mathrm{DMS}}$.

Here $\mathrm{F}_{\mathrm{DMS}}$ is the flux of DMS $\left(\mathrm{kg} \mathrm{m}^{-2} \mathrm{~s}^{-1}\right), C$ is a unit conversion coefficient in the model code (not a tuning factor), $C_{\mathrm{DMS}}$ is the DMS concentration in the ocean given as monthly averages by Lana et al. (2011), $M_{\text {DMS }}$ is the molar mass of DMS, and $k_{600}$ is a transfer coefficient $\left(\mathrm{cm} \mathrm{h}^{-1}\right)$ from Nightingale et al. (2000):

$k_{600}=0.222 \cdot U_{10}^{2}+0.333 \cdot U_{10}$,

where $U_{10}$ is the $10 \mathrm{~m}$ wind speed.

The flux of oceanic primary organic aerosols is given by O'Dowd et al. (2008) and Vignati et al. (2010) to be proportional to the submicron sea salt flux of the finest mode (SS_A1) and to the (monthly) organic matter concentration fraction in the water. Vignati et al. (2010) give the OM fraction as

$\mathrm{OM}_{\mathrm{frac}}=0.435 \cdot \rho_{\mathrm{Chl} \mathrm{a}}+0.13805$.

$\mathrm{OM}_{\text {frac }}$ is saturated at $90 \%$ according to O'Dowd et al. (2008). $\rho_{\mathrm{Chl}}$ a is the mass concentration of chlorophyll $a$ $\left(\mathrm{mg} \mathrm{m}^{-3}\right)$ in the surface water using SeaWiFS climatology (O'Reilly et al., 2000). A tuning constant has been added to the equation so that the OM flux from the ocean (still) matches the estimate of Spracklen et al. (2008) of approximately $8 \mathrm{Tg} \mathrm{yr}^{-1}$.

The treatment of sea salt fluxes in K13 has been changed to the formulation used for CAM4-Oslo in Salter et al. (2015), 


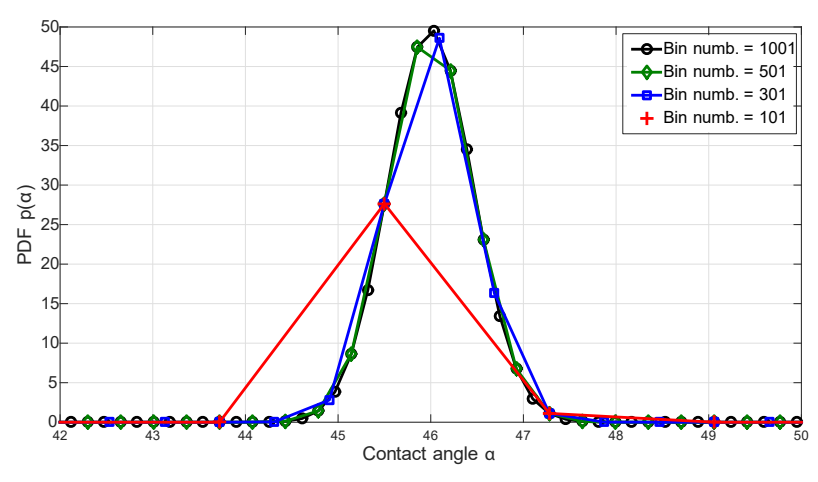

Figure 3. Probability $p(\alpha)$ of the $\alpha$-PDF model used for calculating the contact angle for immersion freezing. Different bin numbers are tested in order to correct the numerical formulation that is used in Wang et al. (2014).

both being functions of near-surface wind and sea surface temperature. Dust sources were prescribed in K13. They are now wind driven and calculated from the Dust Entrainment and Deposition (DEAD) model (Zender et al., 2003), which is implemented in the Community Land Model and is made available to OsloAero5.3. The parameterization is the same as that used by Liu et al. (2012), but fitted to the dust aerosol sizes used in OsloAero5.3.

As described in Sect. 2.2, the biogenic emissions of monoterpene and isoprene are calculated online (called every time step, which is $30 \mathrm{~min}$ ) from MEGAN (Guenther et al., 2012). The oxidant fields are prescribed as monthly averages but with a daily variation superimposed for $\mathrm{OH}$ and $\mathrm{HO}_{2}$ and are therefore decoupled from the BVOC concentrations.

For aerosol and precursors not mentioned above, as in $\mathrm{K} 13$, the emissions are taken from the IPCC AR5/CMIP5 (Lamarque et al., 2010) for the year 2000 (for simplicity called present day, PD) and 1850 (preindustrial, PI) conditions. The emissions and their vertical distribution are essentially the same as those used by Liu et al. (2012): the IPCC AR5 emission data set includes anthropogenic emissions for primary aerosol species $\mathrm{OC}$ and $\mathrm{BC}$, as well as the precursor gas $\mathrm{SO}_{2}$. We assume that $2.5 \%$ of the sulfur emissions are emitted directly as primary sulfate aerosols and the rest as $\mathrm{SO}_{2}$. Anthropogenic emissions are defined as originating from industrial, energy, transportation, domestic, and agricultural activity sectors.

\subsection{Heterogeneous ice nucleation}

In this new version of CAM5.3-Oslo, the stochastic nature of freezing is considered for heterogeneous freezing in mixedphase clouds, which is described according to classical nucleation theory (CNT; Pruppacher and Klett, 1997). Dust (DST_A2 and DST_A3) and black carbon (BC_AI) can act as ice nucleating particles (INP). Water molecules can form small agglomerates of ice on the surface of INP, and if these ice clusters reach a critical size the thermodynamic energy barrier $\Delta G$ of the water-ice transformation is passed.

A common formulation for the ice nucleation rate is used for deposition and immersion freezing, as well as for contact nucleation, which is identical to Eq. (1) in Wang et al. (2014). Deposition freezing and contact nucleation take place if the particles are uncoated or not completely coated. The coating thickness is calculated from the coated volume of the tracers and the volume of the dust and black carbon cores. The particle ability to act as INP in these mixtures is suppressed if the coated volume exceeds the thickness of one monolayer of sulfate. Particles can be coated according to Table 2. Immersion freezing is allowed to take place on cloud-borne dust and black carbon, which becomes cloud-borne when interstitial particles merge with an already existing droplet or act as condensation nuclei themselves.

Two different approaches are considered for describing the contact angle for immersion freezing. The single contact angle $(\alpha)$ model is similar to previous descriptions with CNT (Hoose et al., 2010). An $\alpha$-PDF model can also be applied for dust immersion freezing, in which the contact angle is formulated by a lognormal probability density function (Wang et al., 2014). Thus, the inhomogeneity within the aerosol population can be represented by accounting for differences in the individual particle's ice nucleation properties (described in detail by Wang et al., 2014).

Compared to the study of Wang et al. (2014), we have used a small correction to the $\alpha$-PDF model, which is also being taken into account in later releases of CAM versions by the National Center for Atmospheric Research (NCAR). The original calculation of the probability $p(\alpha)$ in the $\alpha$-PDF model relies on a bin number of 101, which we have found to be too small to represent the lognormal distribution with a small standard deviation $\sigma$ (e.g., 0.01) properly (Fig. 3). This resulted in an unphysical lower limit of the activated fraction of INP so that the INP activated fraction values were not able to fall below this limit and therefore stayed constant above a certain temperature (e.g., at $\sim 5 \times 10^{-5}$ for $T>-15^{\circ} \mathrm{C}$ in Fig. 1 in Wang et al., 2014). By increasing the bin number to 501, the distribution can be described more accurately (Fig. 3) and the unphysical behavior of the activated fraction is no longer present.

\section{Model configuration and simulation setup}

All simulations have been run with $0.9^{\circ}$ (latitude) by $1.25^{\circ}$ (longitude) horizontal resolution and with 30 layers in the vertical. In hybrid sigma pressure coordinates, the uppermost eta level (or top of the level) mid-value is $3.64(2.26) \mathrm{hPa}$, and for the lowermost level it is $992.56(985.11) \mathrm{hPa}$. The number of layers below approximately 1 and $2 \mathrm{~km}$ of height a.s.1. are five and eight, respectively. CAM5.3, and therefore also CAM5.3-Oslo, has two choices for stratiform microphysical cloud schemes: MG1.0 (Morrison and Gettelman, 
Table 3. Overview of the experiments in this study. Note that the land model (CLM4.5) setup is for a PD climate, so BVOC emissions are based on PD land use. All simulations have been run with $0.9^{\circ} \times 1.25^{\circ}$ horizontal resolution and with 30 layers in the vertical.

\begin{tabular}{llrr}
\hline Name & Meteorology & Emission year & $\begin{array}{r}\text { Years simulated } \\
\text { (years analyzed) }\end{array}$ \\
\hline NUDGE_PD & ERA-Interim & 2000 & $\begin{array}{r}2004-2010 \\
(2006-2010)\end{array}$ \\
NUDGE_PI & ERA-Interim & 1850 & $2004-2010$ \\
& & & $(2006-2010)$ \\
AMIP_PD & CAM5.3-Oslo/AMIP & 2000 & $1-30(3-30)$ \\
AMIP_PI & CAM5.3-Oslo/AMIP & 1850 & $1-30(3-30)$ \\
\hline
\end{tabular}

2008) and MG1.5 (Gettelman and Morrison, 2015). Both are double-moment (i.e., mass and number predicting) bulk cloud microphysics schemes with prognostic cloud droplet and cloud ice mass mixing ratios and number concentrations. MG1.5 is an update of the original formulation MG1, in which the location for updating prognostic droplet number mixing ratios with the tendency for droplet activation has been moved to the beginning of the scheme. We have in this study used MG1.5. The land model CLM4.5 (Oleson et al., 2013) is configured with satellite-observed phenology.

Two different configurations have been used to study and evaluate the aerosols: the nudged configuration (in the NUDGE_PD and NUDGE_PI simulations) and the AMIP configuration (in the AMIP_PD and AMIP_PI simulations); see Table 3 for an overview. The model has been run with aerosol and aerosol precursor emissions from year 2000 (PD) and 1850 (PI) for both configurations. We have also used PD oxidant levels in the PI simulations, as in K13. The effects of using PI oxidant levels on the effective radiative forcing in CAM5.3-Oslo, and on the indirect effects in particular, are being studied by Karset et al. (2018). Only the aerosol and aerosol precursor emissions or concentrations differ between the PD and PI simulations, while greenhouse gas concentrations, land use, and prescribed SSTs and sea ice concentrations are identical. The concentrations of DMS and biogenic $\mathrm{OM}$ in the ocean surface layer are also the same, although the emissions of these into the atmosphere differ slightly due to different meteorological conditions.

The difference between the AMIP and the nudged configuration is that the latter includes additional terms to the dynamical equations that push (nudge) the model meteorology towards the observed (or reanalyzed, read in 6-hourly, and interpolated in time) meteorology using a relaxation time of $6 \mathrm{~h}$ (Kooperman et al., 2012; Zhang et al., 2014). The main purpose of using the nudged configuration is to constrain natural variability, as a significantly higher number of simulated years is required to isolate statistically significant differences in cloud radiative forcing (due to anthropogenic aerosols) with the free AMIP configuration (Kooperman et al., 2012). Another objective is to obtain a model meteorology that more closely resembles actual meteorological con- ditions during the period of observations, which the model is compared with in the aerosol and cloud validation in Sect. 4. We have run both configurations in order to verify that the results are coherent and to be able to study how much the nudging affects the results.

In the nudged configuration, we use meteorological data from ERA-Interim (Berrisford et al., 2011) for the period 2004-2010. We nudge only to horizontal winds and surface pressures (Zhang et al., 2014). This way of nudging will allow the aerosols to influence temperatures and clouds. While nudging to observed temperatures might also improve the comparison of aerosol properties with observations, leaving the temperature un-nudged is important for the calculation of the indirect and semi-direct effect of aerosols (Zhang et al., 2014), since these are most realistically (or at least consistently) estimated with the model's own vertical temperature gradients, which again are crucial for atmospheric stability and vertical mixing.

\section{Results and discussion}

The predecessor model version CAM4-Oslo has been extensively validated and compared with other models through the AeroCom project (Aerosol Comparisons between Observations and Models: http://aerocom.met.no, last access: 24 September 2018) in studies by Jiao et al. (2014), Tsigaridis et al. (2014), Kipling et al. (2016), and Koffi et al. (2016), as well as in K13. A separate evaluation of CAM4-Oslo and other CMIP5 models by using the remote sensing of aerosols in the Arctic was made by Glantz et al. (2014). In this section we attempt to answer the following question: how does CAM5.3-Oslo perform with respect to aerosol and aerosolrelated cloud properties compared with observations? We first compare some of the results with CAM4-Oslo (K13) and other studies, both in order to discuss properties that cannot easily (or at all) be compared with observations and to be able to see whether the updates and extended physical parameterizations have improved the model performance with respect to aerosols or not. The latter question is not straightforward, since the host model itself has undergone a great number of changes in moving from CAM4 to CAM5.3. Additionally, CAM4-Oslo was run with a coarser horizontal resolution of $2^{\circ}$.

\subsection{Concentrations and budgets}

\subsubsection{Budgets and vertical profiles}

Table 4 shows the budgets for the different species in the model simulations. For each term in the table, results from both present day (PD) and preindustrial (PI) conditions are listed, together with the respective values found in K13. Unless otherwise stated, the discussed model values are from the NUDGE_PD simulation. 

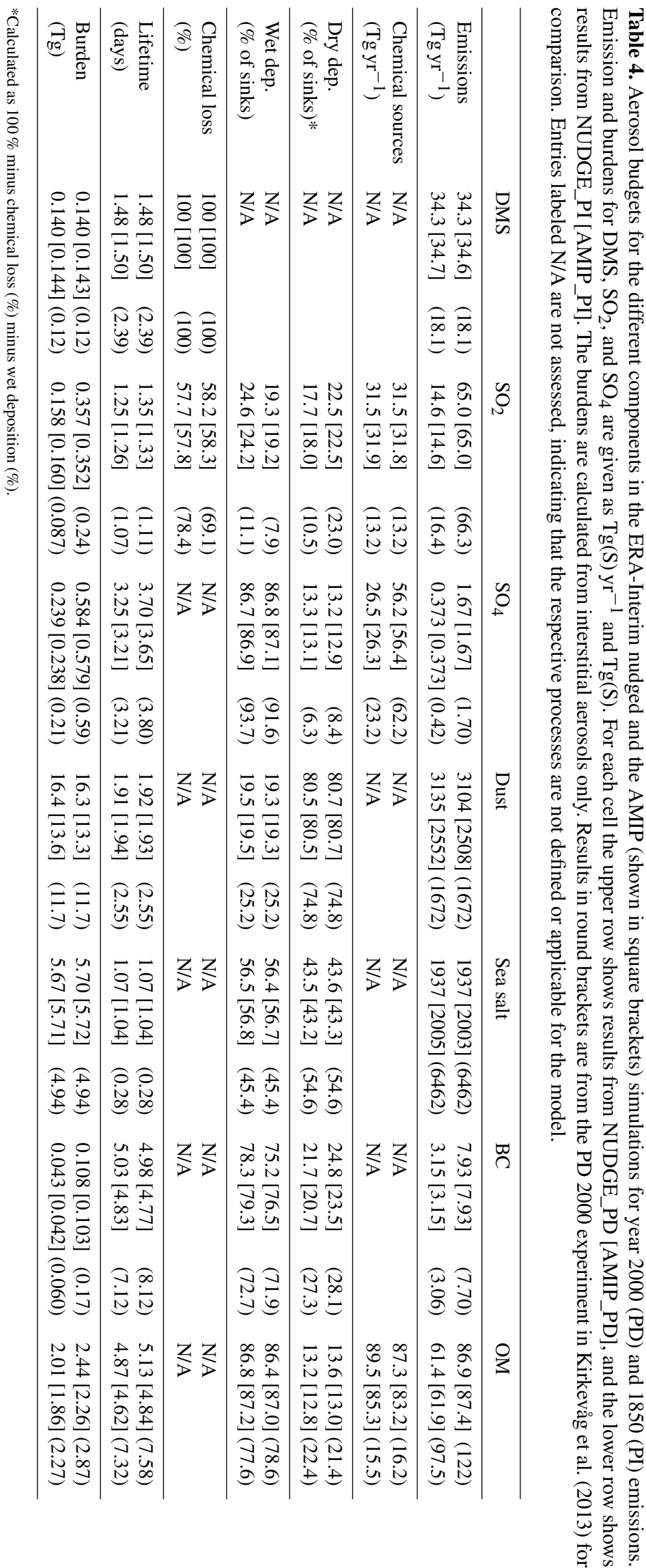
The result of the change in DMS emission parameterization described in Sect. 2.4 is an almost doubled DMS emission (34-35 $\mathrm{Tg} \mathrm{S} \mathrm{yr}^{-1}$ ) compared to the $18.1 \mathrm{Tg} \mathrm{S} \mathrm{yr}^{-1}$ found in $\mathrm{K} 13$, accompanied by a similar increase in the $\mathrm{SO}_{2}$ source term from the oxidation of DMS. The main reason for the increase is that the DMS emissions in Dentener et al. (2006) (applied in K13) were based on the DMS climatology of Kettle and Andreae (2000), with generally lower DMS concentrations in seawater than in the updated version of Lana et al. (2011). An experiment with wind-driven DMS emissions in a research version of CAM4-Oslo using the same transfer function gave $22.0 \mathrm{Tg} \mathrm{S} \mathrm{yr}^{-1}$ with the Kettle and Andreae (2000) data and 34.2 $\mathrm{Tg} \mathrm{S} \mathrm{yr}^{-1}$ with the Lana et al. (2011) data. The shorter lifetime of DMS (1.5 days) compared to K13 (2.4 days) is likely caused by the use of different oxidant fields. Liu et al. (2012) obtain a lifetime of 1.3 days using nearly the same chemical mechanism (see Sect. 2) and the same oxidant fields as in the present work, but with emissions from Dentener et al. (2006). An additional test simulation with CAM5.3-Oslo with the AMIP PD setup and $2^{\circ}$ resolution shows that the effect of increased resolution (to $1^{\circ}$ ) on DMS emissions and lifetime alone is only about $5 \%$ and $0.2 \%$, respectively (not shown). Note also that the increase in column burden from CAM4-Oslo to CAM5.3Oslo is much smaller than the increase in emissions (see Table 1), going from 0.12 to $0.14 \mathrm{Tg} \mathrm{S}$. These both lie well within the range of estimates $(0.015-0.17 \mathrm{Tg} \mathrm{S})$ from other model studies reported by Liu et al. (2007); see their Table 1.

The chemical source for $\mathrm{SO}_{4}$ is divided into clear-air sources through the $\mathrm{SO}_{2}+\mathrm{OH}$ reaction and production in cloud water. The chemical sources of OM (via SOA) are mainly from monoterpene and isoprene. This gives a total of $78 \mathrm{Tg}(\mathrm{OM}) \mathrm{yr}^{-1}$ of SOA produced from terpenes, which lies within the range of AeroCom models published by Tsigaridis et al. (2014). For comparison, the total amounts of BVOC emitted as isoprene and monoterpene are 438 and $119 \mathrm{Tg} \mathrm{yr}^{-1}$, respectively. There is also a source from the oxidation of DMS to MSA assumed to form organics (ca. $\left.9 \mathrm{Tg}(\mathrm{OM}) \mathrm{yr}^{-1}\right)$, adding up to a total of $87 \mathrm{Tg}(\mathrm{OM}) \mathrm{yr}^{-1}$. As mentioned in Sect. 2.2, for the MSA contribution to SOA, $20 \%$ and $80 \%$ of the MSA mass is added to the $\mathrm{SOAG}_{\mathrm{LV}}$ and $\mathrm{SOAG}_{\mathrm{SV}}$ tracers, respectively. The exact LVto-SV ratio is unknown, but we find a quite low sensitivity of the anthropogenic change in cloud effective radiative forcing (i.e., the indirect effect, which is the most important in a climate change perspective) to the assumed apportionment of MSA: test simulations indicate that the total shortwave and longwave indirect effect only changes by about $-0.03 \mathrm{~W} \mathrm{~m}^{-2}$ if all MSA goes into SOAG $\mathrm{SV}_{\text {(no nu- }}$ cleation) and by $0.00 \mathrm{~W} \mathrm{~m}^{-2}$ if we instead feed all MSA into the $\mathrm{SOAG}_{\mathrm{LV}}$ tracer. The effect of neglecting the MSA contribution to SOA altogether is similarly estimated to give a $-0.10 \mathrm{~W} \mathrm{~m}^{-2}$ change.

The zonal mean mass mixing ratios and their variation with height for $\mathrm{SO}_{2}, \mathrm{BC}, \mathrm{OM}$, sulfate, mineral dust, and sea salt (SS) are shown in Fig. 4, both for NUDGE_PD and AMIP_PD. The figure shows that some BC is transported to the stratosphere where the lifetime is longer. OM and sulfate also have this secondary maximum in the stratosphere, but the concentrations aloft are smaller in CAM5.3-Oslo than in CAM4-Oslo (not shown). Dust and sea salt do not exhibit the same clear secondary maxima in the stratosphere, since these particles are generally larger and more readily removed by sedimentation. The additional $2^{\circ}$ test simulation with CAM5.3-Oslo reveals that the effect of increased resolution on vertical profiles is very small compared to the differences between the two model versions for all species (not shown).

For BC we can compare the model with profiles from the HIAPER (High-Performance Instrumented Airborne Platform for Environmental Research) Pole-to-Pole Observations (HIPPO) of carbon and greenhouse gases study over the (mainly remote) Pacific Ocean in January and November 2009, March-April 2010, and June-July and AugustSeptember 2011 (Wofsy et al., 2011; Schwarz et al., 2013); see Fig. 5. It is clear that the new model version does produce less excessive $\mathrm{BC}$ concentrations in the upper troposphere and in the stratosphere globally (Fig. 5a) and that it now compares better with the HIPPO observations in the Pacific (Fig. 5b), although the concentrations are still too high in the upper troposphere and lower stratosphere for this region, similar to the findings for CAM5.3-MAM4 in Liu et al. (2016). This is probably related to the way aerosols are transported and scavenged in deep convective clouds in the model (see, e.g., Kipling et al., 2013, 2016). There are currently ongoing tests with alternative treatments of convective transport and mixing (see Sect. 2.1.5 of K13 for a sensitivity test on this in CAM4-Oslo); these are improved treatments which will possibly be included in the upcoming CAM6-Oslo version for CMIP6. The additional $2^{\circ}$ test simulation reveals that the effect of increased resolution on the lifetime of BC is only about $0.3 \%$ (not shown). Note that NUDGE_PD and AMIP_PD yield almost identical results in the troposphere. This indicates that the nudging, as long as we are not nudging the temperature, only has modest effects on the convective transport and mixing of $\mathrm{BC}$ in the model (see also Fig. 4).

Some of the changes in aerosol concentration fields are connected to changes in cloud microphysics in the host model. Two major factors that affect both aerosols and aerosol precursors are the amount of liquid cloud water and the cloud fraction. Globally averaged, CAM5.3-Oslo has only about one-third as high cloud liquid water path (LWP) as CAM4-Oslo, while the precipitation rate is slightly (7\%) larger. Since the loss rate of aerosol activated to cloud droplets in the model is assumed to be proportional to the precipitation-to-LWP ratio, an increased scavenging efficiency and a subsequent reduction in aerosols away from source regions as a result of the reduced LWP is to be expected. A reduction in aerosol transport to remote regions is 

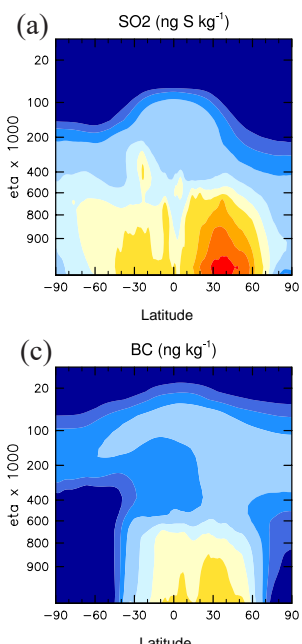

Latitude
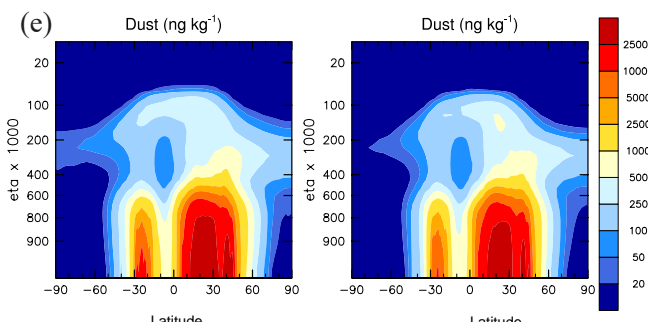

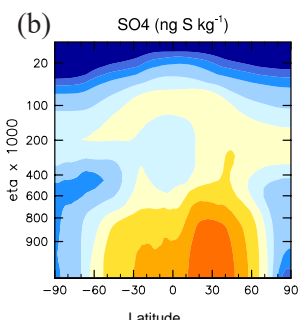

Latitude

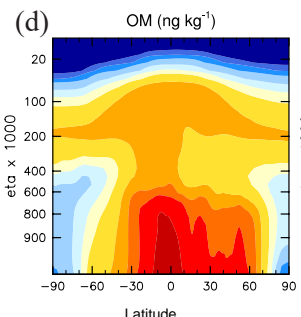

Latitude

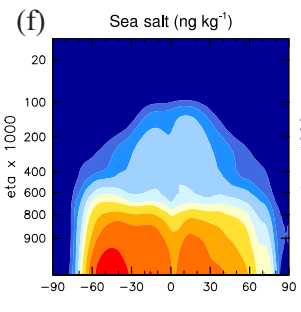

Latitude

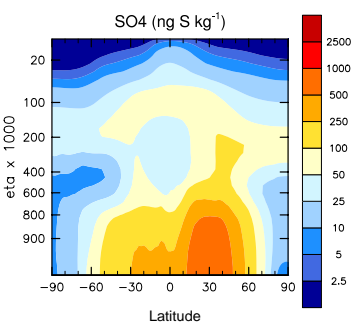

$\mathrm{OM}\left(\mathrm{ng} \mathrm{kg}^{-1}\right)$
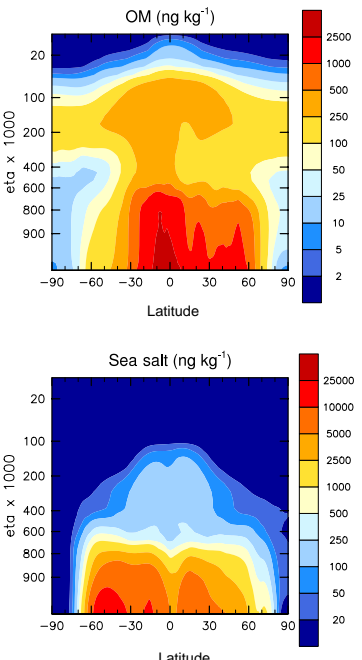

Latitude

Figure 4. Modeled zonal mean mass mixing ratios of (a) $\mathrm{SO}_{2}$, (b) sulfate (as $\mathrm{S}$ ), (c) BC, (d) OM, (e) dust, and (f) sea salt in the NUDGE_PD (left panels) and the AMIP_PD (right panels) simulation (eta $\times 1000$ is the model hybrid coordinate eta level multiplied by 1000$)$. Note the different scales for mineral dust and sea salt vs. the other components.
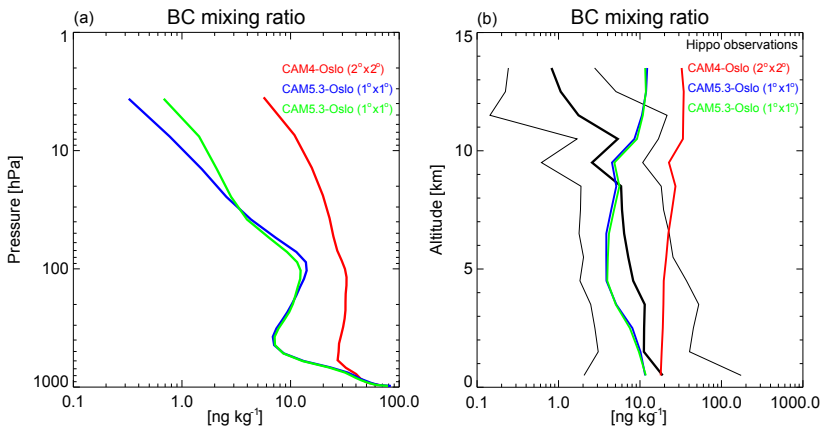

Figure 5. (a) Globally averaged annual BC mass mixing ratio profiles as modeled in the NUDGE_PD (blue line) and AMIP_PD (green line) experiments and in CAM4-Oslo (red line) for comparison. (b) Modeled BC mass mixing ratio profiles from the same simulations as in (a) compared to HIPPO aircraft campaigns averaged over the areas and months in which the campaign took place (Schwarz et al., 2013; see also Samset et al., 2014).

indeed found for all aerosol components and is particularly pronounced in the Arctic and Antarctic regions. At the same time, the total (low) cloud cover has increased from $53 \%$ $(34 \%)$ in CAM4-Oslo to $66 \%$ (43\%) in CAM5.3-Oslo, with the largest changes at high latitudes. This increase in cloud cover likely also gives an increase in the frequency of precipitation events, which tends to reduce aerosol lifetimes. The additional $2^{\circ}$ test simulation (note that this by default setup has a slightly different cloud tuning) reveals that the effect of increased resolution on LWP and on total (low) cloud cover is small compared to the differences between the two model versions, only about $1 \%$ and $-1 \%(-3 \%)$, respectively (not shown).

Even sea salt burdens have been reduced away from the source regions, despite an almost 4 times increase in global lifetime, which is now 1.07 days. This is to a large degree due to the shift towards more long-lived (i.e., accumulation mode) particle sizes (compare Table 2 with Table 1 in K13). While the lifetime is now longer, the emissions have decreased even more so that the overall sea salt burdens are about $35 \%$ smaller than in CAM4-Oslo. In Liu et al. (2012), the sea salt lifetime lies between CAM4-Oslo and CAM5.3Oslo, but is quite dependent on the aerosol microphysics ( 0.76 days in MAM3 and 0.55 days in MAM7). The effect of increased resolution from 2 to $1^{\circ}$ is found here to be $11 \%$ for the emissions (due to stronger winds), $9 \%$ for the burden, and only $-2 \%$ for the lifetime (not shown).

As for $\mathrm{BC}$, the concentrations of $\mathrm{OM}$, sulfate, and mineral dust have also dropped in the upper troposphere and lower 
stratosphere when going from CAM4-Oslo to CAM5.3-Oslo. This reduction is more substantial for carbonaceous aerosols than for the other species, however. In addition to the increased overall scavenging efficiency, $\mathrm{BC}$ and primary $\mathrm{OM}$ now experience a more rapid transition from external to internal mixtures; see Sect. 2.3. The lifetimes of $\mathrm{BC}$ and $\mathrm{OM}$ of approximately 5 days in CAM5.3-Oslo are now more comparable to the MAM7 values in Liu et al. (2012), which are 4.4, 4.9, and 4.1 days for BC, OM, and SOA, respectively. The additional $2^{\circ}$ test simulation reveals that the effect of increased resolution on the OM lifetime is only about $1 \%$ (not shown).

The situation for sulfur is more complex. While the scavenging efficiency of $\mathrm{SO}_{2}$ is increased on the one hand, as for aerosols, the lower liquid water content in CAM5.3-Oslo, on the other hand, acts to reduce the aqueous-phase reaction rates. The net effect of all changes is a ca. $20 \%$ increase in lifetime. Furthermore, while $\mathrm{SO}_{2}$ (and thus the potential for the formation of sulfate) is now transported higher into the atmosphere, the increase in aerosol activation scavenging tends to counteract the effect of this enhanced transport. The combined effect of a longer lifetime for $\mathrm{SO}_{2}$ and increased aerosol loss rates in the lower troposphere is just a $3 \%$ overall reduction in the atmospheric residence time of $\mathrm{SO}_{4}$. The estimate at 3.70 days is very close to the sulfate lifetimes in Liu et al. (2012): 3.72 days for MAM7 and 3.77 days for MAM3. The additional $2^{\circ}$ test simulation reveals that the effect of increased resolution on the $\mathrm{SO}_{2}$ lifetime is only about $-0.4 \%$ (not shown).

As for carbonaceous aerosols, the lifetime of mineral dust is also reduced. The main reason for this reduction is most likely the general increase in activation scavenging. Below-cloud collection efficiencies are still as in Seland et al. (2008), so any changes in below-cloud scavenging are due to changes in precipitation and aerosol life cycling. The relative amount of dust emitted in the accumulation mode (DST_A2) in the new emission parameterization $(13 \%)$ is larger than for the prescribed emissions in CAM4Oslo (11\%), which should rather contribute to a longer dust lifetime in CAM5.3-Oslo due to reduced gravitational settling. A test simulation performed with an earlier model version showed that a tuning of the relative amount of emissions taking place through the accumulation mode from $13 \%$ to $20 \%$ led to a $20 \%$ increase in lifetime globally. The inherent assumption of OsloAero that there is a constant size background aerosol - the particles cannot shrink to smaller sizes than that of the background as the largest particles are deposited - may result in a shorter lifetime of the coarse mode compared to the modal aerosol schemes (MAM3 and MAM7) in Liu et al. (2012). Since Liu et al. (2012) calculate number and mass independently, the size of the coarse-mode particles may decrease with time, thereby increasing the lifetime of that mode. The estimated dust lifetime of 1.9 days is shorter than in both MAM3 (2.6 days) and MAM7 (3.1 days) in Liu et al. (2012). The additional $2^{\circ}$ test simulation reveals that the effect of increased resolution on the mineral dust lifetime is only about $2 \%$ (not shown).

According to Kok et al. (2017), mineral dust in global models is probably often too fine based on constrained atmospheric dust properties and abundance. AeroCom emission rates and loadings (Textor et al., 2006) are below the central estimates in Kok et al. (2017) of 1000-2700 $\mathrm{Tg} \mathrm{yr}^{-1}$ and 13$29 \mathrm{Tg}$, respectively. We get a slightly higher global emission rate of $3100 \mathrm{Tg} \mathrm{yr}^{-1}$ in NUDGE_PD, but $2500 \mathrm{Tg} \mathrm{yr}^{-1}$ in the AMIP_PD simulation. The estimated global dust burden of 13 (NUDGE_PD) or 16 Tg (AMIP_PD) that follows, however, falls within the central estimates of Kok et al. (2017). The global emission rate may be adjusted by a tuning factor (a constant in the emission flux term) in CAM5.3, but in the present version we have retained the value used in the original CAM5.3 code.

Some of the aerosol burden changes from CAM4-Oslo to CAM5.3-Oslo are due to differences in meteorology. To roughly estimate the magnitude of such an effect, we compare the NUDGE_PD and AMIP_PD results in Table 4.

The globally averaged burdens of DMS and $\mathrm{SO}_{2}$ differ by less than $2 \%$, and $\mathrm{SO}_{4}$ and sea salt by less than $1 \%$, while $\mathrm{BC}$ and $\mathrm{OM}$ and mineral dust are ca. $5 \%$ and $7 \%$ lower in the free-running AMIP simulations, respectively. So for these species the differences between NUDGE and AMIP are quite small. We would probably have obtained even smaller changes if the model was self-nudged, i.e., being nudged to a meteorology produced by the model itself (e.g., the AMIP_PD simulation) instead of the ERA meteorology. In a similar comparison by Liu et al. (2016), they obtain as much as ca. $20 \%$ lower BC and OM burdens with nudged (towards 1-year recurrent meteorology) vs. a free simulation (10 years). They partly attribute this to interannual variability, but mainly to (climatological) differences in the meteorological conditions between the free and nudged model simulations, which affect aerosol transport and cloud processing. Unlike the nudging procedure applied here, Liu et al. (2016) also nudged the model meteorology to reanalyzed temperatures (Tilmes et al., 2015), which may explain the larger difference in simulated aerosol burdens between their nudged and free AMIP simulations. A similar effect was found in an older version of CAM5.3-Oslo as we went from nudging temperatures, specific humidity, and $U, V, \mathrm{PS}$, and some surface fields to only nudging $U, V$, and PS: the difference in globally averaged LWP between the nudged and free simulations was reduced by an order of magnitude. An important effect of nudging is that it constrains the model's natural variability (Kooperman et al., 2012), which is useful in calculations of the indirect effect of aerosols since it reduces the simulation length required to obtain sufficiently high signal-to-noise ratios. When nudging to an atmospheric circulation produced by the model itself (self-nudging) instead of using data from reanalysis (such as the ERA data), the circulation mean and variability characteristics are less affected, resulting in ERF estimates more consistent with the 
Table 5. Seasonal and annual normalized mean biases (NMBs) and Pearson correlation coefficients $(R)$ for NUDGE_PD vs. observed climatological surface concentrations (see http://aerocom.met.no, last access: 24 September 2018; cf. Fig. 6). NMBs with absolute values of $50 \%$ or more are listed in bold font.

\begin{tabular}{|c|c|c|c|c|c|c|c|c|c|c|c|c|}
\hline & \multicolumn{2}{|c|}{$\mathrm{BC}$} & \multicolumn{2}{|c|}{$\mathrm{SO}_{2}$} & \multicolumn{2}{|c|}{$\mathrm{SO}_{4}$} & \multicolumn{2}{|c|}{$\mathrm{OM}(\mathrm{OA})$} & \multicolumn{2}{|c|}{ SS } & \multicolumn{2}{|c|}{ DUST } \\
\hline & NMB & $R$ & NMB & $R$ & NMB & $R$ & NMB & $R$ & NMB & $R$ & NMB & $R$ \\
\hline DJF & $-53 \%$ & 0.32 & $154 \%$ & 0.45 & $-19 \%$ & 0.66 & $-34 \%$ & 0.31 & $20 \%$ & 0.49 & $-8.4 \%$ & 0.43 \\
\hline MAM & $-21 \%$ & 0.47 & $124 \%$ & 0.23 & $19 \%$ & 0.69 & $63 \%$ & 0.44 & $13 \%$ & 0.57 & $-39 \%$ & 0.82 \\
\hline JJA & $8.2 \%$ & 0.61 & $143 \%$ & 0.21 & $46 \%$ & 0.87 & $294 \%$ & 0.37 & $28 \%$ & 0.59 & $-52 \%$ & 0.47 \\
\hline SON & $-28 \%$ & 0.38 & $180 \%$ & 0.26 & $31 \%$ & 0.70 & $96 \%$ & 0.25 & $26 \%$ & 0.53 & $-42 \%$ & 0.45 \\
\hline ANN & $-28 \%$ & 0.38 & $150 \%$ & 0.35 & $22 \%$ & 0.72 & $122 \%$ & 0.29 & $22 \%$ & 0.54 & $-39 \%$ & 0.52 \\
\hline
\end{tabular}

model's own innate behavior. However, since the circulation variability is not "synchronized" here with the observed variability of a specific time period, self-nudging does not facilitate a comparison of modeled aerosol properties with observations for that time period.

The 3\% increase in sea salt emissions in going from NUDGE_PD to AMIP_PD, which is consistent with larger simulated $10 \mathrm{~m}$ wind speeds in the extratropical storm track regions, is almost offset by a reduction in lifetime (more wet scavenging), giving only a $1 \%$ net increase in column burden. There is one exception for which the difference between NUDGE_PD and AMIP_PD seems to be important, namely for mineral dust. This is most readily seen from the global dust emissions, varying with wind speed and soil humidity, which are $19 \%$ lower in AMIP_PD than in NUDGE_PD, very close to the $18 \%$ difference in atmospheric burden.

The contribution by interannual variations in the NUDGE_PD simulation to global aerosol or aerosol precursor burdens, given here as normalized standard deviations, is found to be about $3.6 \%$ for DMS, $0.8 \%$ for $\mathrm{SO}_{2}, 1.2 \%$ for $\mathrm{SO}_{4}$, only $0.1 \%$ for $\mathrm{BC}, 1.0 \%$ for $\mathrm{OM}, 2.6 \%$ for sea salt, and $2.5 \%$ for mineral dust. Hence, the above-estimated changes in burdens from NUDGE_PD to AMIP_PD are actually smaller than 1 standard deviation of the interannual variation (in NUDGE_PD) for DMS, $\mathrm{SO}_{4}$, and sea salt so that only $\mathrm{SO}_{2}, \mathrm{BC}, \mathrm{OM}$, and mineral dust can be said with some confidence to be different (smaller) in the AMIP_PD than the NUDGE_PD simulation.

\subsubsection{Evaluation of near-surface mass concentrations}

Column burdens cannot be measured and observed surface concentrations are used here for validating the aerosol masses in the model. Figure 6 and Table 5 show surface mass concentrations of $\mathrm{BC}, \mathrm{SO}_{2}, \mathrm{OA}$ (modeled $\mathrm{OM}$ vs. observed $\mathrm{OC}^{*} 1.4$; see explanation in the figure caption and below), SS (sea salt), $\mathrm{SO}_{4}$ (sulfate), and DUST (mineral dust) in NUDGE_PD compared with various observations as available via the AeroCom intercomparison project (http: //aerocom.met.no, last access: 24 September 2018). Note that the amount of data and spatiotemporal coverage available for the different parameters is inhomogeneous because of data network fluctuations and incomplete storage in the databases used (EBAS: Tørseth et al., 2012; see also http://ebas.nilu.no, last access: 25 September 2018; AEROCE: Arimoto et al., 1995; Huneeus et al., 2011). Tables 6-8 give an overview of statistical evaluation for the NUDGE_PD and AMIP_PD simulations as well as a range of AeroCom Phase II (AP2) and AeroCom Phase III (AP3) models. These are compared for different years, both for individual years (meteorology of 2006 for AP2 and 2010 for AP3) and our model climatology against a climatology from the observational data.

We find that the model mainly overestimates $\mathrm{SO}_{2}$ concentrations. One possible explanation for the large positive bias is the low vertical and horizontal resolution in the model. With such low resolution the model does not capture the dispersion of primary emissions of $\mathrm{SO}_{2}$ well from large point sources or shipping routes. A part of this bias probably comes from the fact that we are comparing concentrations at the midpoint of the lowermost model layer $(\sim 50 \mathrm{~m})$ with ground-based observations (see discussion in Simpson et al., 2012). For the climatologically averaged $\mathrm{SO}_{2}$ data, the Pearson correlation coefficient $R$ (hereafter often just referred to as the correlation) is slightly better for the nudged than for the un-nudged AMIP simulation, in which instead the normalized mean bias (NMB; hereafter often just referred to as the bias) is slightly better. The bias and correlation for each of the continents are $216 \%$ and 0.52 for Europe, $134 \%$ and 0.94 for North America, and $-53 \%$ and -0.02 for Asia. None of the AP3 models have available $\mathrm{SO}_{2}$ statistics, while four of the five AP2 models that do exhibit higher biases than ours. The correlations are also lower than ours in all the AP2 models, while three of them have a higher percentage of monthly model values within a factor of 2 of the observed values (Fact2).

Sulfate is also somewhat overestimated, with a positive bias of $22 \%$ and a correlation as high as 0.72 for the monthly climatological data, slightly above that of the free AMIP simulation. CAM4-Oslo exhibits a smaller, slightly negative bias, but is less correlated with the observations. The new model version still yields a lower Fact 2 value, all in all performing slightly worse than the predecessor. Biases and correlations for each of the continents are $15 \%$ and 0.54 for 

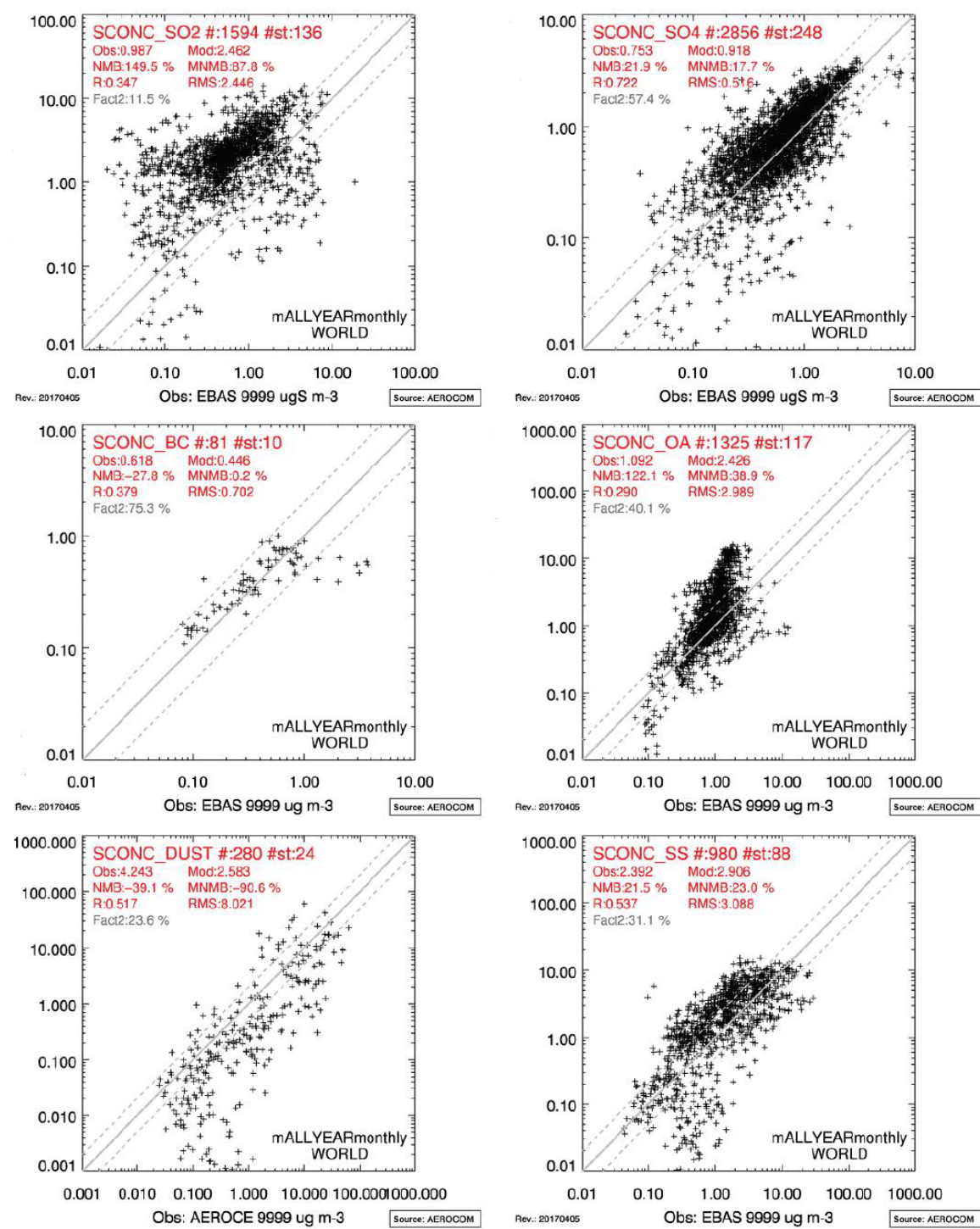

Figure 6. Surface concentrations in the NUDGE_PD experiment compared with EBAS and AEROCE data through the AeroCom tools. OA represents modeled OM concentrations vs. observed OC concentrations multiplied by 1.4 (the assumed OM/OC ratio for fossil fuel OC in the model).

Europe, $38 \%$ and 0.92 for North America, and $-9 \%$ and 0.59 for Asia. The bias for sulfate is better than in four of the eight AP3 models with available concentration data (for year 2010), while the correlation falls just below the AP3 range. Comparing against the 23 AP2 models (for year 2006), however, CAM5.3-Oslo has a lower bias than only 6 of the AP2 models, while outperforming or matching 14 models with respect to correlation.

We see that the model mainly underestimates $\mathrm{BC}$, especially the highest concentrations. The bias is $-28 \%$ and the correlation 0.38, which is also higher here than for the AMIP simulation. CAM4-Oslo has an almost twice as large bias and a much lower correlation coefficient, so apparently there has been an improvement in modeled $\mathrm{BC}$ surface concentra- tions for the very limited number and geographical coverage of stations available (in Europe only). As much as $75 \%$ of the model values lie within a factor of 2 of the observed values, compared to $68 \%$ for CAM4-Oslo. The BC bias is also better than in six of the eight AP3 models. Although the correlations for $\mathrm{BC}$ are quite low for all the AP3 models, only one has a lower correlation than CAM5.3-Oslo. Similarly, comparing against the 23 AP2 models, CAM5.3-Oslo outperforms only 7 of the models bias-wise and 6 with respect to correlation.

For the calculation of mass concentrations of OM from OC the model does not distinguish between tracers from different source types, since they are lumped together for each of the background and size-modifying tracers. This has been 
Table 6. Normalized mean bias (NMB, in \%) statistics from 1 year of monthly data (see AeroCom web interface for details on coverage and networks). Compared are NMBs for the near-surface aerosol mass concentrations and column-integrated optical properties for CAM5.3-Oslo, as well as for CAM4-Oslo and AeroCom models in the aerocom.met.no database (represented here by an NMB range). The top row indicates the meteorological year for observations and nudged simulations; climatology means that all available years from the model or observations are used for the statistics. The regional coverage areas for observations are abbreviated as follows: E: Europe, N: North America, A: Asia, global: nearly all continents or world oceans (island sites) are represented. The control versions of the AeroCom Phase II (AP2) and Phase III (AP3) models used in the model intercomparison are listed below the table, with names as on the AeroCom web interface. Optics diagnostics listed for most of the AP2 and AP3 models (exact number is not available) are clear-sky values, in the sense that the clear-sky humidity of the grid cell is used for calculating hygroscopic swelling of the aerosol (Michael Schulz, personal communication, 6 September 2018). Supplementary information as provided by AeroCom modeling teams about optics diagnostics for 11 of the AP2 models included in this study may be found at https://wiki.met.no/aerocom/optical_properties (last access: 25 September 2018). CAM4-Oslo and CAM5.3-Oslo compute all-sky optical properties using the average humidity $(\mathrm{RH})$ of the grid cell. Clear-sky (CS) properties are instead represented by a 2-D cloud-free fraction-weighted average of the all-sky properties. Only a few other AeroCom models follow a similar clear-sky optics definition, and the optics data submitted to AeroCom for a few of the models are all-sky values both in terms of cloud conditions and RH for hygroscopic growth. Data from CAM4-Oslo and the two simulations with CAM5.3-Oslo, all run with 2000 (PD) emissions, can be found in the aerocom.met.no database under the project label NorESM, subset NorESM-Ref2017. NMBs with absolute values of $50 \%$ or more are listed in bold font. Entries labeled N/A indicate that the respective model data are not available.

\begin{tabular}{|c|c|c|c|c|c|c|c|c|c|}
\hline \multirow{2}{*}{ NMB (\%) } & \multicolumn{3}{|c|}{ Climatology } & \multicolumn{3}{|c|}{2006} & \multicolumn{3}{|c|}{2010} \\
\hline & Coverage & $\begin{array}{r}\text { CAM4- } \\
\text { Oslo }\end{array}$ & $\begin{array}{r}\text { CAM5.3-Oslo } \\
\text { NUDGE_PD } \\
\text { (AMIP_PD) }\end{array}$ & Coverage & $\begin{array}{r}\text { AP2 range } \\
(\leq 23 \text { models*) }\end{array}$ & $\begin{array}{l}\text { CAM5.3-Oslo } \\
\text { NUDGE_PD }\end{array}$ & Coverage & $\begin{array}{r}\text { AP3 range } \\
(\leq 8 \text { models } *)\end{array}$ & $\begin{array}{l}\text { CAM5.3-Oslo } \\
\text { NUDGE_PD }\end{array}$ \\
\hline $\mathrm{SO}_{2}$ conc. & $\mathrm{E} ; \mathrm{N} ; \mathrm{A}$ & 16 & $150(137)$ & $E ; N$ & 65-977 & 223 & E & NA & 328 \\
\hline $\mathrm{SO}_{4}$ conc. & $\mathrm{E} ; \mathrm{N} ; \mathrm{A}$ & -5 & $22(27)$ & $\mathrm{E} ; \mathrm{N}$ & $-61-186$ & 37 & $\mathrm{E}$ & $-40-199$ & 31 \\
\hline $\mathrm{BC}$ conc. & E & -54 & $-28(-34)$ & $\mathrm{E}$ & $-40-64$ & -32 & $\mathrm{E}$ & $-65-35$ & -16 \\
\hline $\mathrm{OA}(\mathrm{OM})$ conc. & $\mathrm{E} ; \mathrm{N}$ & 108 & $122(125)$ & $\mathrm{E} ; \mathrm{N}$ & $-60-335$ & 141 & E & $-70-71$ & 23 \\
\hline Sea salt conc. & $\mathrm{E} ; \mathrm{N} ; \mathrm{A}$ & 50 & $22(40)$ & $\mathrm{E} ; \mathrm{N}$ & $-97-477$ & 66 & $\mathrm{E}$ & $-56-301$ & 36 \\
\hline Dust conc. & Global & -14 & $-39(-24)$ & Global & $-64-106$ & -34 & Global & $-82-4$ & -46 \\
\hline $\begin{array}{l}\text { OD550CS } \\
\text { OD550 }\end{array}$ & $\begin{array}{l}\text { Global } \\
\text { Global }\end{array}$ & $\begin{array}{r}-22 \\
-8\end{array}$ & $\begin{array}{r}-16(-27) \\
15(3)\end{array}$ & $\begin{array}{l}\text { Global } \\
\text { Global }\end{array}$ & $-50-133$ & $\begin{array}{r}-18 \\
11\end{array}$ & $\begin{array}{l}\text { Global } \\
\text { Global }\end{array}$ & $-\mathbf{5 3}--3$ & $\begin{array}{r}-24 \\
12\end{array}$ \\
\hline $\begin{array}{l}\text { ABS550CS } \\
\text { ABS550 }\end{array}$ & $\begin{array}{l}\text { Global } \\
\text { Global }\end{array}$ & $\begin{array}{l}-32 \\
-33\end{array}$ & $\begin{array}{l}-25(-30) \\
-20(-30)\end{array}$ & $\begin{array}{l}\text { Global } \\
\text { Global }\end{array}$ & $-\mathbf{8 0}-21$ & $\begin{array}{l}-38 \\
-30\end{array}$ & $\begin{array}{l}\text { Global } \\
\text { Global }\end{array}$ & NA & $\begin{array}{l}-36 \\
-35\end{array}$ \\
\hline $\begin{array}{l}\text { ANG4487CS } \\
\text { ANG4487 }\end{array}$ & $\begin{array}{l}\text { Global } \\
\text { Global }\end{array}$ & $\begin{array}{r}\text { NA } \\
-19\end{array}$ & $\begin{array}{l}-17(-15) \\
-44(-42)\end{array}$ & $\begin{array}{l}\text { Global } \\
\text { Global }\end{array}$ & $-30-31$ & $\begin{array}{l}-15 \\
-44\end{array}$ & $\begin{array}{l}\text { Global } \\
\text { Global }\end{array}$ & NA & $\begin{array}{l}-16 \\
-45\end{array}$ \\
\hline
\end{tabular}

*Excluding models with missing data or with NMB $<-99 \%$ or NMB $>1000 \%$ (see the main text for more details). AP2 models: CAM5.1-MAM3-PNNL.A2.CTRL, ECHAM-SALSA.A2.CTRL, ECHAM-SALSA.A2.CTRL.emi2000, GISS-MATRIX.A2.CTRL, GISS-modelE.A2.CTRL, GLOMAPbin1pt1.A2.CTRL, GLOMAPmodev4.A2.CTRL, GLOMAPmodev6R.A2.CTRL, GMI.A2.CTRL, GMI-v3.A2.CTRL, GOCART-v4.A2.CTRL, GOCART-v4Ed.A2.CTRL, HADGEM2-ES.A2.CTRL, HADGEM3-A-GLOMAP.A2.CTRL, INCA.A2.CTRL, MPIHAM_V1_KZ.A2.CTRL,

MPIHAM_V2_KZ.A2.CTRL, OsloCTM-v2.A2.CTRL, OsloCTM.A2.CTRL, SALSA_v1_TB.A2.CTRL, SPRINTARS-v384.A2.CTRL, SPRINTARS-v385.A2.CTRL, and TM5.V3.A2.CTRL. AP3 models: CNRM-CM6.2Nut127_AP3-CTRL2015, CNMR-CM6.2t127_AP3-CTRL2015, ETHZ-ECHAM-HAM2_CTRL2015, GEOS-Chem-v10-01_AP3-CTRL2015, OsloCTM3_AP3-CTRL2015, SPRINTARS-T106_AP3-CTRL2015, SPRINTARS-T213_AP3-CTRL2015, and TM5_AP3-CTRL2015.

done in order to limit the CPU requirements as much as possible, as the model (when fully coupled with the ocean and sea ice modules) is built for use in long climate simulations. We compare modeled OM with observed OC values that have been multiplied by 1.4 (defined as OA for the observations in Fig. 6, while OA simply means OM for the model values) to account for the conversion factor in going from fossil fuel OC to OM in the model (K13). For OM from biomass burning, defined as agricultural waste burning, grass fires, and forest fires in the model, the respective conversion factor is assumed to be 2.6 (K13; see also Formenti et al., 2003), i.e., 1.86 that of the fossil fuel emissions. If all $\mathrm{OM}$ originated from biomass burning, the bias would therefore be $19 \%$ instead of $122 \%$. The latter value is simply based on the assumption of zero OC contribution from biomass burning. The truth concerning the validation probably lies somewhere between these two estimates, even though $\mathrm{OM} / \mathrm{OC}$ ratios exceeding
2.6 might be more representative for some sources, such as MSA (see Sect. 4.2.1 in K13). For comparison, the respective bias values in CAM4-Oslo are $108 \%$ and $12 \%$. The correlation coefficient for OM in CAM5.3-Oslo's NUDGE_PD is substantially lower than for both $\mathrm{BC}$ and $\mathrm{SO}_{4}$, but very close to that for OM in both AMIP_PD and CAM4-Oslo. Regional bias and correlation values are $143 \%$ and 0.44 for North America, where most of the observation sites are located, and $-26 \%$ and 0.01 for Europe.

Assuming that OA is representative for the modeled OM, in North America the concentrations are most overestimated in the months JJA, while being underestimated in DJF. In Europe OM is overestimated only in JJA. This may indicate that $\mathrm{OC}$ is overestimated in summer or that sources with $\mathrm{OM} / \mathrm{OC}$ ratios exceeding 1.4 dominate during summer, as should be expected since relative contributions to OM from SOA (e.g., Gelencsér et al., 2007) and forest fires are gener- 


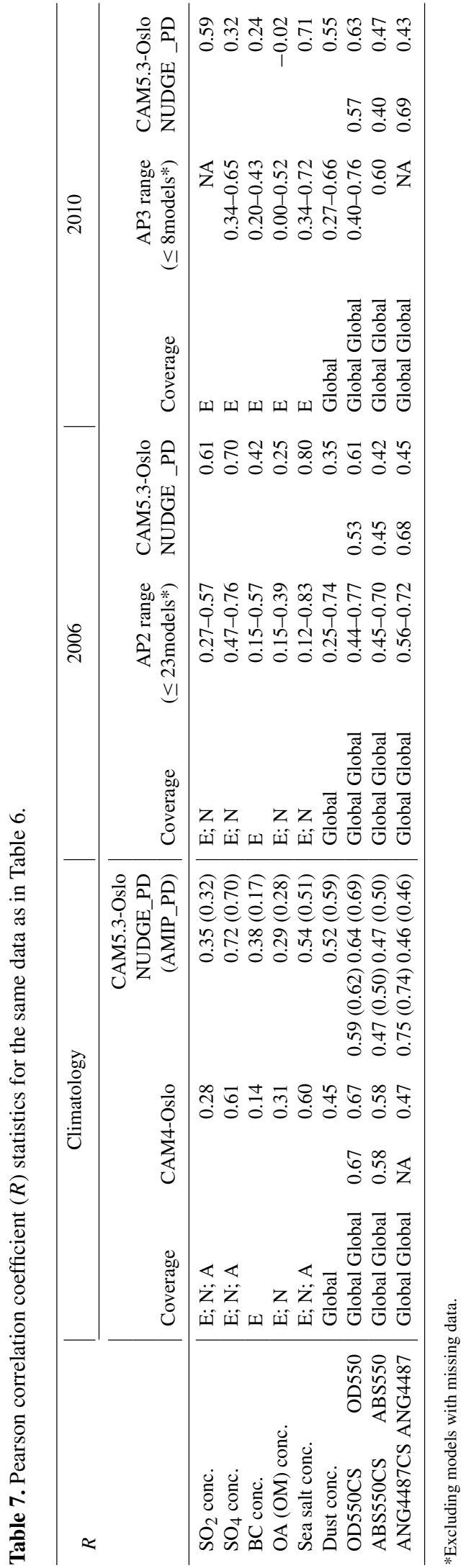

www.geosci-model-dev.net/11/3945/2018/

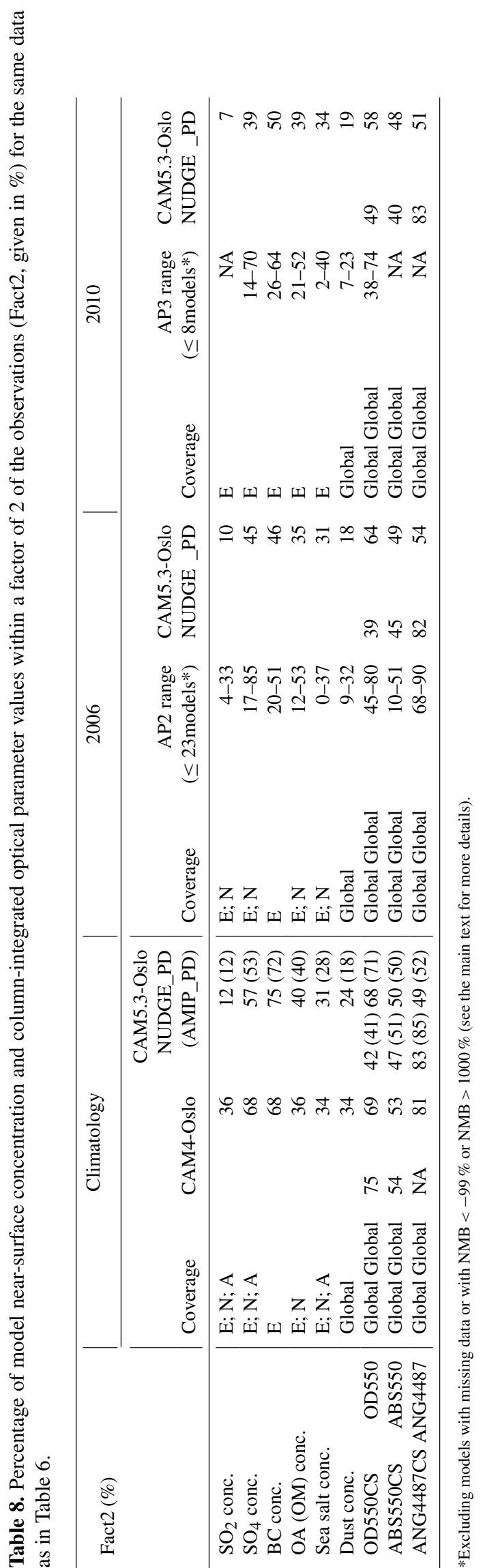

Geosci. Model Dev., 11, 3945-3982, 2018 
Table 9. Globally and annually averaged PD mass extinction coefficients at $550 \mathrm{~nm}$ for each of the main aerosol components in CAM5.3Oslo compared to CAM4-Oslo and to AeroCom Phase I models. For a component $X$ we calculate $\mathrm{MEC}_{X}=\mathrm{AOD}_{X} / B_{X}$, where $B_{X}$ is the burden of the component.

\begin{tabular}{llll}
\hline MEC $\left(\mathrm{m}^{2} \mathrm{~g}^{-1}\right)$ & & $\begin{array}{l}\text { CAM5.3-Oslo } \\
\text { NUDGE_PD }\end{array}$ & $\begin{array}{l}\text { AeroCom Phase I } \\
\text { median (min-max) }\end{array}$ \\
\hline Sulfate $\left(\mathrm{SO}_{4}\right)$ & 6.7 & $5.84(5.78)$ & $8.5(4.2-28.3)$ \\
OM & 8.6 & $5.99(6.06)$ & $5.7(3.2-11.4)$ \\
BC & 6.5 & $7.56(7.64)$ & $8.9(5.3-18.9)$ \\
Dust & 1.4 & $1.64(1.66)$ & $0.95(0.46-2.1)$ \\
Sea salt & 3.1 & $5.04(5.05)$ & $3.0(0.88-7.5)$ \\
Reference & Kirkevåg & This work & Kinne et al. (2006) \\
& et al. (2013) & & \\
\hline
\end{tabular}

Table 10. Globally and annually averaged aerosol radiative forcing (RF) and effective radiative forcing (ERF) decomposed into its SW and LW components for CAM5.3-Oslo and CAM4-Oslo compared with the respective mean values and ranges reported in IPCC AR5. Note that the estimates from IPCC AR5 are only available as sums of the SW and LW contributions and have been estimated for the period 1750 to 2011 (with one exception, see the footnote), whereas the CAM4-Oslo and CAM5.3-Oslo estimates are for year 1850 to 2000.

\begin{tabular}{|c|c|c|c|c|}
\hline $\begin{array}{l}\mathrm{RF} / \mathrm{ERF} \\
\text { decomposition }\end{array}$ & $\begin{array}{l}\text { CAM4-Oslo } \\
\mathrm{RF}\left(\mathrm{W} \mathrm{m}^{-2}\right)\end{array}$ & $\begin{array}{r}\text { CAM5.3-Oslo ERF }\left(\mathrm{W} \mathrm{m}^{-2}\right) \\
\text { NUDGE_PD (AMIP_PD) }\end{array}$ & $\begin{array}{r}\text { IPCC AR5 } \\
\mathrm{RF}\left(\mathrm{W} \mathrm{m}^{-2}\right)\end{array}$ & $\begin{array}{r}\text { IPCC AR5 } \\
\operatorname{ERF}\left(\mathrm{W} \mathrm{m}^{-2}\right)\end{array}$ \\
\hline SW ari & -0.10 & $-0.095(-0.092)^{*}$ & \multirow{2}{*}{$-0.35(-0.85$ to 0.15$)$} & \multirow{2}{*}{$-0.45(-0.95$ to 0.05$)$} \\
\hline LW ari & - & $0.026(0.026)^{*}$ & & \\
\hline SW aci & -0.91 & $-1.50(-1.45)^{*}$ & \multirow{2}{*}{ Not assessed } & \multirow{2}{*}{$-0.45(-1.20$ to 0.0$)$} \\
\hline LW aci & 0.01 & $0.161(0.155)^{*}$ & & \\
\hline \multirow{2}{*}{ ari \& aci } & \multirow{2}{*}{-1.00} & \multirow{2}{*}{$-1.41(-1.36)^{*}$} & \multirow{2}{*}{ Not assessed } & $-0.9(-1.9$ to -0.1$)$ \\
\hline & & & & $-1.08(-1.40 \text { to }-0.76)^{* *}$ \\
\hline Reference & Kirkevåg et al. (2013) & This work & Boucher et al. (2013) & Boucher et al. (2013) \\
\hline
\end{tabular}

ally larger in this season. As discussed in $\mathrm{K} 13$, in addition to the various $\mathrm{OM} / \mathrm{OC}$ ratios in the model, as in nature, a further complicating factor comes from the use of different standards and methods for measuring OC mass concentrations. While being integrated over all particle sizes in the model, the measured quantities may be based on PM2.5 or PM10 values in different observation networks, as is the case for North America (PM2.5 in IMPROVE) vs. Europe (PM10 in EMEP). This hampers reliable validation of OM in the model in its present form. Ideally the model should carry separate tracers for OC from SOA (preferably speciated), fossil fuel, and biomass burning sources and also have separate mass diagnostics for the different size intervals, which would better facilitate a more comprehensive evaluation of organic matter in the model.

Compared to the eight AP3 models, the bias (i.e., modeled OM-measured OA) is found to be smaller than in all but one model. The correlation, however, is just below the range for the AP3 models. It is slightly negative for the whole year of 2010 (Europe only), as for the months MAM that year, while being 0.15 or higher in the other seasons. Comparing against the 22 AP2 models (1 model is missing surface concentration data), CAM5.3-Oslo has a smaller bias than only 1 of the models, while it performs better than 6 models with respect to correlations for the year 2006. The Pearson correlation in our model varies between 0.16 and 0.25 for years 2004-2006, when both North American and European stations are included, while being closer to zero or negative in 2007-2010 based only on European station data, in which it varies between -0.12 and 0.12 . It is surprising that there has been practically no change in correlation for the all-year climatology since K13 (CAM4-Oslo in Table 7), for which the SOA treatment was very simplistic. This should be investigated in future studies.

For the sea salt surface concentrations we obtain a bias of $22 \%$ and a correlation of 0.54 , and $31 \%$ of the model values are within a factor of 2 of the observations. Compared to CAM4-Oslo this is much better bias-wise, but with nearly 
Table 11. All-sky and clear-sky aerosol optical depth (OD) and absorptive optical depth (ABS) at 550 nm, liquid water path (LWP), in-cloud cloud droplet number concentrations (CDNCs)* and effective cloud droplet radius (Reffl)** at $860 \mathrm{hPa}$ (model layer 24), and ice water path (IWP). Also shown are the column-integrated CDNC (CDNCcol) and ice crystal number concentration values (ICNCcol, calculated as part of the post-processing).

\begin{tabular}{lrrrrrrrr}
\hline & $\begin{array}{r}\text { OD550 } \\
\text { Experiment }\end{array}$ & $\begin{array}{r}\text { ABS550 } \\
(\text { OD550CS })\end{array}$ & $\begin{array}{r}\text { LWP } \\
(\text { ABS55 CS })\end{array}$ & $\begin{array}{r}\text { CDNCcol } \\
(1 . e 6 \\
\left.\mathrm{cm}^{-2}\right)\end{array}$ & $\begin{array}{r}\text { CDNC } \\
860 \mathrm{hPa} \\
\left(\mathrm{cm}^{-3}\right)\end{array}$ & $\begin{array}{r}\text { Reffl } \\
860 \mathrm{hPa} \\
\left(\mathrm{m}^{-2}\right)\end{array}$ & $\begin{array}{r}\text { IWP } \\
\left(\mathrm{g} \mathrm{m}^{-2}\right)\end{array}$ & $\begin{array}{r}\text { ICNCcol } \\
\left(\mathrm{cm}^{-2}\right)\end{array}$ \\
\hline NUDGE PD & $0.152(0.124)$ & $0.0048(0.0049)$ & 53.85 & 1.39 & 58.93 & 11.25 & 10.00 & 6874.16 \\
NUDGE PI & $0.128(0.109)$ & $0.0036(0.0037)$ & 50.29 & 1.10 & 49.12 & 11.56 & 10.03 & 6876.01 \\
NUDGE PD-PI & $0.025(0.015)$ & $0.0012(0.0012)$ & 3.56 & 0.29 & 9.81 & -0.31 & -0.03 & -1.9 \\
AMIP PD & $0.142(0.113)$ & $0.0042(0.0044)$ & 53.52 & 1.37 & 57.57 & 11.50 & 10.25 & 6882.92 \\
AMIP PI & $0.119(0.098)$ & $0.0031(0.0032)$ & 50.10 & 1.08 & 47.78 & 11.86 & 10.29 & 6882.97 \\
AMIP PD-PI & $0.023(0.014)$ & $0.0011(0.0012)$ & 3.42 & 0.29 & 9.79 & -0.36 & -0.04 & -0.05 \\
\hline
\end{tabular}

*CDNC is calculated as the average cloud water concentration AWNC (a grid average multiplied with the fractional occurrence of liquid at each time step) divided by the fractional occurrence of liquid, FREQL. **Reffl is calculated as the average cloud droplet effective radius AREL (a grid average multiplied with the fractional occurrence of liquid at each time step) divided by the fractional occurrence of liquid, FREQL.

the same Fact2 value. The bias is also about half of that in the free-running AMIP_PD simulation. Regional biases and correlations are $59 \%$ and 0.76 for Europe, $19 \%$ and 0.72 for North America, and $31 \%$ and -0.04 for Asia. A considerable number of the observation stations for sea salt are coastal and inland, however, and are perhaps therefore not very representative for sea salt aerosol as such in the model. CAM5.3-Oslo performs better than all the AP3 models bias-wise, and only one of the AP3 models has a higher Pearson correlation for sea salt. Our model is also less biased than 20 of the 23 AP2 models, and with higher correlation than 21 models.

For mineral dust we only have climatological observations to compare with. The bias for all stations and months is found to be $-39 \%$, with a correlation of 0.52 , which is slightly lower here than in the free AMIP_PD simulation. The observation stations for mineral dust surface concentrations are all quite distant from the largest dust source regions. Hence, the negative bias found in CAM5.3-Oslo may very well be a result of underestimated long-range transport rather than toosmall emissions. This is corroborated by the fact that aerosol optical depths in the largest source regions (see Sect. 4.2) are biased high compared to the remotely retrieved values. Although the correlation coefficient is slightly better than in CAM4-Oslo, in which mineral dust emissions are simply prescribed, CAM5.3-Oslo is more biased and has a lower Fact 2 value. We note, however, that even for the nudged simulation, the year-to-year variation for mineral dust is large enough to affect these validation results. Comparing monthly data from each individual model year with the observed climatological dust concentrations, the bias here varies between $-46 \%$ and $-23 \%$ and the correlation between 0.29 and 0.71. Part of this variability may be due to a varying number of stations for which there are enough data to be included in the multiyear climatology. Compared to the eight AP3 models, our model performs better than only three models biaswise, but lies above the middle of the AP3 range with respect to correlations. It is also less biased than 14 of the 23 AP2 models and has a higher correlation than 7 of the models.

\subsection{Optical properties}

\subsubsection{Mass specific extinction and absorption}

Table 9 gives the modeled mass extinction coefficients (MEC) for each of the aerosol components, calculated as the component's aerosol optical depth at $550 \mathrm{~nm}$ divided by its atmospheric burden. What determines MEC for a monodisperse aerosol consisting of spherical (which we assume) and homogeneous particles is the particle size (divided by the radiative wavelength of interest), its mass density, and refractive index. For an internally mixed component of an aerosol size distribution, the size-integrated and atmospheric column-averaged MEC depends on a range of factors in the model. In addition to the refractive index of the components in a given mixture and the mixture's lognormal modal parameters (median radii and standard deviations) at the point of emission or nucleation, the growth by added process tracers and by hygroscopic swelling also play important roles. Aerosol lifetimes and aerosol life cycling in general, including transport and deposition, can further affect the results by shifting the "center of mass" of the aerosol components in question to areas and altitudes with different relative humidity, which consequently also affects the globally averaged MEC value.

Since neither the assumed mass density nor the initial lognormal modal parameters of the sulfate background modes in mixture nos. 1 and 5 have changed relative to the treatment in $\mathrm{K} 13$, i.e., in CAM4-Oslo, the ca $14 \%$ reduction in MEC globally must be due to changes in growth, including the effects of life cycling on growth. As outlined in Sect. 2.3, the hygroscopicity of sulfuric acid has been reduced by about $17 \%$ for relative humidities close to $\mathrm{RH}_{\max }$, while for ammonium sulfate there has been an equally large increase for 
these highest RH values but a larger reduction in large parts of the hysteresis domain $(\mathrm{RH} \approx 50-80 \%)$, up to a $50 \%$ reduction at $\mathrm{RH} \approx 80 \%$. The net effect of this when introduced into the model at the time (in an older model version), however, was small compared to the change from CAM4-Oslo to the present model version, which points to changes in meteorology and life cycling as the main cause. Although the atmospheric residence times and burdens of sulfate are quite similar globally (Table 4), in CAM5.3-Oslo they are both considerably smaller at middle to high latitudes and somewhat larger in the subtropics. At these low latitudes the relative humidity (and cloud cover) in the lower troposphere is also somewhat lower in CAM5.3-Oslo. Hence the sulfate "center of mass" is in effect shifted towards typically less humid regions, which is consistent with less hygroscopic growth and the smaller MEC values found in CAM5.3-Oslo. Some of the reduction may in addition be a result of having relatively larger amounts of (less hygroscopic) OM internally mixed with sulfate in the present model version, due to the co-nucleation of sulfate and SOA (mixture no. 1) and to the condensation of sulfuric acid and $\mathrm{SOAG}_{\mathrm{SV}} / \mathrm{SOAG}_{\mathrm{LV}}$ onto larger particles (mixture nos. 1-10). The sulfate MEC estimates lie within the inter-model variability of the AeroCom Phase I models (Kinne et al., 2006) for both configurations of CAM5.3-Oslo, as for CAM4-Oslo.

MEC for OM aerosol has decreased by about $30 \%$ compared to CAM4-Oslo, also still within the range of the AeroCom I models, but now closer to the AeroCom I median value. Looking back on results from earlier model versions of CAM5.3-Oslo, we find that the larger part of this change is most likely due to a shift in OM burdens to less humid areas (mainly at lower latitudes), just as for sulfate. An additional change that might be of importance is that SOA now comes as nucleation- or Aitken-mode particles (mixture no. 1) and is distributed onto larger particles by condensation instead of in the internally mixed primary $\mathrm{OM} / \mathrm{BC}$ (a) mode (mixtures 4 and 14), which generally has a higher specific extinction. For instance, MEC is about $0.4(0.6) \mathrm{m}^{2} \mathrm{~g}^{-1}$ for mixture 1 if only consisting of nucleated $\mathrm{OM}$ at $\mathrm{RH}=0 \%(80 \%)$ compared to $3.0(4.5) \mathrm{m}^{2} \mathrm{~g}^{-1}$ for mixtures 4 and 14 when only consisting of OM (and condensed water).

Despite a shift in burdens towards lower latitudes also for BC, the mass specific extinction for BC $\left(7.6 \mathrm{~m}^{2} \mathrm{~g}^{-1}\right)$ has increased by about $17 \%$ from CAM4-Oslo to CAM5.3Oslo. This is also closer to the AeroCom I median value $\left(8.9 \mathrm{~m}^{2} \mathrm{~g}^{-1}\right)$. Regionally the increase is largest in areas downwind of relatively large sulfate and SOA or biomass burning sources in northern South America (where MEC is now at its largest at about $20 \mathrm{~m}^{2} \mathrm{~g}^{-1}$ ) and Indonesia ( $\left.15 \mathrm{~m}^{2} \mathrm{~g}^{-1}\right)$, as well as over and downwind of eastern North America to eastern Europe $\left(\sim 10-15 \mathrm{~m}^{2} \mathrm{~g}^{-1}\right)$. As mentioned, there is more growth by condensation in CAM5.3Oslo since SOA is no longer treated as primary particles as in CAM4-Oslo. It is reasonable to assume that this extra aerosol growth may also be linked to the increase in MEC.
Most importantly, however, the changes in $\mathrm{BC}$ emissions size, mass density, and refractive index (see Sect. 2.3) did change MEC for the pure and dry $(\mathrm{RH}=0 \%)$ background particles of mixture nos. 2 (when containing only BC) and 12 from about 7.0 to $8.5 \mathrm{~m}^{2} \mathrm{~g}^{-1}$, i.e., a $20 \%$ increase from the background tracer with the largest mass-wise contribution $(90 \%)$ to fossil fuel $\mathrm{BC}$ emissions. For mixture no. 0, the fractal fossil fuel BC particles, the net change in MEC from altered size, density, and refractive index is just a $0.3 \%$ increase to $8.2 \mathrm{~m}^{2} \mathrm{~g}^{-1}$, due to compensating effects. The increase in MEC is also very small $(\sim 3 \%)$ for fresh BC particles from biomass burning in mixture nos. 4 and 14 if we assume that only $\mathrm{BC}$ is present in the $\mathrm{OM} / \mathrm{BC}(\mathrm{a})$ mode.

MEC for mineral dust has increased by about $19 \%$ globally and with a regional pattern quite similar to that of BC. Mass densities and particle sizes at the point of emission are the same here as in CAM4-Oslo for both tracers (DST_A2 and DST_A3). The effect of the change in refractive index (see Sect. 2.3) only yields a $0.4 \%$ increase in MEC at $550 \mathrm{~nm}$ for pure dust in both mixture 6 and 7. Dust hygroscopicity has increased somewhat (see Sect. 2.3), which together with the extra growth potential from SOA is consistent with an increase in MEC. We note, however, that MEC is now higher even in the most arid source regions (e.g., Sahara) due to a slightly larger fraction of accumulation-mode (DST_A2) to total dust mass in the new emission parameterization (0.13) compared to CAM4-Oslo (0.11). With MEC $=2.44 \mathrm{~m}^{2} \mathrm{~g}^{-1}$ and $0.335 \mathrm{~m}^{2} \mathrm{~g}^{-1}$ for DST_A1 and DST_A2 (assuming no growth), this shift towards smaller sizes alone (i.e., before further growth and deposition) can account for a $7 \%$ larger MEC for dust in CAM5.3-Oslo. Mineral dust MEC is still within the range of the AeroCom I models, although it is now closer to the highest model estimates. Note that the (common) assumption that dust particles are spherical leads to a substantial underestimate in MEC for coarse particles, while the error is much smaller for particles with geometric diameters below about $0.6 \mu \mathrm{m}$ (Kok et al., 2017). The bias towards smaller emission sizes, however (see the discussion above), should lead to an opposite-directed bias in MEC, since coarse mineral dust has much lower MEC than submicron dust (e.g., $86 \%$ lower for DST_A3 than for DST_A2).

The hygroscopicity of sea salt has increased by about $4 \%$ for high ambient relative humidities, now being smaller throughout much of the hysteresis domain compared to CAM4-Oslo (see Sect. 2.3). Together with changes in particle growth by the process tracers, such as by the condensation of SOA (missing in K13 and M14), this might explain some of the changes in sea salt MEC in moving to CAM5.3-Oslo. The main cause of the about $63 \%$ increase, however, is the shift in particle effective radii towards sizes with higher specific extinction: globally averaged MEC for sea salt in CAM5.3-Oslo $\left(5.04 \mathrm{~m}^{2} \mathrm{~g}^{-1}\right)$ is just $1 \%$ lower than in the CAM4-Oslo development version of Salter et al. (2015), which used the same model parameters for sea salt as in Table 2 while otherwise being the same as in K13. 
Note that these MEC estimates are based on the common assumption that an internally mixed component's contribution to the total extinction increases linearly with its volume fraction, which in our model (in AeroTab) is allowed to vary with size. The same goes for the absorption or scattering when we focus on either of their contributions to the extinction separately. In this way nonabsorbing aerosols, such as sulfate and sea salt, contribute to the total aerosol absorption wherever internally mixed with absorptive aerosols, such as BC. Although the total extinction, scattering, and absorption is thus correctly found by summing up the contributions from each of the aerosol components, the method is expected to give biased extinction estimates, especially for the absorption part, compared to in situ measurements for each aerosol component separately (or for less aged and/or internally mixed particles close to the sources). Furthermore, the refractive indices of mixtures consisting of absorbing and nonabsorbing components are calculated by using the semi-empirical Maxwell-Garnett mixing rule, which gives less absorption (in better agreement with measurements) than the volume mixing rule for homogeneous mixtures (Chýlek et al., 1998), but more absorption than for purely external mixtures (Chýlek et al., 1998; see also Fig. 6 in Kirkevåg et al., 2005).

To obtain a first rough estimate of the magnitude of at least parts of the uncertainty in connection with the choice of methodology for calculating BC MEC and the corresponding mass specific absorption, MAC (defined as absorption aerosol optical depth (AOD) divided by aerosol burden), we have also calculated the corresponding coefficients for the anthropogenic part (i.e., using PD-PI AODs and burdens). This means a shift towards sizes and specific extinctions more representative of fossil fuel sources. The anthropogenic MEC is found to be about $8 \%$ larger than for PD BC, $8.18 \mathrm{~m}^{2} \mathrm{~g}^{-1}$ for NUDGE_PD and $8.28 \mathrm{~m}^{2} \mathrm{~g}^{-1}$ for AMIP_PD, and $10 \%$ higher $\left(7.14 \mathrm{~m}^{2} \mathrm{~g}^{-1}\right)$ than for PD BC in CAM4-Oslo. Similarly, the anthropogenic MAC value is as much as $30 \%$ higher than for PD BC, $3.15 \mathrm{~m}^{2} \mathrm{~g}^{-1}$ for NUDGE_PD and $3.27 \mathrm{~m}^{2} \mathrm{~g}^{-1}$ for AMIP_PD, and $31 \%$ higher for anthropogenic $\mathrm{BC}\left(3.15 \mathrm{~m}^{2} \mathrm{~g}^{-1}\right)$ than for $\mathrm{PD}$ $\mathrm{BC}$ in CAM4-Oslo. We note that this is still low compared to measured values and the recommended range of $7.5 \pm 1.2 \mathrm{~m}^{2} \mathrm{~g}^{-1}$ for fresh, uncoated $\mathrm{BC}$ in Bond and Bergström (2006). According to that review paper, MAC can drop to about $5 \mathrm{~m}^{2} \mathrm{~g}^{-1}$ for collapsed BC aggregates, while coating by negligibly absorbing aerosol typically enhances MAC by $50 \%$ (to ca. $11 \mathrm{~m}^{2} \mathrm{~g}^{-1}$ ).

One may also calculate alternative MAC values from the PD simulations by assuming that nonabsorptive or less absorptive components do not contribute to the light absorption of the mixture containing BC. First, leaving out only sulfate and sea salt and letting $\mathrm{MAC}=\mathrm{ABS}_{(\mathrm{BC}+\mathrm{SO} 4+\mathrm{SS})} / \mathrm{B}_{\mathrm{BC}}$, we find that $\mathrm{MAC}=4.82$ and $4.95 \mathrm{~m}^{2} \mathrm{~g}^{-1}$ in NUDGE_PD and AMIP_PD, respectively, compared to $5.07 \mathrm{~m}^{2} \mathrm{~g}^{-1}$ in CAM4-Oslo. MAC here exceeds $7 \mathrm{~m}^{2} \mathrm{~g}^{-1}$ over large areas (for all the above simulations) somewhat downstream of major BC emissions in North and South America and over several smaller areas in Southeast Asia. Similarly, assuming that mineral dust and OM do not contribute to the absorption either (as in Stjern et al., 2017), which is a much less realistic assumption in many regions, we obtain global MAC values of 23.2 and $21.4 \mathrm{~m}^{2} \mathrm{~g}^{-1}$ in NUDGE_PD and AMIP_PD, respectively, and $13.6 \mathrm{~m}^{2} \mathrm{~g}^{-1}$ in CAM4-Oslo. Assuming that the truth lies somewhere between the two last assumptions we could even obtain globally averaged BC MAC values within the recommended range of Bond and Bergström (2006). The problem with this line of reasoning is, of course, that $\mathrm{BC}$ is not the only absorbing aerosol component and that nonabsorptive components also add to, and even enhance (e.g., Chen et al., 2017), the total absorption for internal mixtures. Finally, although both mineral dust and OM individually have small MAC values, they have much larger atmospheric burdens than $\mathrm{BC}$ and thus also contribute considerably to the total absorption, even dominating regionally. In a test simulation with less absorptive mineral dust at most wavelengths - the imaginary refractive index at $550 \mathrm{~nm}$ is reduced from 0.0055 to 0.0024 - otherwise being identical to NUDGE_PD, the latter BC MAC estimate is reduced by $25 \%$ globally, from 23.2 to $17.5 \mathrm{~m}^{2} \mathrm{~g}^{-1}$. Assuming linearity in MAC with respect to the imaginary part of the refractive index, MAC for BC partially internally mixed with nonabsorptive dust can be estimated from this at ca. $10.1 \mathrm{~m}^{2} \mathrm{~g}^{-1}$. The absorption by OM is still included in this estimate, however.

\subsubsection{Column-integrated optical properties}

Figure 7 shows aerosol optical depth and absorptive optical depth at $550 \mathrm{~nm}$ as well as the Ångström parameter for wavelengths 440 to $870 \mathrm{~nm}$ in the NUDGE_PD simulation compared with AERONET (Holben et al., 1998). The results discussed and referred to below are shown in Fig. 7 and Tables 6-8.

We first look at modeled clear-sky aerosol optical depth at $550 \mathrm{~nm}$ (OD550CS). This is in the model calculated as the all-sky optical depth weighted (at each time step in the simulation) with the clear-sky fraction and with hygroscopic swelling calculated from average grid cell RH. This is the method adapted in K13, while a more common method for simulating the cloud-screened remote sensing assumes hygroscopic swelling based on the clear-sky RH fraction, but for all-sky conditions (no sampling or weighting). Due to the relatively large coverage (which we somewhat loosely call global here; see Fig. 7 and http://aerocom.met.no (last access: 25 September 2018) for the actual coverage) we find an apparently wide spread for modeled vs. observed (monthly) values, but with a relatively low NMB of $-16 \%$, $R=0.59$, and Fact $2=42 \%$. The all-sky values (OD550) look slightly better, with a positive NMB of $15 \%, R=0.64$, and Fact $2=68 \%$. In comparison, CAM4-Oslo has a slightly 


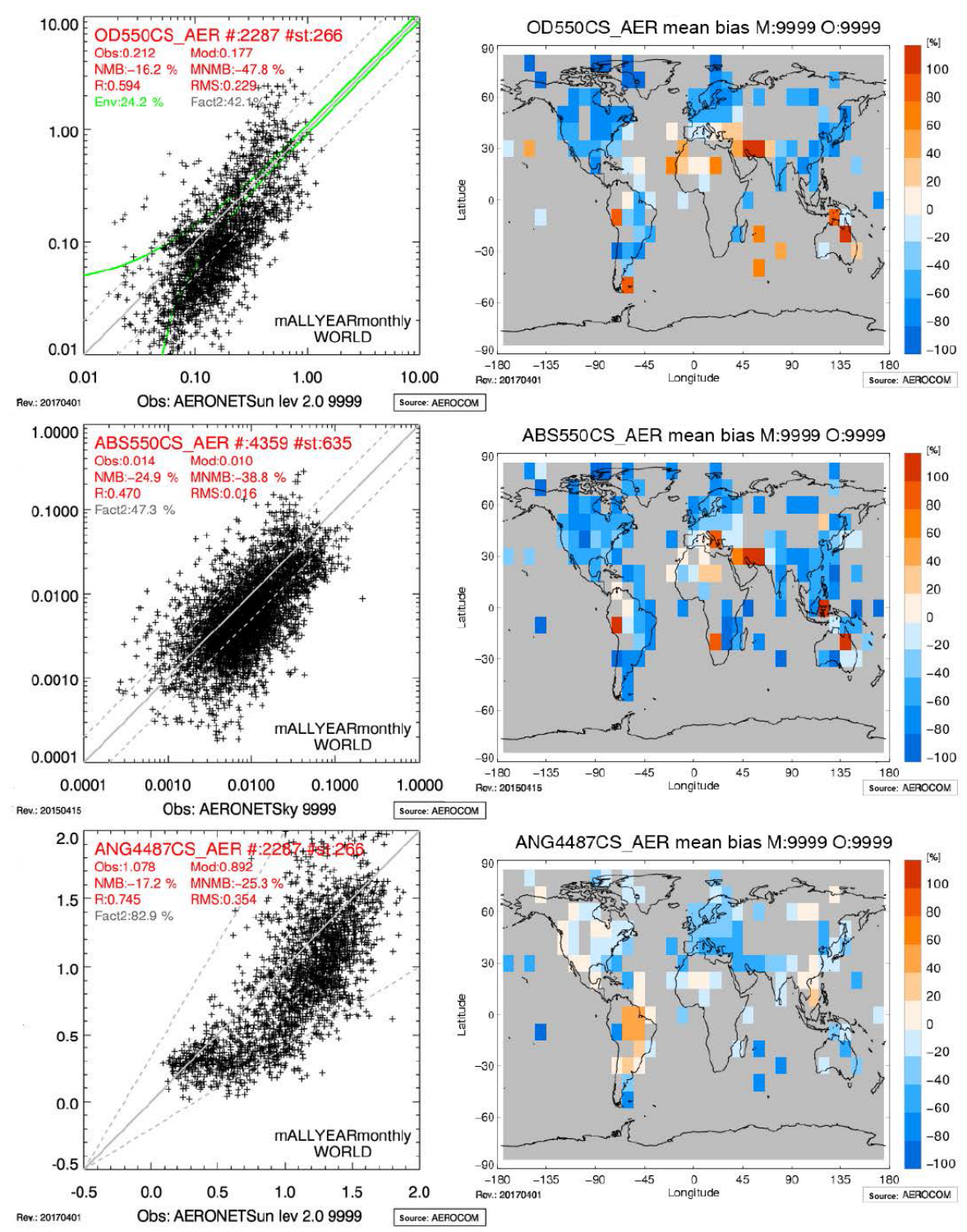

Figure 7. Scatter plots (left panels) and annual relative bias plots with respect to AERONET observations and retrievals (right panels) of clearsky aerosol optical depth (top), all-sky absorption optical depth (middle) at $550 \mathrm{~nm}$, and Ångström parameter (bottom) for the wavelength range $440-870 \mathrm{~nm}$ for the NUDGE_PD simulation.

stronger negative bias for OD550CS and a slightly smaller, but negative, bias for OD550.

Across the various available observation years 2004-2010, MNB for OD550CS varies between $-27 \%$ and $-6 \%$. Regionally, OD550CS is most underestimated in East Asia $(\mathrm{NMB}=-59 \%)$, followed by North America $(-56 \%)$, Europe $(-38 \%)$, South and Central America $(-21 \%)$, and India $(-19 \%)$. Europe is also defined here to include sites at the northern coast of Africa. For northern Africa, which again is defined to include sites at the Mediterranean coast in Europe, the bias is positive (12\%). The positive bias is even larger in Australia (71\%), where mineral dust is also estimated to dominate as the most optically thick aerosol. In spite of the apparent underestimation of near-surface dust mass concentrations discussed in Sect. 4.1.2, we may add here that the global all-sky optical depth contribution to mineral dust is biased by $65 \%$ (not shown; see results at http://aerocom.met.no, last access: 25 September 2018), i.e., much more than the $15 \%$ bias for total OD550. It is furthermore clear from Fig. 7 that OD550CS is underestimated at high latitudes. What is not known, however, is how much of this negative bias is caused by missing or inaccurate emissions (see, e.g., Stohl et al., 2013) and how much of it is a result of other systematic biases such as deficiencies in the modeling of transport, aerosol chemistry, microphysics, and subsequent scavenging or dry deposition. 
Comparing OD550CS with the simulated aerosol optical depth from the same eight AP3 models as in Sect. 4.1.2, we find that four of the models have approximately the same (one model) or larger (in absolute value) NMB values than ours. The correlations are higher in six of the AP3 models, and five models also exhibit higher Fact 2 values. Comparing with the 20 models with available data among the 23 AP2 models, we find that only 7 of these are less biased, but the correlations are smaller than ours in only 3 of the models. Although CAM5.3-Oslo performs well in terms of NMB, the spread is so large that the Fact2 value is lower than in all of these AP2 models.

Moving on to the clear-sky absorption aerosol optical depth at $550 \mathrm{~nm}$ (ABS550CS), we similarly find that $\mathrm{NMB}=$ $-25 \%, R=0.47$, and Fact $2=47 \%$. The all-sky values also look slightly better here, with $\mathrm{NMB}=-20 \%, R=0.47$, and Fact $2=50 \%$. In comparison, CAM4-Oslo has a slightly stronger negative bias for both ABS550CS and ABS550.

Across the individual years 2004-2010, MNB for ABS550CS only varies very little between $-41 \%$ and $-36 \%$. Regionally it is most underestimated in India $(-52 \%)$, followed by East Asia $(-44 \%)$, North America $(-39 \%)$, Europe (defined as above, $-29 \%)$, South and Central America $(-20 \%)$, and Australia $(-13 \%)$. For northern Africa (defined as above), the bias is slightly positive (4\%). Regionally the biases in ABS550CS and OD550CS thus mainly have the same sign, which is consistent with toolow or too-high (depending on the sign of the bias) modeled aerosol burdens. Some exceptions are found, however, such as for Australia as a whole and in (e.g.) some mineral-dustdominated areas over and downwind of the Sahara Desert where the absorption optical depth is underestimated, while the optical depth (at $550 \mathrm{~nm}$ ) is overestimated. This may indicate that the assumed imaginary part of the refractive index at $550 \mathrm{~nm}$ is too small or that the effective size of the mineral dust particles is underestimated, which has been identified as a problem in many AeroCom models (Kok et al., 2017).

A few AP2 models and one AP3 model also have absorption data available (ABS550). Comparing with the AP3 model (MNB $=-56 \%$ ) CAM5.3-Oslo is less biased $(-38 \%)$. Comparing with the 16 models with available data among the 23 AP2 models, we find that only 5 of these are less biased than our model. The correlations are higher than ours in all these AP2 models, however, and nine models have larger Fact2 values.

Finally, we look at the statistics for the clear-sky Ångström parameter, defined here through the clear-sky aerosol optical depths at the wavelengths 440 and $870 \mathrm{~nm}$ in OD440CS and OD870CS, respectively:

ANG4487CS $=\frac{-\ln (\mathrm{OD} 870 \mathrm{CS} / \mathrm{OD} 440 \mathrm{CS})}{\ln (870 / 440)}$.

Globally, for ANG4487CS we obtain $\mathrm{NMB}=-17 \%$, $R=0.75$, and Fact $2=83 \%$, a quite decent result indicating that the aerosol size for the clear-sky atmospheric column is fairly well modeled in terms of its relative abundance of large vs. small particles. The all-sky equivalent ANG4487, however, yields a much poorer match with AERONET, having $\mathrm{NMB}=-44 \%, R=0.46$, and Fact $2=49 \%$. In comparison, CAM4-Oslo has a smaller negative bias for ANG4487 (no clear-sky value is available from that model version), indicating that the effective particle sizes are indeed smaller there than in CAM5.3-Oslo. For all-sky conditions the aerosol sizes are biased much more towards large particles (small ANG values), which is consistent with higher relative humidities and thus more extensive hygroscopic swelling.

Across the individual years 2004-2010, the bias varies as little as between $-15 \%$ and $-16 \%$. Regionally, ANG4487CS is most underestimated in northern Africa (defined as above, i.e., extended to include sites along the European coast of the Mediterranean, $-35 \%$ ), followed by Europe (defined as above, $-32 \%$ ), Australia ( $-31 \%$ ), India $(-20 \%)$, East Asia $(-10 \%)$, and North America $(-7 \%)$. The pattern (see also Fig. 7) seems to point towards dust as a source of large negative biases, which is consistent with an excessive mineral dust contribution to the total aerosol (as also indicated by the regional OD550CS biases) or, alternatively, overestimated dust particles sizes (opposite of what we found as a potential cause of the positive bias in ABS550CS). For South and Central America NMB $=15 \%$, i.e., an overestimate indicating slightly too-fine particles. This positive bias is smallest $(8 \%)$ for the SON months, i.e., late in the biomass burning season for the region, while it is largest $(22 \%)$ for DJF. Since the negative biases for OD550CS and ABS550CS here are smallest $(-5 \%$ and $-6 \%$, respectively) in JJA and largest ( $-32 \%$ and $-35 \%)$ in DJF, there is still a theoretical possibility that the biomass burning aerosol contribution is exaggerated. This could be the case if contributions from other sources are generally underestimated, e.g., due to missing emissions or exaggerated scavenging. Just based on these results, however, we cannot conclude whether this is the case or not nor whether the assumed OM / OC ratio of 2.6 for biomass burning aerosols is too high or not.

None of the AP3 models but 13 of the AP2 models also have ANG4487 information available at http://aerocom.met. no (last access: 25 September 2018). Comparing with the 13 AP2 models, we find that 5 have larger biases than in ours. The correlations are smaller in six models, and the Fact 2 values are also smaller than ours in six models.

The particle sizes globally seem to be well represented. Based on modeled ANG4487CS, the consistent low bias in OD550CS and ABS550CS, and the assumption that the intrinsic optical properties and other factors that might affect the result are fairly well represented, the modeled aerosol column burdens may be underestimated. For the surface concentrations, only BC and mineral dust are underestimated compared to in situ observations, as discussed in Sect. 4.1.2. However, considering that the available in situ measurements are very sparsely distributed globally and that we know little 

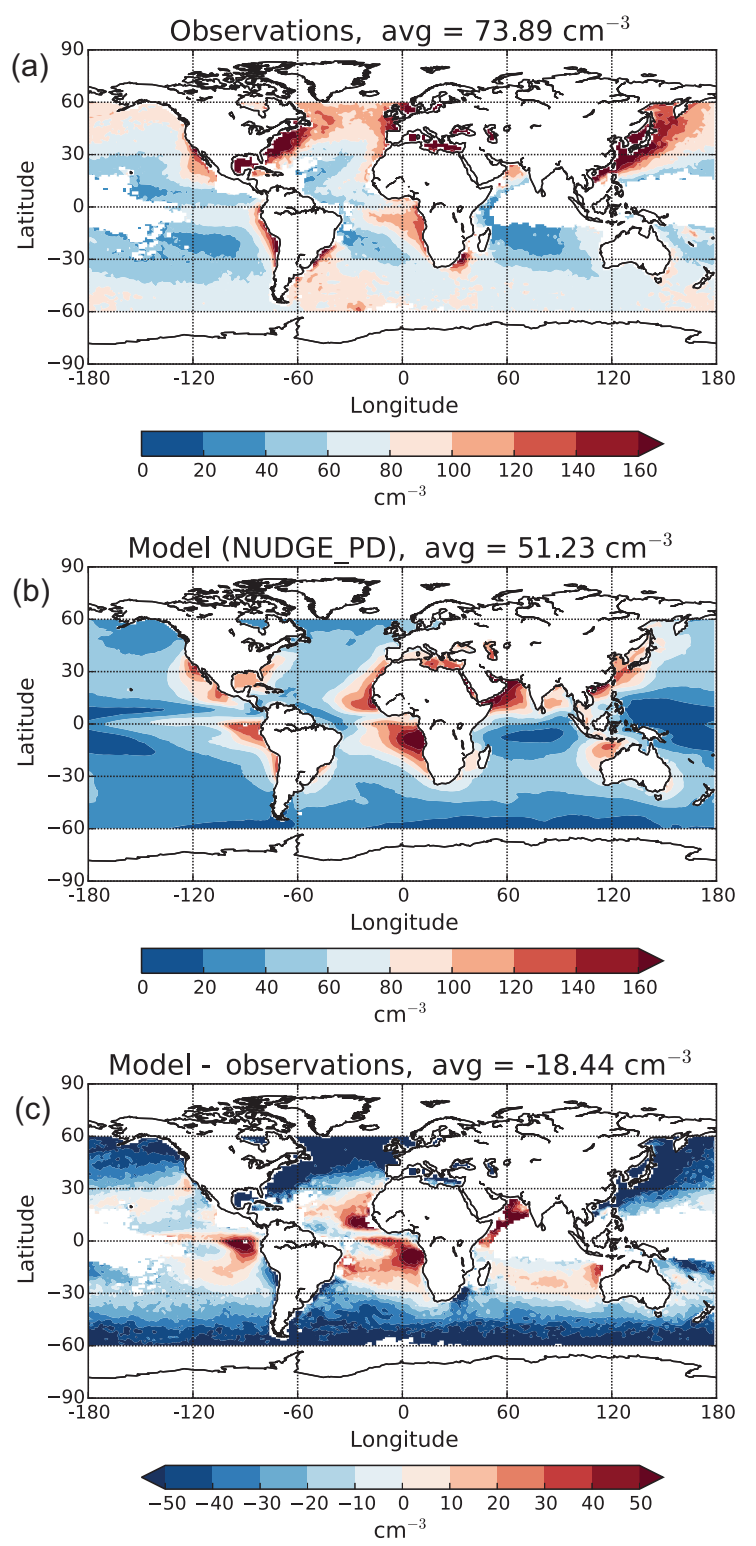

Figure 8. In-cloud cloud droplet number concentrations at cloud top in (b) CAM5.3-Oslo (NUDGE_PD) compared to (a) Bennartz and Rausch (2017), with the difference shown in (c). White areas indicate a lack of observations from MODIS meeting the criteria on temperature and cloud fraction given by Bennartz and Rausch (2017).

about the model performance in terms of the vertical distribution of mass concentrations (except for BC), we cannot expect these very different measures of model performance to fully agree.

Further aerosol model validation is taking place through ongoing multi-model studies that include results from the present model version. These studies are the AeroCom Control EXPERIMENT 2016, the remote sensing evaluation for AeroCom Control 2016, the AeroCom in situ measurement comparison (for optical properties) (https://wiki.met.no/aerocom/phase3-experiments, last access: 25 September), and the BACCHUS CCN global model intercomparison exercise (http://lists.met.no/pipermail/ aerocom-modeller/2017-January/000109.html, last access: 25 September 2018).

\subsection{Cloud droplet concentrations}

We also compare the modeled in-cloud droplet concentration (CDNC) to the data set provided by Bennartz and Rausch (2017). This data set is a climatology of cloud droplet number concentration (monthly mean, in-cloud $1^{\circ} \times 1^{\circ}$ CDNC values plus associated uncertainties for warm clouds) based on 13 years of Aqua MODIS observations over the global ice-free oceans. To facilitate this comparison, we take out in-cloud droplet concentrations at the cloud top, defined as the first layer - starting from the model top - in which the stratiform liquid cloud fraction in a grid cell exceeds $10 \%$ and the temperature criterion of Bennartz and Rausch (2017) is fulfilled, i.e., $268 \mathrm{~K}<T<300 \mathrm{~K}$. The annually averaged result for the NUDGE_PD simulation is given in Fig. 8, which shows that, globally averaged, we calculate lower droplet number concentrations than what is observed. CAM5.3-Oslo mostly underestimates cloud droplet concentrations over coastal ocean areas in East Asia, Europe, and North America. The model overestimates the droplet concentrations close to mineral-dust- and biomass-burningdominated areas, typically downwind of Saudi Arabia and Africa. The results from AMIP_PD (not shown) are very similar with an average of $49.8 \mathrm{~cm}^{-3}$ compared to $51.2 \mathrm{~cm}^{-3}$ for NUDGE_PD. One possible reason for the discrepancies between the model and observations is that we have not applied a satellite simulator, and the simple way of outputting the droplet concentration described above does not necessarily correspond to what the satellite is seeing. A comprehensive analysis of the discrepancies for the different regions, however, is beyond the scope of this study.

\section{Interaction with radiation and clouds}

The effective radiative forcing (ERF) of aerosols has been calculated using the method of Ghan (2013), in which radiative fluxes for a "clean" (no aerosol extinction) and a "clear" (cloud-free, but including aerosol extinction) atmosphere are used together with the standard all-sky (including aerosol extinction) radiative fluxes in order to decompose the ERF into its separate components. Differences between the PD and PI simulations thus yield the anthropogenic ERF as a direct radiative forcing, a cloud radiative forcing (note that this is the contribution by anthropogenic aerosols, not the total cloud forcing itself), and a surface albedo forcing term. We only show and discuss the results for the cloud forcing and the direct radiative forcing components here. The surface albedo 
forcing is small on a global scale and is not discussed. Neither is the semi-direct effect of aerosols, which is included as part of the cloud radiative forcing term (Ghan, 2013) but not calculated and shown separately, since this particular diagnostic requires extra sets of simulations in which (potentially) anthropogenic aerosols are assumed to be totally nonabsorptive (Ghan et al., 2012). Results from such simulations with an earlier, slightly differently tuned model version suggest that the semi-direct effect in CAM5.3-Oslo contributes very little to the total aerosol ERF. The globally averaged $\mathrm{SW}+\mathrm{LW}$ semi-direct radiative forcing was estimated to be $-0.02 \mathrm{~W} \mathrm{~m}^{-2}$.

Figure 9 shows modeled shortwave (SW) and longwave (LW) direct radiative forcing at the top of the atmosphere (TOA) annually averaged from both the nudged simulations (i.e., NUDGE_PD-NUDGE_PI) and the longer AMIP simulations (AMIP_PD-AMIP_PI). Global averages are listed and compared to estimates from CAM4-Oslo (direct RF) and IPCC AR5 (direct RF and ERF) in Table 10. Regionally, the SW direct forcing is positive over some areas with high surface albedo or high cloud fractions for low clouds, mainly related to biomass burning activity, which compared to PI conditions has led to increased levels of light-absorbing aerosols such as fossil fuel or biomass burning BC (e.g., Sahara, the Arctic, and off the west coasts of South America and Africa). The direct forcing term is also positive in some areas with reduced absorption, where the scattering aerosol optical depth (mainly from OM) has decreased even more (such as in the eastern USA and parts of Australia and South America). However, negative SW direct forcing is dominant over the industrialized parts of the world due to the general increase in scattering aerosol of anthropogenic origin (sulfate and $\mathrm{OM}$ ). The global annual average is estimated at $-0.095 \mathrm{~W} \mathrm{~m}^{-2}$ $\left(-0.092 \mathrm{~W} \mathrm{~m}^{-2}\right.$ for the AMIP simulations). The LW direct forcing is much smaller, having a regional maximum over the Middle East where both large mineral dust and (internally mixed) anthropogenic aerosol are abundant: the sulfate column burden has a local maximum in this region. The global annual average here is $0.026 \mathrm{~W} \mathrm{~m}^{-2}$ for both the NUDGE and the AMIP simulations. Just as for CAM4-Oslo, the estimated total (joint SW and $\mathrm{LW}$ ) global direct radiative forcing in CAM5.3-Oslo lies within the range of the ERFari estimates of IPCC AR5 (Boucher et al., 2013); see Table 10. Since the AR5 range has been evaluated for the period 1750 2011 and ERFari in AR5 includes the semi-direct effect, the numbers are not entirely comparable.

Figure 10 similarly shows the shortwave (SW) and longwave (LW) cloud radiative forcing (due to anthropogenic aerosols) at TOA. Here we also obtain positive SW forcing in some areas, mainly in the SH subtropics and at high latitudes, consistent with the lower PD than PI cloud droplet concentrations (CDNC) and liquid water path (LWP) found in these areas. Some of the positive cloud forcing is due to a reduction in organic emissions from biomass burning since 1850 (e.g., in England, Australia, and the eastern United States).
Also over the Southern Ocean there are areas with slightly positive values, coinciding with areas with slightly smaller column vertically integrated CDNC and LWP values in the PD than in the PI simulations. This pattern has been found to be even more prominent when the PI simulations apply PI oxidant levels (instead of PD as in this study); see Karset et al. (2018) for a more thorough discussion on the effect of different oxidant levels on the cloud forcing. Areas with a negative SW cloud forcing term, however, are dominant due to the general increase in CDNC from PI to PD conditions, being large (negative) over oceans downstream of areas with high aerosol emissions from industrial activity, biofuel consumption, or biomass burning. The negative SW cloud forcing peaks over the northern Pacific Ocean near the coast of East Asia. The global annual average value is estimated at $-1.50 \mathrm{~W} \mathrm{~m}^{-2}\left(-1.45 \mathrm{~W} \mathrm{~m}^{-2}\right.$ for the AMIP simulations). The LW cloud forcing is smaller and is in most regions of opposite sign to the SW contribution. Its global and annual average is $0.161 \mathrm{~W} \mathrm{~m}^{-2}\left(0.155 \mathrm{~W} \mathrm{~m}^{-2}\right.$ for the AMIP simulations). Compared to the ERFaci estimates in Table 10, the total global cloud radiative forcing in CAM5.3-Oslo is thus on the high side, lying just outside the 5 to $95 \%$ confidence range given by IPCC AR5. As mentioned, the AR5 range in Table 10 is for the period 1750-2011 instead of 18502000. Compared to this extended period we should expect a somewhat smaller negative forcing contribution, since the reference state in 1850 is less pristine than in 1750, while changes due to aerosols in the latter part of the period are of less importance (Carslaw et al., 2013). For the same time period, however, we should expect a stronger negative cloud forcing than that of AR5 since the second indirect effect is included in our model (although not calculated separately), whereas the ERFaci range in IPCC AR5 is (mainly) for the first indirect effect.

The expert judgment of a 5 to $95 \%$ (medium confidence) uncertainty range for ERFari + ERFaci is in IPCC AR5 estimated to be -1.9 to $-0.1 \mathrm{~W} \mathrm{~m}^{-2}$, while the 17 $83 \%$ (likely) range is -1.5 to $-0.4 \mathrm{~W} \mathrm{~m}^{-2}$ (Boucher et al., 2013). These estimates take into account the fact that GCM studies calculate stronger aerosol ERF values than what is found in satellite studies. Our model values of $-1.4 \mathrm{~W} \mathrm{~m}^{-2}$ (NUDGE_PD-NUDGE_PI) and $-1.36 \mathrm{~W} \mathrm{~m}^{-2}$ (AMIP_PD-AMIP_PI) lie within both ranges of uncertainty. Our model estimates are also very close to 1 standard deviation away from the multi-model estimate for the period 1850-2000 in Boucher et al. (2013), which is given as $-1.08 \pm 0.32 \mathrm{~W} \mathrm{~m}^{-2}$ based on results from the CMIP5 and ACCMIP (Atmospheric Chemistry and Climate Model Intercomparison Project) models.

Table 11 lists some globally and annually averaged variables relevant for understanding the above estimates of effective radiative forcing by aerosols for both the NUDGE and AMIP simulations. Although the globally averaged allsky aerosol optical depth at $550 \mathrm{~nm}$ (OD550) for PD is found to be larger than in CAM4-Oslo (0.135; see Table 7 in 
(a)

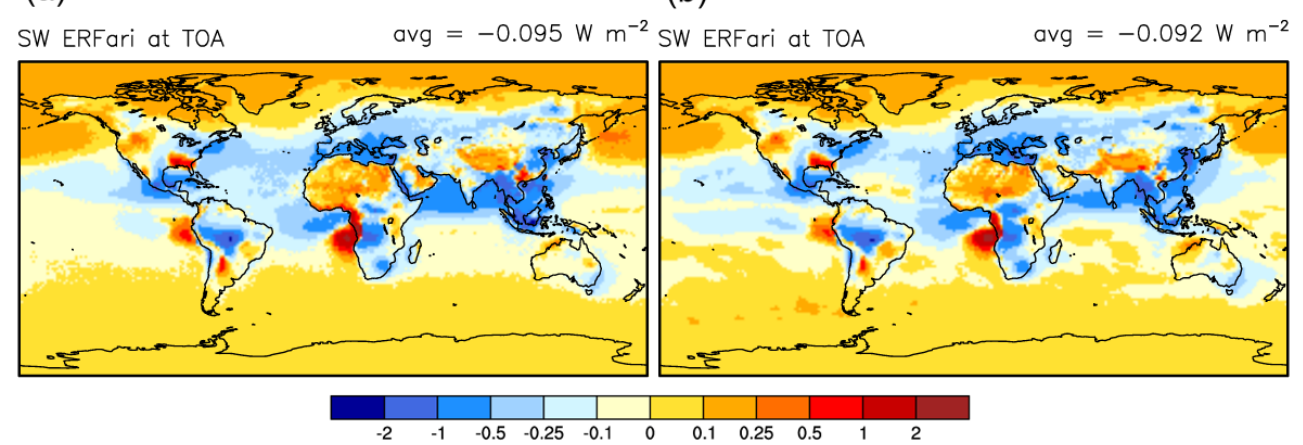

(c)

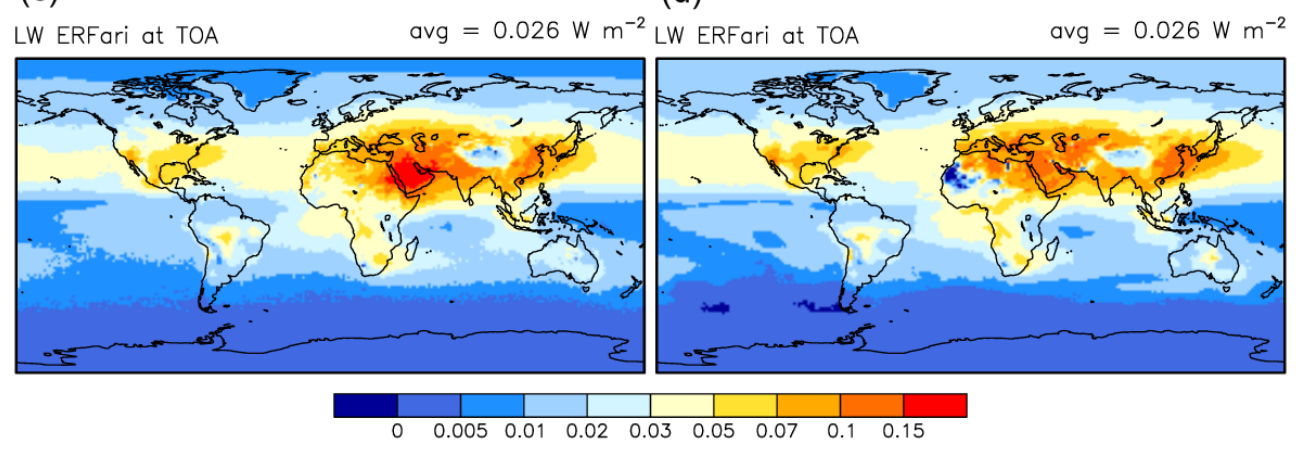

Figure 9. Shortwave (SW, a and b) and longwave (LW, $\mathbf{c}$ and $\mathbf{d}$ ) ERFari at the top of the atmosphere (TOA) for the simulations NUDGE_PDNUDGE_PI (a and c) and AMIP_PD-AMIP_PI (b and d). Note the different color scales. Note also that the semi-direct effect is not included here, since ERFari in this study corresponds to the "direct radiative forcing" component in Ghan (2013).

K13), we now obtain an anthropogenic (PD-PI) AOD that is $29 \%$ smaller than in CAM4-Oslo, mainly due to lower atmospheric residence times and burdens of sulfate, $\mathrm{BC}$, and OM. The simulated anthropogenic AOD fractions of total AOD (about $16 \%$ in both NUDGE_PD and AMIP_PD) are therefore considerably smaller than in CAM4-Oslo (26\%), which is about the same as in the average AeroCom Phase I model (25\%; Schulz et al., 2006). Anthropogenic absorption AOD (ABS) is about 40-45\% smaller than in CAM4Oslo (0.020), and the anthropogenic ABS fraction is estimated at about $25 \%$ compared to $43 \%$ in CAM4-Oslo. Considering that the anthropogenic absorption optical depth has decreased more (39\%) than the anthropogenic optical depth itself $(28 \%)$, one would perhaps expect a more negative direct radiative forcing in CAM5.3-Oslo. It is instead found to be nearly the same: -0.095 (or -0.092 for the AMIP simulations) vs. $-0.10 \mathrm{~W} \mathrm{~m}^{-2}$ (as an instantaneous direct forcing) globally averaged. This can be partly understood as an effect of the substantial increase in the cloud fraction (and thus planetary albedo) for low clouds, 0.43 vs. 0.34 , with the largest increase found at middle to high latitudes. The surface albedo is also higher in CAM5.3-Oslo: 0.163 vs. 0.156 in CAM4-Oslo. Regionally the largest increases $(>0.1)$ are also found here at middle and high latitudes over continents in the NH. The shift towards smaller anthropogenic BC concentrations and to lower altitudes (Fig. 5), which reduces the absorption in the atmospheric column and therefore leads to a less positive direct RF (e.g., Samset et al., 2013), is in other words counteracted by the effect of increased surface or nearsurface albedos from CAM4-Oslo to CAM5.3-Oslo. The reduction in anthropogenic atmospheric absorption is reflected in the difference in SW direct radiative forcing between the TOA and the surface, which in CAM5.3-Oslo is estimated at $0.51 \mathrm{~W} \mathrm{~m}^{-2}$ for NUDGE and $0.47 \mathrm{~W} \mathrm{~m}^{-2}$ for AMIP compared to $0.95 \mathrm{~W} \mathrm{~m}^{-2}$ in CAM4-Oslo (K13).

In-cloud cloud droplet number concentrations and effective droplet radii are defined here differently than in CAM4Oslo by (for each time step) weighting the respective model variables with the stratiform liquid cloud fraction (a number between 0 and 1) in CAM5.3-Oslo instead of the frequency of cloud occurrence (being either 0 or 1). These two model parameters are therefore not directly comparable between the two model versions. We can see, however, that the vertically integrated liquid water path (LWP) in CAM5.3Oslo $\left(\sim 54 \mathrm{~g} \mathrm{~m}^{-2}\right)$ is much smaller than in CAM4-Oslo $(\sim$ $130 \mathrm{~g} \mathrm{~m}^{-2}$; see K13). Some of this drop in LWP may be due to the changes in aerosol treatment, but the relative low sensitivity of LWP to aerosol concentration levels (Table 11; Table 4 in K13) suggests that much of it is a result of switching from the RK cloud microphysics scheme (Rasch and Kristjánsson, 1998) in CAM4-Oslo to MG1.5 (see Sect. 3) in CAM5.3-Oslo and how the respective schemes are tuned. 
(a)

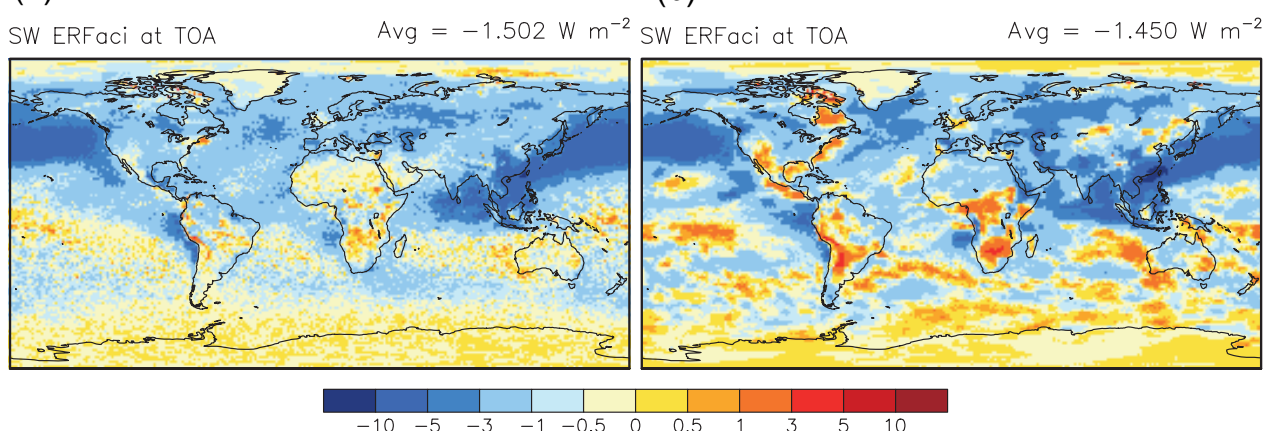

(c)

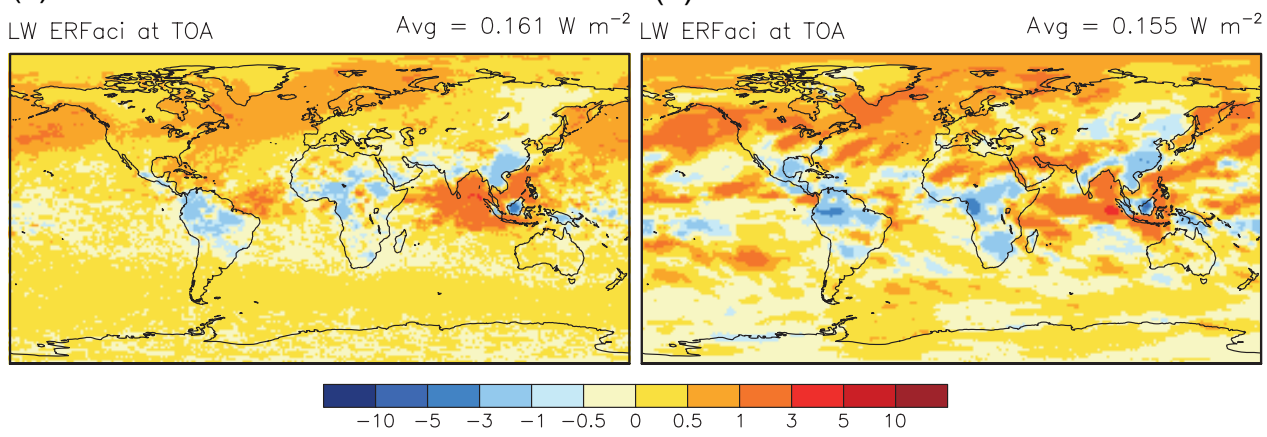

Figure 10. Shortwave (SW, a and b) and longwave (LW, c and d) ERFaci at the top of the atmosphere (TOA) for the simulations NUDGE_PD-NUDGE_PI (a and $\mathbf{c}$ ) and AMIP_PD-AMIP_PI (b and d). Note that the semi-direct effect is embedded here in the ERFaci term, which corresponds to the "cloud radiative forcing" component in Ghan (2013).

This may have contributed to an increase in the modeled cloud susceptibility (Albrecht, 1989), thus leading to enhanced cloud forcing by anthropogenic aerosols. A more thorough investigation of this falls outside the scope of this study and has not been pursued. Note, however, that nudging to the ERA data instead of the model's own meteorology only has small impacts on anthropogenic cloud forcing: Karset et al. (2018), applying self-nudging (and when using the same oxidant levels as in the present study) in CAM5.3-Oslo, estimated it to $-1.32 \mathrm{~W} \mathrm{~m}^{-2}$, which is very close to our estimate of $-1.34 \mathrm{~W} \mathrm{~m}^{-2}$ (SW + LW ERFaci in Table 10).

The size and even sign of the Albrecht (lifetime) effect is very uncertain and has in a recent observationally based study been shown to be small or, more specifically, not detectable above the level of natural variability for the Holuhraun volcanic eruption (Malavelle et al., 2017). In CAM5.3-Oslo the anthropogenic change in LWP is estimated to be about $3.56 \mathrm{~g} \mathrm{~m}^{-2}$ in NUDGE_PDNUDGE_PI ( $3.42 \mathrm{~g} \mathrm{~m}^{-2}$ in the AMIP simulations). Compared to $4.37 \mathrm{~g} \mathrm{~m}^{-2}$ in CAM4-Oslo (K13), this constitutes a much larger relative change in LWP, being $6.6 \%(6.4 \%)$ instead of $3.4 \%$. The lifetime effect was in CAM4-Oslo calculated as a radiative forcing, however, by using double calls to both the radiation and stratiform cloud microphysics modules, following Kristjánsson (2002). Since the cloud cover is independent of liquid water content (mainly depending on $\mathrm{RH}$ ), that approach does not take into account changes in cloud lifetime from changes in the cloud cover, which may result in a low-end estimate of the indirect effect (Kristjánsson, 2002). The relative (anthropogenic divided by total) change in vertically integrated CDNC is about the same in CAM5.3-Oslo (21\% in both NUDGE and AMIP) and in CAM4-Oslo ( $21 \%$, not shown). Hence, a considerable part of the increase in cloud effective radiative forcing from $-0.90 \mathrm{~W} \mathrm{~m}^{-2}$ to $-1.34 \mathrm{~W} \mathrm{~m}^{-2}$ is probably due to the very uncertain lifetime indirect effect.

Since the modeled ice crystal number concentrations (IC$\mathrm{NCs}$ ) can be directly affected by aerosols only through the heterogeneous freezing of mineral dust and BC in mixedphase clouds, it is quite insensitive to anthropogenic aerosols. Vertically integrated ICNC is practically unchanged from PI to PD in both the NUDGE and AMIP simulations (Table 11), so the effect of this on the total cloud radiative forcing is probably negligible.

\section{Summary and conclusions}

We have described in quite some detail changes in the treatment of aerosols and aerosol-cloud interactions in going from the predecessor model version CAM4-Oslo (Kirkevåg et al., 2013; Iversen et al., 2013) to CAM5.3-Oslo. In broad terms the changes consist of explicitly taking into account 
nucleation and secondary organic aerosols (based on Makkonen et al., 2014), using new sea salt emissions and emission sizes (Salter et al., 2015), applying interactive DMS and primary organics emissions by using prescribed oceansurface-layer-concentration- and wind-driven parameterizations (Nightingale et al., 2000; Vignati et al., 2010), and now also online dust emissions (Zender et al., 2003). Aerosol hygroscopicity and some other microphysical properties have also been updated, and heterogeneous ice nucleation has been implemented based on Wang et al. (2014). An updated overview of the main principles behind the productiontagged aerosol module, which is used in CAM5.3-Oslo and a number of predecessor versions, has also been presented.

We have furthermore made an attempt to validate CAM5.3-Oslo with respect to its simulated aerosol properties and aerosol cloud interactions by comparing monthly model output with in situ observations and remote retrievals. This is meant to more thoroughly complement several ongoing intercomparison studies, mainly under the AeroCom project (see http://aerocom.met.no, last access: 25 September 2018), which focus on various model diagnostics at monthly as well as finer time resolutions (down to $1 \mathrm{~h}$ ) using results from the same model version as in this study along with other AeroCom models.

It is shown that the simulated vertical profile of BC concentrations is more realistic in CAM5.3-Oslo than in CAM4Oslo when comparing to in situ measurements from the HIPPO aircraft campaign in the Pacific Ocean. The new model version produces much less excessive BC mass concentrations in the upper troposphere and in the stratosphere, although the concentrations are still overestimated at the highest altitudes. This may be related to aerosol aging and to how aerosols are transported and scavenged in deep convective clouds (see, e.g., Kipling et al., 2016); the mass concentrations of the other aerosol components have also been reduced (aloft) from CAM4-Oslo to CAM5.3-Oslo. This issue is to a large degree dependent on the choice of host model (which is CAM5.3 in this case) and will most likely continue to be an area of focus in future research and development of the model. Note that there is a general tendency for models participating in the AeroCom project to overestimate $\mathrm{BC}$ compared to the aircraft measurements in the free troposphere in remote regions (Samset et al., 2014).

With an approximately doubled DMS emission and a subsequent increase in the $\mathrm{SO}_{2}$ source term, near-surface mass concentrations of $\mathrm{SO}_{2}$ now seem to be considerably overestimated (normalized mean bias NMB $\sim 150 \%$ ) compared to in situ observations available via the AeroCom intercomparison project (http://aerocom.met.no, last access: 25 September 2018), more so than in CAM4-Oslo. However, the modeled concentrations are not adjusted with respect to representative height above the ground surface before comparing with observations, which is an important factor for $\mathrm{SO}_{2}$ and therefore hampers reliable evaluation of the model performance.
Near-surface sulfate concentrations are biased slightly high $(22 \%)$, more so than in CAM4-Oslo $(-5 \%)$, which instead exhibits a slightly lower Pearson correlation coefficient, $R$. All eight AeroCom Phase III (AP3) models with available information at aerocom.met.no have higher correlations, and half of them also have smaller (in absolute value) biases. The sulfate concentrations in CAM5.3-Oslo are found to be less biased than only 6 of the 23 available AeroCom Phase II (AP2) models, although with similar or better correlations than 14 of the models.

Near-surface BC concentrations are mainly biased low $(-28 \%)$, but less than in CAM4-Oslo $(-54 \%)$, which together with the more realistic vertical profiles indicates an improvement in modeling of $\mathrm{BC}$. The bias is also found to be smaller than in 6 of 8 AP3 models, but only in 7 of the 23 AP2 models. The correlation values lie within the ranges spanned by the AP2 and AP3 models, although in the lower range for both AeroCom phases.

Since OsloAero5.3 (like earlier module versions) does not trace OM from different source types with different assumed $\mathrm{OM} / \mathrm{OC}$ ratios, a reliable evaluation of the modeled mass concentrations for OM cannot be obtained without doing further work with this particular aim in mind. However, if we simply assume that the $\mathrm{OM} / \mathrm{OC}$ ratio in the model is 1.4 or 2.6 for all $\mathrm{OC}$, which is assumed to be representative for cases with no biomass burning and only biomass burning emission sources, respectively, we find respective biases of $122 \%$ or $19 \%$ compared to $108 \%$ or $12 \%$ in CAM4-Oslo. Unless the sparsely distributed in situ observation data represent OC very poorly globally (which is a possibility since only North America and Europe are represented), these results do indicate an overestimation that is now slightly larger than in the predecessor model despite the increased level of sophistication in the new parameterization of SOA and primary biogenic OM emissions from the ocean. The correlation value of 0.29 is just below that of CAM4-Oslo. The correlation is also lower than in most of the AP2 models and all of the AP3 models. If we assume that $\mathrm{OM} / \mathrm{OC}=1.4$, the bias is also larger than in the AP3 models and in all but one of the AP2 models. Although CAM4-Oslo apparently performs slightly better in this particular evaluation and for the current $\mathrm{OM} / \mathrm{OC}$ ratio assumption, we should keep in mind that both SOA (treated as primary $\mathrm{OM}$ ) and biogenic $\mathrm{OC}$ from the ocean use prescribed emissions, rendering that model version less useful for Earth system modeling and studies of past and future climates, as well as for more detailed process studies and sensitivity studies in general.

The sea salt aerosol concentrations are found to have a bias of $22 \%$, which is an improvement compared to CAM4-Oslo, although the correlation is slightly lower. Both model versions apply wind- and temperature-dependent emissions, but CAM5.3-Oslo is using particle size parameters at the point of emission that are closer to observed values in (and fully consistent with) the updated treatment. Our model outperforms the AP3 models bias-wise and has the second highest Pear- 
son correlation. It also ends up among the best in comparison to the AP2 models.

The surface concentrations of mineral dust are biased low by $-39 \%$, but with a decent correlation of 0.52 . The available observation sites are not representative for the source regions of dust, however, and we have reasons to believe that the negative bias is a result of an underestimate in dust transport rather than in the emissions; see the summary for aerosol optics below. The dust concentrations have quite large yearto-year variations and differ the most between the nudged and the free-running AMIP simulations, for which the bias is smaller. Compared to the eight AP3 models, CAM5.3-Oslo performs better than three bias-wise and four with respect to correlation. Compared to the 23 AP2 models it performs better than 14 models bias-wise, but only 7 with respect to correlations. CAM4-Oslo is less biased, but uses prescribed dust emissions and is therefore less applicable for climate and Earth system modeling studies.

We have also compared column-integrated optical parameters with estimates from other models, most importantly with ground-based remote sensing data (AERONET). Looking first at the modeled mass extinction coefficients (MECs), we find changes in all components compared to CAM4-Oslo: a ca. $13 \%$ decrease in MEC for sulfate and $30 \%$ for OM, while it has increased by ca. $17 \%$ for BC, $18 \%$ for mineral dust, and as much as $63 \%$ for sea salt, for which considerable changes in assumed particle size at the point of emission have had a large impact. The new estimates are all within the range of models that participated in AeroCom Phase I. The globally averaged mass absorption coefficient (MAC) for $\mathrm{BC}$ is smaller or larger than in the predecessor and in observations, depending on how it is being calculated. The practice for evaluating this parameter in climate models is to our knowledge not standardized for internally mixed aerosols and is often estimated based on the assumption that $\mathrm{BC}$ is the only aerosol component that contributes to absorption. This approach yields high globally averaged MAC values of about 21-23 $\mathrm{m}^{2} \mathrm{~g}^{-1}$ in CAM5.3-Oslo and $13.6 \mathrm{~m}^{2} \mathrm{~g}^{-1}$ in CAM4Oslo. Adopting the more realistic assumption that mineral dust and $\mathrm{OM}$ also contribute to the absorption, a lower bound of the globally averaged modeled MAC is estimated to be approximately $5 \mathrm{~m}^{2} \mathrm{~g}^{-1}$. If we take this lower bound as a representative model value, it just touches the lower end of a recommended range of 5 to $11 \mathrm{~m}^{2} \mathrm{~g}^{-1}$ based on in situ measurements. However, even here we find areas regionally where MAC exceeds the recommended central value of $7.5 \mathrm{~m}^{2} \mathrm{~g}^{-1}$.

Comparing clear-sky aerosol optical depth at $550 \mathrm{~nm}$ (OD550CS) with remotely retrieved values from AERONET sun-photometer stations worldwide, we find a negative bias of $-16 \%$ globally compared to $-22 \%$ in CAM4-Oslo. The respective all-sky bias for CAM5.3-Oslo is positive at $15 \%$. OD550CS is generally biased low at high NH latitudes and high over and downstream of major mineral dust emission areas. Compared to the eight AP3 models, half of these have smaller bias values globally, while six perform better than
CAM5.3-Oslo with respect to correlations. Compared to 20 AP2 models, only 7 of these have lower biases, while correlations are higher in 17 of the models.

For clear-sky absorption optical depth (ABS550CS) there is a slightly stronger negative bias of $-25 \%$, but smaller than in CAM4-Oslo. The all-sky model variable is slightly less biased. The ABS550CS bias is of same sign and roughly the same magnitude as for OD550CS for most regions worldwide. The 1 AP3 model with data available has a stronger low bias, and only 5 of 16 AP2 models have smaller biases than CAM5.3-Oslo. All of these AeroCom models yield better correlation values, however.

The clear-sky Ångström parameter (ANG4487CS) is found to have a relatively small negative bias globally of $-17 \%$, while the all-sky variable has a much stronger negative bias. ANG4487CS is most underestimated in northern Africa, which is consistent with exaggerated dust emissions. Comparing with 13 AP2 models, CAM5.3-Oslo is outperformed by 7 models bias-wise and 5 models with respect to correlation.

In an attempt to also evaluate an important aspect of cloud microphysics with respect to the calculation of cloud-aerosol interactions, we have compared modeled droplet concentrations (CDNC) at the cloud top with remotely retrieved CDNC from MODIS. This is done for ocean areas only, but these are the areas contributing most to the global effective radiative effect due to aerosol-cloud interactions. While overestimating droplet concentrations downwind of major emissions of mineral dust and biomass burning aerosols, CAM5.3Oslo (in NUDGE_PD) mainly underestimates CDNC over the other coastal areas in East Asia and North America. This might be related to biases in aerosol concentrations in the respective continental source regions, but this cannot be known for sure as long as we only have near-surface concentrations for very limited areas to compare with and only mass (not number) concentrations. The largest regional biases in OD550CS from AERONET, which have mainly continental sites, seem to be consistent with the positive biases in CDNC, however. Globally averaged (low-latitude to midlatitude ocean grid points only), cloud-top CDNC has a low bias of $-32 \%$.

Finally, we have presented and discussed model estimates of effective radiative forcing (ERF) by anthropogenic aerosols for comparison with previous radiative forcing (RF) results from CAM4-Oslo and RF and ERF estimates from IPCC AR5. Globally averaged, the SW direct effect is estimated at $-0.095 \mathrm{~W} \mathrm{~m}^{-2}$ compared to $-0.100 \mathrm{~W} \mathrm{~m}^{-2}$ in CAM4-Oslo. The LW direct effect was not taken into account in CAM4-Oslo and in CAM5.3-Oslo is estimated to be $0.026 \mathrm{~W} \mathrm{~m}^{-2}$. The joint $\mathrm{SW}$ and $\mathrm{LW}$ direct effective radiative forcing $\left(-0.069 \mathrm{~W} \mathrm{~m}^{-2}\right)$ lies well within the range of estimates in IPCC AR5. The effective radiative cloud forcing due to anthropogenic aerosols for SW and LW radiation is estimated at $-1.50 \mathrm{~W} \mathrm{~m}^{-2}$ and $0.16 \mathrm{~W} \mathrm{~m}^{-2}$, respectively, compared to $-0.91 \mathrm{~W} \mathrm{~m}^{-2}$ and $0.01 \mathrm{~W} \mathrm{~m}^{-2}$ in CAM4-Oslo. The 
joint SW and LW cloud forcing by anthropogenic aerosols in CAM5.3-Oslo $\left(-1.34 \mathrm{~W} \mathrm{~m}^{-2}\right)$ is at the lower end of the $5-95 \%$ confidence interval of IPCC AR5 based on model and satellite studies, but lies just within 1 standard deviation of the reported multi-model range of the CMIP5 and ACCMIP models.

Whether we use the short (7-year) simulations that have been nudged to ERA-Interim meteorology or the longer (30-year) free AMIP simulations does not make much of a difference for the global averaged results, e.g., for the ERF estimates (only $4 \%$ weaker total aerosol ERF in the free-running simulations). Regionally, differences are larger, however, both for ERF estimates and for anthropogenic contributions to model fields in general (i.e., differences PD-PI).

After the simulations for use in this study were finalized, it was found that the median radius for mixture no. 12 (Aitkenmode BC) with respect to dry deposition had not been increased to the new number in Table 2, as intended. Instead the old value of $0.0118 \mu \mathrm{m}$ (K13) has been used. This only affects the dry deposition (in OsloAero5.3), while the treatment of aerosol optics and sizes for use in cloud droplet activation (in AeroTab5.3, as well as in the lookup tables and the use of those in the model) is correct and unaffected. The impact of the bug has been tested by rerunning two of the least timeconsuming simulations (NUDGE_PD and NUDGE_PI) with the bug fixed. This reveals that the code used in this study has underestimated the $\mathrm{BC}$ lifetime and column burden by about $9 \%$ and the globally averaged direct effective radiative forcing by $0.02 \mathrm{~W} \mathrm{~m}^{-2}$. Since the bug affects only a small part of the results discussed in this study and since the exact same model version has been used in several ongoing AeroCom Phase III intercomparison experiments (with additional simulations with finer time-resolved model output), we have decided to keep this model version and the results as they are for this particular study. In addition to correcting this bug for BC, the presented results suggest that we should retune (reduce) the dust emission strength in future work with CAM5.3-Oslo in order to better match remotely retrieved aerosol optical depths over the most dust-dominated areas. The somewhat surprisingly small changes in OM results (including the validation) compared to the predecessor model, in which the SOA treatment is very simplistic, should also be investigated in more detail. Vertical transport and aerosol cloud interactions in convective clouds are other areas of great interest.

Code and data availability. The source code for CAM5.3-Oslo is part of a restricted NorESM2 prerelease and stored within the private GitHub NorESM repository (https://github.com/metno/ noresm/tree/NorESM1.2-v1.0.0, last access: 25 September 2018). Access to the code and simulation output data produced in this study can be obtained upon reasonable request to noresm-ncc@met.no and requires entering a NorESM Climate modeling Consortium (NCC) user agreement. The CAM4-Oslo and CAM5.3-Oslo data in Tables 5-8 and Figs. 6 and 7 are available from the Aero-
Com database at http://aerocom.met.no (last access: 25 September 2018) under the project label NorESM, subset NorESMRef2017. Most of the discussed model data (in the form of tables and figures) are also available at http://ns2345k.web.sigma2.no/ nudged_NorESM_c12 (last access: 25 September 2018); see especially 53OSLO_PDandPIwPDoxi_vs_AMIP_PDandPIwPDoxi for comparisons of NUDGE_PD with AMIP_PD and NUDGE_PDNUDGE_PI with AMIP_PD-AMIP_PI.

Competing interests. The authors declare that they have no conflict of interest.

Acknowledgements. This study has been financed by the Research Council of Norway (RCN) through the project EVA (229771) and the NOTUR/Norstore projects (Sigma2 accounts nn2345k and nn9448k; Norstore account NS2345K), by the Nordic projects eSTICC (57001) and CRAICC (26060), and by the EU projects BACCHUS (FP7-ENV-2013-603445), CRESCENDO (641816), and IS-ENES2. Xiaohong Liu was supported by the Office of Science of the US Department of Energy as part of the Earth system modeling program. General NorESM1.2/CAM5.3-Oslo model development has also benefited from contributions by other scientists affiliated with NCAR and PNNL in the USA, member institutions of the Norwegian Climate Centre (BCCR, MET Norway, MetOs-UiO, NERSC, Cicero, NILU and NP), MISU, the Bolin Centre in Sweden, and the University of Helsinki, Finland. Special thanks go to NCAR for granting early access to development versions of CESM, to the AeroCom community for making their model data available at aerocom.met.no (last access: 25 September 2018), and to Jón Egill Kristjánsson at the Department of Geosciences, University of Oslo (UiO), for his dedicated work on cloud microphysics and aerosol-cloud interactions and his leading role in this field at $\mathrm{UiO}$ until he passed away on 14 August 2016. Finally, we would like to thank two anonymous reviewers, the topical editor (Graham Mann), and the executive editor (Lutz Gross) of GMD for their very constructive comments and reviews, which significantly improved the clarity and quality of the paper.

Edited by: Graham Mann

Reviewed by: two anonymous referees

\section{References}

Abdul-Razzak, H. and Ghan, S. J.: A parameterization of aerosol activation: 2. Multiple aerosol types, J. Geophys. Res., 105, 68376844, https://doi.org/10.1029/1999JD901161, 2000.

Albrecht, B. A.: Aerosols, Cloud Microphysics, and Fractional Cloudiness, Science, 245, 1227-1230, 1989.

Arimoto, R., Duce, R. A., Ray, B. J., Ellis, W. G., Cullen, J. D., and Merrill, J. T.: Trace-Elements in the Atmosphere over the NorthAtlantic, J. Geophys. Res.-Atmos., 100, 1199-1213, 1995.

Atkinson, R., Baulch, D. L., Cox, R. A., Crowley, J. N., Hampson, R. F., Hynes, R. G., Jenkin, M. E., Rossi, M. J., Troe, J., and IUPAC Subcommittee: Evaluated kinetic and photochemical data for atmospheric chemistry: Volume II - gas phase re- 
actions of organic species, Atmos. Chem. Phys., 6, 3625-4055, https://doi.org/10.5194/acp-6-3625-2006, 2006.

Atkinson, R., Baulch, D. L., Cox, R. A., Crowley, J. N., Hampson, R. F., Hynes, R. G., Jenkin, M. E., Rossi, M. J., and Troe, J.: Evaluated kinetic and photochemical data for atmospheric chemistry: Volume $\mathrm{I}-$ gas phase reactions of $\mathrm{O}_{x}, \mathrm{HO}_{x}$, $\mathrm{NO}_{x}$ and $\mathrm{SO}_{x}$ species, Atmos. Chem. Phys., 4, 1461-1738, https://doi.org/10.5194/acp-4-1461-2004, 2004.

Bennartz, R. and Rausch, J.: Global and regional estimates of warm cloud droplet number concentration based on 13 years of AQUA-MODIS observations, Atmos. Chem. Phys., 17, 98159836, https://doi.org/10.5194/acp-17-9815-2017, 2017.

Bentsen, M., Bethke, I., Debernard, J. B., Iversen, T., Kirkevåg, A., Seland, Ø., Drange, H., Roelandt, C., Seierstad, I. A., Hoose, C., and Kristjánsson, J. E.: The Norwegian Earth System Model, NorESM1-M - Part 1: Description and basic evaluation of the physical climate, Geosci. Model Dev., 6, 687-720, https://doi.org/10.5194/gmd-6-687-2013, 2013.

Bergman, T., Kerminen, V.-M., Korhonen, H., Lehtinen, K. J., Makkonen, R., Arola, A., Mielonen, T., Romakkaniemi, S., Kulmala, M., and Kokkola, H.: Evaluation of the sectional aerosol microphysics module SALSA implementation in ECHAM5HAM aerosol-climate model, Geosci. Model Dev., 5, 845-868, https://doi.org/10.5194/gmd-5-845-2012, 2012.

Berrisford, P., Dee, P. D., Poli, P.,Brugge, R., Fielding, K., Fuentes, M., Kållberg, P. W. Kobayashi, S., Uppala, S., and Simmons, A.: The ERA-Interim archive Version 2.0, ERA report series, number 1, 2011.

Binkowski, F. S. and Shankar, U.: The Regional Particulate Matter Model: 1. Model description and preliminary results, J. Geophys. Res., 100, 26191-26209, https://doi.org/10.1029/95JD02093, 1995.

Bond, T. C. and Bergstrom, R. W.: Light Absorption by Carbonaceous Particles: An Investigative Review, Aerosol Sci. Technol., 40, 27-67, https://doi.org/10.1080/02786820500421521, 2006.

Boucher, O., Randall, D., Artaxo, P., Bretherton, C., Feingold, G., Forster, P., Kerminen, V.-M., Kondo, Y., Liao, H., Lohmann, U., Rasch, P., Satheesh, S., Sherwood, S., Stevens, B., and Zhang, X.: Clouds and aerosols, in: Climate Change 2013: The Physical Science Basis, Contribution of Working Group I to the Fifth Assessment Report of the Intergovernmental Panel on Climate Change, edited by: Stocker, T., Qin, D., Plattner, G.-K., Tignor, M., Allen, S. K., Boschung, J., Nauels, A., Xia, Y., Bex, V., and Midgley, P. M., Chapter 8, 659-740, Cambridge University Press, Cambridge, United Kingdom and New York, NY, USA, 2013.

Boy, M., Thomson, E. S., Acosta Navarro, J.-C., Arnalds, O., Batchvarova, E., Bäck, J., Berninger, F., Bilde, M., DagssonWaldhauserova, P., Castarède, D., Dalirian, M., de Leeuw, G., Dragosics, M., Duplissy, E.-M., Duplissy, J., Ekman, A. M. L., Fang, K., Gallet, J.-C., Glasius, M., Gryning, S.-E., Grythe, H., Hansson, H.-C., Hansson, M., Isaksson, E., Iversen, T., Jonsdottir, I., Kasurinen, V., Kirkevåg, A., Korhola, A., Krejci, R., Kristjansson, J. E., Lappalainen, H. K., Lauri, A., Leppäranta, M., Lihavainen, H., Makkonen, R., Massling, A., Meinander, O., Nilsson, E. D., Olafsson, H., Pettersson, J. B. C., Prisle, N. L., Riipinen, I., Roldin, P., Ruppel, M., Salter, M., Sand, M., Seland, Ø., Seppä, H., Skov, H., Soares, J., Stohl, A., Ström, J., Svensson, J., Swietlicki, E., Tabakova, K., Thorsteinsson, T., Virkkula, A., Weyhenmeyer, G. A., Wu, Y., Zieger, P., and Kulmala, M.:
Interactions between the atmosphere, cryosphere and ecosystems at northern high latitudes, Atmos. Chem. Phys. Discuss., https://doi.org/10.5194/acp-2018-733, in review, 2018.

Carslaw, K. S., Lee, L. A., Reddington, C. L., Pringle, K. J., Rap., A., Forster, P. M., Mann, G. W., Spracklen, D. V., Woodhouse, M. T., Regayre, L.-A., and Pierce, J. R.: Large contribution of natural aerosols to uncertainty in indirect forcing, Nature, 503, 67-71, https://doi.org/10.1038/nature12674, 2013.

Chen, B., Zhu, Z., Wang, X., Andersson, A., Chen, J., Zhang, Q., and Gustafsson, Ö.: Reconciling modeling with observations of radiative absorption of black carbon aerosols, J. Geophys. Res.-Atmos., 122, 5932-5942, https://doi.org/10.1002/2017JD026548, 2017.

Chen, H. and Finlayson-Pitts, B. J.: New Particle Formation from Methanesulfonic Acid and Amines/Ammonia as a Function of Temperature, Environ. Sci. Technol., 51, 243-252, https://doi.org/10.1021/acs.est.6b04173, 2017.

Chýlek, P., Srivastava, V., Pinnic, R. G., and Wang, R. T.: Scattering of electromagnetic waves by composite spherical particles: experiment and effective medium approximations, Appl. Opt., 27, 2396-2404, 1998.

Dentener, F., Kinne, S., Bond, T., Boucher, O., Cofala, J., Generoso, S., Ginoux, P., Gong, S., Hoelzemann, J. J., Ito, A., Marelli, L., Penner, J. E., Putaud, J.-P., Textor, C., Schulz, M., van der Werf, G. R., and Wilson, J.: Emissions of primary aerosol and precursor gases in the years 2000 and 1750 prescribed data-sets for AeroCom, Atmos. Chem. Phys., 6, 43214344, https://doi.org/10.5194/acp-6-4321-2006, 2006.

Emmons, L. K., Walters, S., Hess, P. G., Lamarque, J.-F., Pfister, G. G., Fillmore, D., Granier, C., Guenther, A., Kinnison, D., Laepple, T., Orlando, J., Tie, X., Tyndall, G., Wiedinmyer, C., Baughcum, S. L., and Kloster, S.: Description and evaluation of the Model for Ozone and Related chemical Tracers, version 4 (MOZART-4), Geosci. Model Dev., 3, 43-67, https://doi.org/10.5194/gmd-3-43-2010, 2010.

Formenti, P., Elbert, W., Maenhaut, W., Haywood, J., Osborne, S., and Andreae, M.-O.: Inorganic and carbonaceous aerosols during the Southern African Regional Science Initiative (SAFARI 2000) experiment: Chemical characteristics, physical properties, and emission data for smoke from African biomass burning, J. Geophys. Res., 108, 8488, https://doi.org/10.1029/2002JD002408, 2003.

Gelencsér, A., May, B., Simpson, D., Sánchez-Ochoa,A., Kasper-Giebl, A., Puxbaum, H., Caseiro, A., Pio, C., and Legrand, M.: Source apportionment of PM2.5 organic aerosol over Europe: Primary/secondary, natural/anthropogenic, and fossil/biogenic origin, J. Geophys. Res., 112, D23S04, https://doi.org/10.1029/2006JD008094, 2007.

Gettelman, A. and Morrison, H.: Advanced two-moment bulk microphysics for global models. part I: Off-line tests and comparison with other schemes, J. Climate, 28, 1268-1287, 2015.

Ghan, S. J.: Technical Note: Estimating aerosol effects on cloud radiative forcing, Atmos. Chem. Phys., 13, 9971-9974, https://doi.org/10.5194/acp-13-9971-2013, 2013.

Ghan, S. J. and Easter, R. C.: Impact of cloud-borne aerosol representation on aerosol direct and indirect effects, Atmos. Chem. Phys., 6, 4163-4174, https://doi.org/10.5194/acp-6-4163-2006, 2006. 
Ghan, S. J., Laulainen, N., Easter, R., Wagener, R., Nemesure, S., Chapman, E., Zhang, Y., and Leung, R.: Evaluation of aerosol direct radiative forcing in MIRAGE. J. Geophys. Res., 106, 52955316, 2001.

Ghan, S. J., Liu, X., Easter, R. C., Zaveri, R., Rasch, P. J., and Yoon, J.-H.: Toward a minimal representation of aerosols in climate models: comparative decomposition of aerosol direct, semidirect, and indirect radiative forcing, J. Climate, 25, 6461-6476, 2012.

Glantz, P., Bourassa, A. E., Herber, A., Iversen, T., Karlsson, J., Kirkevåg, A., Maturilli, M., Seland, Ø., Stebel, K., Struthers, H., Tesche, M., and Thomason, L.: Remote sensing of aerosols in the Arctic for an evaluation of global climate model simulations, J. Geophys. Res.-Atmos., 119, 8169-8188, https://doi.org/10.1002/2013JD021279, 2014.

Guenther, A. B., Jiang, X., Heald, C. L., Sakulyanontvittaya, T., Duhl, T., Emmons, L. K., and Wang, X.: The Model of Emissions of Gases and Aerosols from Nature version 2.1 (MEGAN2.1): an extended and updated framework for modeling biogenic emissions, Geosci. Model Dev., 5, 1471-1492, https://doi.org/10.5194/gmd-5-1471-2012, 2012.

Hess, M., Koepke, P., and Schult, I.: Optical properties of aerosols and clouds: The software package OPAC, B. Am. Meteorol. Assoc., 79, 831-844, 1998.

Holben, B. N., Eck, T. F., Slutsker, I., Tanre, D., Buis, J. P., Setzer, A., Vermote, E., Reagan, J. A., Kaufman, Y., Nakajima, T., Lavenu, F., Jankowiak, I., and Smirnov, A.: AERONET - A federated instrument network and data archive for aerosol characterization, Remote Sens. Environ., 66, 1-16, 1998.

Hoose, C., Kristjánsson, J. E., Chen, J. P., and Hazra, A.: A Classical-Theory-Based Parameterization of Heterogeneous Ice Nucleation by Mineral Dust, Soot and Biological Particles in a Global Climate Model, J. Atmos. Sci., 67, 2483-2503, 2010.

Horowitz, L. W., Walters, S., Mauzerall, D. L., Emmons, L. K., Rasch, P. J., Granier, C., Tie, X., Lamarque, J.-F., Schultz, M. G., Tyndall, G. S., Orlando, J. J., and Brasseur, G. P.: A global simulation of tropospheric ozone and related tracers: Description and evaluation of MOZART, version 2, J. Geophys. Res., 108, 4784, https://doi.org/10.1029/2002JD002853, 2003.

Huneeus, N., Schulz, M., Balkanski, Y., Griesfeller, J., Prospero, J., Kinne, S., Bauer, S., Boucher, O., Chin, M., Dentener, F., Diehl, T., Easter, R., Fillmore, D., Ghan, S., Ginoux, P., Grini, A., Horowitz, L., Koch, D., Krol, M. C., Landing, W., Liu, X., Mahowald, N., Miller, R., Morcrette, J.-J., Myhre, G., Penner, J., Perlwitz, J., Stier, P., Takemura, T., and Zender, C. S.: Global dust model intercomparison in AeroCom phase I, Atmos. Chem. Phys., 11, 7781-7816, https://doi.org/10.5194/acp11-7781-2011, 2011.

Iversen, T. and Seland, Ø.: A scheme for process-tagged $\mathrm{SO}_{4}$ and $\mathrm{BC}$ aerosols in NCAR CAM3: Validation and sensitivity to cloud processes, J. Geophys. Res., 107, 4751, https://doi.org/10.1029/2001JD000885, 2002.

Iversen, T. and Seland, Ø.: Correction to "A scheme for processtagged $\mathrm{SO}_{4}$ and $\mathrm{BC}$ aerosols in NCAR-CCM3, Validation and sensitivity to cloud processes", J. Geophys. Res., 108, 4502, https://doi.org/10.1029/2003JD003840, 2003.

Iversen, T., Bentsen, M., Bethke, I., Debernard, J. B., Kirkevåg, A., Seland, Ø., Drange, H., Kristjansson, J. E., Medhaug, I., Sand, M., and Seierstad, I. A.: The Norwegian Earth
System Model, NorESM1-M - Part 2: Climate response and scenario projections, Geosci. Model Dev., 6, 389-415, https://doi.org/10.5194/gmd-6-389-2013, 2013.

Iversen, T., Bethke, I., Debernard, J. B., Graff, L. S., Seland, Ø., Bentsen, M., Kirkevåg, A., Li, C., and Olivié, D. J. L.: The "NorESM1-Happi" used for evaluating differences between a global warming of $1.5^{\circ} \mathrm{C}$ and $2{ }^{\circ} \mathrm{C}$, and the role of Arctic Amplification, Earth Syst. Dynam. Discuss., https://doi.org/10.5194/esd-2017-115, in review, 2017.

Jiao, C., Flanner, M. G., Balkanski, Y., Bauer, S. E., Bellouin, N., Berntsen, T. K., Bian, H., Carslaw, K. S., Chin, M., De Luca, N., Diehl, T., Ghan, S. J., Iversen, T., Kirkevåg, A., Koch, D., Liu, X., Mann, G. W., Penner, J. E., Pitari, G., Schulz, M., Seland, Ø., Skeie, R. B., Steenrod, S. D., Stier, P., Takemura, T., Tsigaridis, K., van Noije, T., Yun, Y., and Zhang, K.: An AeroCom assessment of black carbon in Arctic snow and sea ice, Atmos. Chem. Phys., 14, 2399-2417, https://doi.org/10.5194/acp14-2399-2014, 2014.

Jokinen, T., Berndt, T., Makkonen, R., Kerminen, V.-M., Junninen, H., Paasonen, P., Stratmann, F., Herrmann, H., Guenther, A. B., Worsnop, D. R., Kulmala, M., Ehn, M., and Sipilä, M.: Production of extremely low volatile organic compounds from biogenic emissions: Measured yields and atmospheric implications, Proc. Natl. Acad. Sci., 112, 7123-7128, https://doi.org/10.1073/pnas.1423977112, 2015.

Karset, I. H. H., Berntsen, T. K., Storelvmo, T., Alterskjær, K., Grini, A., Olivié, D., Kirkevåg, A., Seland, Ø., Iversen, T., and Schulz, M.: Strong impacts on aerosol indirect effects from historical oxidant changes, Atmos. Chem. Phys., 18, 7669-7690, https://doi.org/10.5194/acp-18-7669-2018, 2018.

Keskinen, H., Virtanen, A., Joutsensaari, J., Tsagkogeorgas, G., Duplissy, J., Schobesberger, S., Gysel, M., Riccobono, F., Slowik, J. G., Bianchi, F., Yli-Juuti, T., Lehtipalo, K., Rondo, L., Breitenlechner, M., Kupc, A., Almeida, J., Amorim, A., Dunne, E. M., Downard, A. J., Ehrhart, S., Franchin, A., Kajos, M. K., Kirkby, J., Kürten, A., Nieminen, T., Makhmutov, V., Mathot, S., Miettinen, P., Onnela, A., Petäjä, T., Praplan, A., Santos, F. D., Schallhart, S., Sipilä, M., Stozhkov, Y., Tomé, A., Vaattovaara, P., Wimmer, D., Prevot, A., Dommen, J., Donahue, N. M., Flagan, R. C., Weingartner, E., Viisanen, Y., Riipinen, I., Hansel, A., Curtius, J., Kulmala, M., Worsnop, D. R., Baltensperger, U., Wex, H., Stratmann, F., and Laaksonen, A.: Evolution of particle composition in CLOUD nucleation experiments, Atmos. Chem. Phys., 13, 5587-5600, https://doi.org/10.5194/acp-13-5587-2013, 2013.

Kettle, A. J. and Andreae, M. O.: Flux of dimethylsulfide from the oceans: A comparison of updated data sets and flux models, J. Geophys. Res., 105, 26793-26808, 2000.

Kinne, S., Schulz, M., Textor, C., Guibert, S., Balkanski, Y., Bauer, S. E., Berntsen, T., Berglen, T. F., Boucher, O., Chin, M., Collins, W., Dentener, F., Diehl, T., Easter, R., Feichter, J., Fillmore, D., Ghan, S., Ginoux, P., Gong, S., Grini, A., Hendricks, J., Herzog, M., Horowitz, L., Isaksen, I., Iversen, T., Kirkevåg, A., Kloster, S., Koch, D., Kristjansson, J. E., Krol, M., Lauer, A., Lamarque, J. F., Lesins, G., Liu, X., Lohmann, U., Montanaro, V., Myhre, G., Penner, J., Pitari, G., Reddy, S., Seland, O., Stier, P., Takemura, T., and Tie, X.: An AeroCom initial assessment - optical properties in aerosol component modules of global models, Atmos. Chem. Phys., 6, 1815-1834, https://doi.org/10.5194/acp-61815-2006, 2006. 
Kipling, Z., Stier, P., Schwarz, J. P., Perring, A. E., Spackman, J. R., Mann, G. W., Johnson, C. E., and Telford, P. J.: Constraints on aerosol processes in climate models from vertically-resolved aircraft observations of black carbon, Atmos. Chem. Phys., 13, 5969-5986, https://doi.org/https://doi.org/10.5194/acp-13-59692013, 2013.

Kipling, Z., Stier, P., Johnson, C. E., Mann, G. W., Bellouin, N., Bauer, S. E., Bergman, T., Chin, M., Diehl, T., Ghan, S. J., Iversen, T., Kirkevåg, A., Kokkola, H., Liu, X., Luo, G., van Noije, T., Pringle, K. J., von Salzen, K., Schulz, M., Seland, Ø., Skeie, R. B., Takemura, T., Tsigaridis, K., and Zhang, K.: What controls the vertical distribution of aerosol? Relationships between process sensitivity in HadGEM3-UKCA and inter-model variation from AeroCom Phase II, Atmos. Chem. Phys., 16, 2221-2241, https://doi.org/10.5194/acp-16-2221-2016, 2016.

Kirkevåg, A. and Iversen, T.: Global direct radiative forcing by process-parameterized aerosol optical properties, J. Geophys. Res., 107, 4433, https://doi.org/10.1029/2001JD000886, 2002.

Kirkevåg, A., Iversen, T., and Dahlback, A.: On radiative effects of black carbon and sulphate aerosols, Atmos. Environ., 33, 26212635, 1999.

Kirkevåg, A., Iversen, T., Seland, Ø., and Kristjánsson, J. E.: Revised schemes for optical parameters and cloud condensation nuclei in CCM-Oslo. Institute Report Series, Department of Geosciences, University of Oslo, 29 pp., ISBN 82-91885-31-1, ISSN 1501-6854-128, 2005.

Kirkevåg, A., Iversen, T., Seland, Ø., Debernard, J. B., Storelvmo, T., and Kristjánsson, J. E.: Aerosol-cloud-climate interactions in the climate model CAM-Oslo, Tellus A, 60, 492-512, 2008.

Kirkevåg, A., Iversen, T., Seland, Ø., Hoose, C., Kristjánsson, J. E., Struthers, H., Ekman, A. M. L., Ghan, S., Griesfeller, J., Nilsson, E. D., and Schulz, M.: Aerosol-climate interactions in the Norwegian Earth System Model - NorESM1-M, Geosci. Model Dev., 6, 207-244, https://doi.org/10.5194/gmd-6207-2013, 2013.

Koehler, K. A., Kreidenweis, S. M., DeMott, P. J., Petters, M. D., Prenni, A. J., and Carrico, C. M.: Hygroscopicity and cloud droplet activation of mineral dust aerosol, Geophys. Res. Lett., 36, L08805, https://doi.org/10.1029/2009GL037348, 2009.

Koffi, B., Schulz, M., Breon, F.-M., Dentener, F., Steensen, B. M., Griesfeller, J., Winker, D., Balkanski, Y., Bauer, S. E., Bellouin, N., Berntsen, T., Bian, H., Chin, M., Diehl, T., Easter, R., Ghan, S., Hauglustaine, D., Iversen, T., Kirkevåg, A., Liu, X., Lohmann, U., Myhre, G., Rasch, P., Seland, Ø., Skeie, R. B., Steenrod, S. D., Stier, P., Tackett, J., Takemura, T., Tsigaridis, K., Vuolo, M. R., Yoon, J., and Zhang, K.: Evaluation of the aerosol vertical distribution in global aerosol models through comparison against CALIOP measurements: AeroCom phase II results. J. Geophys. Res.-Atmos, 121, 7254-7283, https://doi.org/10.1002/2015JD024639, 2016.

Kok, J. F., Ridley, D. A., Zhou, Q., Miller, R. L., Zhao, C., Heald, C. L., Ward, D. S., Albani, S., and Haustein, K.: Smaller desert dust cooling effect estimated from analysis of dust size and abundance, Nat. Geosci., 10, 274-278, https://doi.org/10.1038/ngeo2912, 2017.

Kooperman, G. J., Pritchard, M. S., Ghan, S. J., Wang, M., Somerville, R. C. J., and Russell, L. M.: Constraining the influence of natural variability to improve estimates of global aerosol indirect effects in a nudged version of the Commu- nity Atmosphere Model 5, J. Geophys. Res., 117, D23204, https://doi.org/10.1029/2012JD018588, 2012.

Köpke, P., Hess, M., Schult, I., and Shettle, E. P.: Global Aerosol Data Set, MPI Report no. 243, 1997.

Kristjánsson, J. E.: Studies of the aerosol indirect effect from sulfate and black carbon aerosols, J. Geophys. Res.-Atmos, 107, 4246, https://doi.org/10.1029/2001JD000887, 2002.

Kulmala, M., Kerminen, V.-M., Anttila, T., Laaksonen, A., and O'Dowd, C. D.: Organic aerosol formation via sulphate cluster activation, J. Geophys. Res., 109, D04205, https://doi.org/10.1029/2003JD003961, 2004.

Lamarque, J.-F., Bond, T. C., Eyring, V., Granier, C., Heil, A., Klimont, Z., Lee, D., Liousse, C., Mieville, A., Owen, B., Schultz, M. G., Shindell, D., Smith, S. J., Stehfest, E., Van Aardenne, J., Cooper, O. R., Kainuma, M., Mahowald, N., McConnell, J. R., Naik, V., Riahi, K., and van Vuuren, D. P.: Historical (1850-2000) gridded anthropogenic and biomass burning emissions of reactive gases and aerosols: methodology and application, Atmos. Chem. Phys., 10, 7017-7039, https://doi.org/10.5194/acp-10-7017-2010, 2010.

Lana, A., Bell, T. G., Simo, R., Vallina, S. M., Ballabrera-Poy, J., Kettle, A. J., Dachs, J., Bopp, L., Saltzman, E. S., Stefels, J., Johnson, J. E., and Liss, P. S.: An updated climatology of surface dimethylsulfide concentrations and emission fluxes in the global ocean, Global Biogeochem. Cy., 25, GB1004, https://doi.org/10.1029/2010GB003850, 2011

Lehtinen, K. E. J., Dal Maso, M., Kulmala, M., and Kerminen, V-M.: Estimating nucleation rates from apparent particle formation rates and vice versa: Revised formulation of the Kerminen-Kulmala equation, J. Aerosol Sci., 38, 988-994, https://doi.org/10.1016/j.jaerosci.2007.06.009, 2007.

Liu, X., Penner, J. E., Das, B., Bergmann, D., Rodriguez, J. M., Strahan. S., Wang, M., and Feng, Y.: Uncertainties in global aerosol simulations: Assessment using three meteorological data sets, J. Geophys. Res., 112, D11212, https://doi.org/10.1029/2006JD008216, 2007.

Liu, X., Easter, R. C., Ghan, S. J., Zaveri, R., Rasch, P., Shi, X., Lamarque, J.-F., Gettelman, A., Morrison, H., Vitt, F., Conley, A., Park, S., Neale, R., Hannay, C., Ekman, A. M. L., Hess, P., Mahowald, N., Collins, W., Iacono, M. J., Bretherton, C. S., Flanner, M. G., and Mitchell, D.: Toward a minimal representation of aerosols in climate models: description and evaluation in the Community Atmosphere Model CAM5, Geosci. Model Dev., 5, 709-739, https://doi.org/10.5194/gmd-5-709-2012, 2012.

Liu, X., Ma, P.-L., Wang, H., Tilmes, S., Singh, B., Easter, R. C., Ghan, S. J., and Rasch, P. J.: Description and evaluation of a new four-mode version of the Modal Aerosol Module (MAM4) within version 5.3 of the Community Atmosphere Model, Geosci. Model Dev., 9, 505-522, https://doi.org/10.5194/gmd-9505-2016, 2016.

Makkonen, R., Seland, Ø., Kirkevåg, A., Iversen, T., and Kristjánsson, J. E.: Evaluation of aerosol number concentrations in NorESM with improved nucleation parameterization, Atmos. Chem. Phys., 14, 5127-5152, https://doi.org/10.5194/acp-145127-2014, 2014.

Malavelle, F. F., Haywood, J. M., and Jones, A. et al.: Strong constraints on aerosol-cloud interactions from volcanic eruptions, Nature, 546, 485-491, https://doi.org/10.1038/nature22974, 2017. 
Mann, G. W., Carslaw, K. S., Spracklen, D. V., Ridley, D. A., Manktelow, P. T., Chipperfield, M. P., Pickering, S. J., and Johnson, C. E.: Description and evaluation of GLOMAP-mode: a modal global aerosol microphysics model for the UKCA composition-climate model, Geosci. Model Dev., 3, 519-551, https://doi.org/10.5194/gmd-3-519-2010, 2010.

Mann, G. W., Carslaw, K. S., Reddington, C. L., Pringle, K. J., Schulz, M., Asmi, A., Spracklen, D. V., Ridley, D. A., Woodhouse, M. T., Lee, L. A., Zhang, K., Ghan, S. J., Easter, R. C., Liu, X., Stier, P., Lee, Y. H., Adams, P. J., Tost, H., Lelieveld, J., Bauer, S. E., Tsigaridis, K., van Noije, T. P. C., Strunk, A., Vignati, E., Bellouin, N., Dalvi, M., Johnson, C. E., Bergman, T., Kokkola, H., von Salzen, K., Yu, F., Luo, G., Petzold, A., Heintzenberg, J., Clarke, A., Ogren, J. A., Gras, J., Baltensperger, U., Kaminski, U., Jennings, S. G., O’Dowd, C. D., Harrison, R. M., Beddows, D. C. S., Kulmala, M., Viisanen, Y., Ulevicius, V., Mihalopoulos, N., Zdimal, V., Fiebig, M., Hansson, H.-C., Swietlicki, E., and Henzing, J. S.: Intercomparison and evaluation of global aerosol microphysical properties among AeroCom models of a range of complexity, Atmos. Chem. Phys., 14, 4679-4713, https://doi.org/10.5194/acp-14-4679-2014, 2014.

Morrison, H. and Gettelman, A.: A new two-moment bulk stratiform cloud microphysics scheme in the community atmosphere model, version 3 (CAM3). Part I: Description and numerical tests, J. Climate, 21, 3642-3659, 2008.

Myhre, G., Shindell, D., Bréon, F.-M., Collins, W., Fuglestvedt, J., Huang, J., Koch, D., Lamarque, J.-F., Lee, D., Mendoza, B., Nakajima, T., Robock, A., Stephens, G., Takemura, T., and Zhang, H.: Anthropogenic and Natural Radiative Forcing, in: Climate Change 2013: The Physical Science Basis, Contribution of Working Group I to the Fifth Assessment Report of the Intergovernmental Panel on Climate Change, edited by: Stocker, T. F., Qin, D., Plattner, G.-K., Tignor, M., Allen, S. K., Boschung, J., Nauels, A., Xia, Y., Bex, V., and Midgley, P. M., Cambridge University Press, Cambridge, UK and New York, NY, USA, 659740, 2013.

Neale, R. B., Chen, C.-C., Gettelman, A., Lauritzen, P. H., Park, S., Williamson, D. L., Conley, A. J., Garcia, R., Kinnison, D., Lamarque, J.-F., Marsh, D., Mills, M., Smith, A. K., Tilmes, S., Vitt, F., Morrison, H., Cameron-Smith, P., Collins, W. D., Iacono, M. J., Easter, R. C., Ghan, S. J., Liu, X., Rasch, P. J., and Taylor, M. A.: Description of the NCAR Community Atmosphere Model (CAM 5.0), NCAR Tech. Note NCAR-TN-486CSTR, 274 pp., 2012.

Nightingale, P. D., Malin, G., Law, C. S., Watson, A. J., Liss, P. S., Liddicoat, M. I., Boutin, J., and UpstillGoddard, R. C.: In situ evaluation of air-sea gas exchange parameterizations using novel conservative and volatile tracers, Global Biogeochem. Cy., 14, 373-387, https://doi.org/https://doi.org/10.1029/1999GB900091, 2000.

Ning, Z., Chan, K. L., Wong, K. C., Westerdahl, D., Mocnik, G., Zhou, J. H., and Cheung, C. S.: Black carbon mass size distributions of diesel exhaust and urban aerosols measured using differential mobility analyzer in tandem with Aethalometer, Atmos. Environ., 80, 31-40, 2013

O’Dowd, C., Langmann, B., Varghese, S., Scannell, C., Ceburnis, D., and Facchini, M. C.: A combined organic-inorganic sea-spray source function. Geophys. Res. Lett., 35, L01801, https://doi.org/10.1029/2007GL030331, 2008.
Oleson, K. W., Lawrence, D. M., Bonan, G. B., Drewniak, B., Huang, M., Koven, C. D., Levis, S., Li, F., Riley, W. J., Subin, Z. M., Swenson, S. C., Thornton, P. E., Bozbiyik, A., Fisher, R., Kluzek, E., Lamarque, J.-F., Lawrence, P. J., Leung, L. R., Lipscomb, W., Muszala, S., Ricciuto, D. M., Sacks, W., Sun, Y., Tang, J., and Yang, Z.-L.: Technical Description of version 4.5 of the Community Land Model (CLM), NCAR Technical Note NCAR/TN-503+STR, National Center for Atmospheric Research, Boulder, CO, 422 pp., https://doi.org/10.5065/D6RR1W7M, 2013.

O'Reilly, J. E., Maritorena, S., and O'Brien, M.-C. et al.: SeaWiFS Postlaunch Calibration and Validation Analyses, Part 3. NASA Tech. Memo. 2000-206892, Vol. 11, edited by: Hooker, S. B. and Firestone, E. R., NASA Goddard Space Flight Center, 2000.

Paasonen, P., Nieminen, T., Asmi, E., Manninen, H. E., Petäjä, T., Plass-Dülmer, C., Flentje, H., Birmili, W., Wiedensohler, A., Hõrrak, U., Metzger, A., Hamed, A., Laaksonen, A., Facchini, M. C., Kerminen, V.-M., and Kulmala, M.: On the roles of sulphuric acid and low-volatility organic vapours in the initial steps of atmospheric new particle formation, Atmos. Chem. Phys., 10, 11223-11242, https://doi.org/10.5194/acp-10-112232010, 2010.

Poling, B. E., Prausnitz, J. M., and O'Connell, J. P.: The Properties of Gases and Liquids, Fifth Edition, McGRAW-HILL, https://doi.org/10.1036/0070116822, 2001.

Pozzoli, L., Bey, I., Rast, S., Schultz, M. G., Stier, P., and Feichter, J.: Trace gas and aerosol interactions in the fully coupled model of aerosol-chemistry-climate ECHAM5HAMMOZ: 1. Model description and insights from the spring 2001 TRACE-P experiment, J. Geophys. Res., 113, D07308, https://doi.org/10.1029/2007JD009007, 2008.

Pruppacher, H. R. and Klett, J. D.: Microphysics of Clouds and Precipitation, 954 pp., Kluwer Acad., Norwell, Mass, 1997.

Rasch, P. J. and Kristjánsson, J. E.: A comparison of the CCM3 model climate using diagnosed and predicted condensate parameterizations, J. Climate, 11, 1587-1614, 1998.

Riipinen, I., Pierce, J. R., Yli-Juuti, T., Nieminen, T., Häkkinen, S., Ehn, M., Junninen, H., Lehtipalo, K., Petäjä, T., Slowik, J., Chang, R., Shantz, N. C., Abbatt, J., Leaitch, W. R., Kerminen, V.-M., Worsnop, D. R., Pandis, S. N., Donahue, N. M., and Kulmala, M.: Organic condensation: a vital link connecting aerosol formation to cloud condensation nuclei (CCN) concentrations, Atmos. Chem. Phys., 11, 3865-3878, https://doi.org/10.5194/acp-11-3865-2011, 2011.

Salter, M. E., Zieger, P., Acosta Navarro, J. C., Grythe, H., Kirkevåg, A., Rosati, B., Riipinen, I., and Nilsson, E. D.: An empirically derived inorganic sea spray source function incorporating sea surface temperature, Atmos. Chem. Phys., 15, 1104711066, https://doi.org/10.5194/acp-15-11047-2015, 2015.

Samset, B. H., Myhre, G., Schulz, M., Balkanski, Y., Bauer, S., Berntsen, T. K., Bian, H., Bellouin, N., Diehl, T., Easter, R. C., Ghan, S. J., Iversen, T., Kinne, S., Kirkevåg, A., Lamarque, J.-F., Lin, G., Liu, X., Penner, J. E., Seland, Ø., Skeie, R. B., Stier, P., Takemura, T., Tsigaridis, K., and Zhang, K.: Black carbon vertical profiles strongly affect its radiative forcing uncertainty, Atmos. Chem. Phys., 13, 2423-2434, https://doi.org/10.5194/acp13-2423-2013, 2013.

Samset, B. H., Myhre, G., Herber, A., Kondo, Y., Li, S.-M., Moteki, N., Koike, M., Oshima, N., Schwarz, J. P., Balkanski, Y., Bauer, 
S. E., Bellouin, N., Berntsen, T. K., Bian, H., Chin, M., Diehl, T., Easter, R. C., Ghan, S. J., Iversen, T., Kirkevåg, A., Lamarque, J.F., Lin, G., Liu, X., Penner, J. E., Schulz, M., Seland, Ø., Skeie, R. B., Stier, P., Takemura, T., Tsigaridis, K., and Zhang, K.: Modelled black carbon radiative forcing and atmospheric lifetime in AeroCom Phase II constrained by aircraft observations, Atmos. Chem. Phys., 14, 12465-12477, https://doi.org/10.5194/acp-1412465-2014, 2014

Schulz, M., Textor, C., Kinne, S., Balkanski, Y., Bauer, S., Berntsen, T., Berglen, T., Boucher, O., Dentener, F., Guibert, S., Isaksen, I. S. A., Iversen, T., Koch, D., Kirkevåg, A., Liu, X., Montanaro, V., Myhre, G., Penner, J. E., Pitari, G., Reddy, S., Seland, Ø., Stier, P., and Takemura, T.: Radiative forcing by aerosols as derived from the AeroCom present-day and pre-industrial simulations, Atmos. Chem. Phys., 6, 5225-5246, https://doi.org/10.5194/acp6-5225-2006, 2006.

Schwarz, J. P., Samset, B. H., Perring, A. E., Spackman, J. R., Gao, R. S., Stier, P., Schulz, M., Moore, F. L., Ray, E. A., and Fahey, D. W.: Global-scale seasonally resolved black carbon vertical profiles over the Pacific, Geophys. Res. Lett., 40, 5542-5547, https://doi.org/10.1002/2013g1057775, 2013.

Seland, $\varnothing$. and Iversen, T.: A scheme for black carbon and sulfate aerosols tested in a hemispheric scale, Eulerian dispersion model, Atmos. Environ., 33, 2853-2879, 1999.

Seland, Ø., Iversen, T., Kirkevåg, A., and Storelvmo, T.: Aerosolclimate interactions in the CAM-Oslo atmospheric GCM and investigations of associated shortcomings, Tellus A, 60, 459-491, 2008.

Simpson, D., Benedictow, A., Berge, H., Bergström, R., Emberson, L. D., Fagerli, H., Flechard, C. R., Hayman, G. D., Gauss, M., Jonson, J. E., Jenkin, M. E., Nyíri, A., Richter, C., Semeena, V. S., Tsyro, S., Tuovinen, J.-P., Valdebenito, Á., and Wind, P.: The EMEP MSC-W chemical transport model - technical description, Atmos. Chem. Phys., 12, 7825-7865, https://doi.org/10.5194/acp-12-7825-2012, 2012.

Spracklen, D. V., Arnold, S. R., Sciare, J., Carslaw, K. S., and Pio, C.: Globally significant oceanic source of organic carbon aerosol, Geophys. Res. Lett., 35, L12811, https://doi.org/10.1029/2008GL033359,2008.

Stjern, C. W., Samset, B. H., Myhre, G., Forster, P. M., Hodnebrog, Ø., Andrews, T., Boucher, O., Faluvegi, G., Iversen, T., Kasoar, M., Kharin, V., Kirkevåg, A., Lamarque, J.-F., Olivié, D., Richardson, T., Shawki, D., Shindell, D., Smith, C. J., Takemura, T., and Voulgarakis, A: Rapid adjustments cause weak surface temperature response to increased black carbon concentrations, J. Geophys. Res.-Atmos., 119, 8169-8188, https://doi.org/10.1002/2017JD027326, 2017.

Stohl, A., Klimont, Z., Eckhardt, S., Kupiainen, K., Shevchenko, V. P., Kopeikin, V. M., and Novigatsky, A. N.: Black carbon in the Arctic: the underestimated role of gas flaring and residential combustion emissions, Atmos. Chem. Phys., 13, 8833-8855, https://doi.org/10.5194/acp-13-8833-2013, 2013.

Ström, J., Okada, S. K., and Heintzenberg, J.: On the state of mixing of particles due to Brownian coagulation, J. Aerosol Sci., 23, 467-480, 1992.

Tang, I. N.: Chemical and size effects of hygroscopic aerosols on light scattering coefficients, J. Geophys. Res., 101, 1924519250, 1996.
Tang, I . N. and Munkelwitz, H. R.: Aerosol Phase Transformation and Growth in the Atmosphere, J. Appl. Meteorol., 33, 792-796, 1994.

Textor, C., Schulz, M., Guibert, S., Kinne, S., Balkanski, Y., Bauer, S., Berntsen, T., Berglen, T., Boucher, O., Chin, M., Dentener, F., Diehl, T., Easter, R., Feichter, H., Fillmore, D., Ghan, S., Ginoux, P., Gong, S., Grini, A., Hendricks, J., Horowitz, L., Huang, P., Isaksen, I., Iversen, I., Kloster, S., Koch, D., Kirkevåg, A., Kristjansson, J. E., Krol, M., Lauer, A., Lamarque, J. F., Liu, X., Montanaro, V., Myhre, G., Penner, J., Pitari, G., Reddy, S., Seland, Ø., Stier, P., Takemura, T., and Tie, X.: Analysis and quantification of the diversities of aerosol life cycles within AeroCom, Atmos. Chem. Phys., 6, 1777-1813, https://doi.org/10.5194/acp-6-17772006, 2006.

Tilmes, S., Lamarque, J.-F., Emmons, L. K., Kinnison, D. E., Ma, P.-L., Liu, X., Ghan, S., Bardeen, C., Arnold, S., Deeter, M., Vitt, F., Ryerson, T., Elkins, J. W., Moore, F., Spackman, J. R., and Val Martin, M.: Description and evaluation of tropospheric chemistry and aerosols in the Community Earth System Model (CESM1.2), Geosci. Model Dev., 8, 1395-1426, https://doi.org/10.5194/gmd8-1395-2015, 2015.

Tjiputra, J. F., Roelandt, C., Bentsen, M., Lawrence, D. M., Lorentzen, T., Schwinger, J., Seland, Ø., and Heinze, C.: Evaluation of the carbon cycle components in the Norwegian Earth System Model (NorESM), Geosci. Model Dev., 6, 301-325, https://doi.org/10.5194/gmd-6-301-2013, 2013.

Tørseth, K., Aas, W., Breivik, K., Fjæraa, A. M., Fiebig, M., Hjellbrekke, A. G., Lund Myhre, C., Solberg, S., and Yttri, K. E.: Introduction to the European Monitoring and Evaluation Programme (EMEP) and observed atmospheric composition change during 1972-2009, Atmos. Chem. Phys., 12, 5447-5481, https://doi.org/10.5194/acp-12-5447-2012, 2012.

Tsigaridis, K., Daskalakis, N., Kanakidou, M., Adams, P. J., Artaxo, P., Bahadur, R., Balkanski, Y., Bauer, S. E., Bellouin, N., Benedetti, A., Bergman, T., Berntsen, T. K., Beukes, J. P., Bian, H., Carslaw, K. S., Chin, M., Curci, G., Diehl, T., Easter, R. C., Ghan, S. J., Gong, S. L., Hodzic, A., Hoyle, C. R., Iversen, T., Jathar, S., Jimenez, J. L., Kaiser, J. W., Kirkevåg, A., Koch, D., Kokkola, H., Lee, Y. H., Lin, G., Liu, X., Luo, G., Ma, X., Mann, G. W., Mihalopoulos, N., Morcrette, J.-J., Müller, J.-F., Myhre, G., Myriokefalitakis, S., Ng, N. L., O’Donnell, D., Penner, J. E., Pozzoli, L., Pringle, K. J., Russell, L. M., Schulz, M., Sciare, J., Seland, Ø., Shindell, D. T., Sillman, S., Skeie, R. B., Spracklen, D., Stavrakou, T., Steenrod, S. D., Takemura, T., Tiitta, P., Tilmes, S., Tost, H., van Noije, T., van Zyl, P. G., von Salzen, K., Yu, F., Wang, Z., Wang, Z., Zaveri, R. A., Zhang, H., Zhang, K., Zhang, Q., and Zhang, X.: The AeroCom evaluation and intercomparison of organic aerosol in global models, Atmos. Chem. Phys., 14, 10845-10895, https://doi.org/10.5194/acp-1410845-2014, 2014.

Twomey, S.: The influence of Pollution on the Shortwave Albedo of Clouds, J. Atmos. Sci., 34, 1149-1152, 1977.

Vehkamäki, H., Kulmala, M., Napari, I., Lehtinen, K. E. J., Timmreck, C., Noppel, M., and Laaksonen, A.: An improved parameterization for sulfuric acid-water nucleation rates for tropospheric and stratospheric conditions, J. Geophys. Res., 107, 4622, https://doi.org/10.1029/2002JD002184, 2002.

Vignati, E., Facchini, M. C., Rinaldi, M., Scannell, C., Ceburnis, D., Sciare, J., Kanakidou, M., Myriokefalitakis, S., Dentener, F., and 
O'Dowd, C. D.: Global scale emission and distribution of seaspray aerosol: Sea-salt and organic enrichment, Atmos. Environ., 44, 670-677, 2010.

Wang, Y., Liu, X., Hoose, C., and Wang, B.: Different contact angle distributions for heterogeneous ice nucleation in the Community Atmospheric Model version 5, Atmos. Chem. Phys., 14, 1041110430, https://doi.org/10.5194/acp-14-10411-2014, 2014.

Willis, M. D., Burkart, J., Thomas, J. L., Köllner, F., Schneider, J., Bozem, H., Hoor, P. M., Aliabadi, A. A., Schulz, H., Herber, A. B., Leaitch, W. R., and Abbatt, J. P. D.: Growth of nucleation mode particles in the summertime Arctic: a case study, Atmos. Chem. Phys., 16, 7663-7679, https://doi.org/10.5194/acp16-7663-2016, 2016.

Wofsy, S. C. and the HIPPO team: HIAPER Pole-to-Pole Observations (HIPPO): fine-grained, global-scale measurements of climatically important atmospheric gases and aerosols, Philos. T. Ser. A, 369, 207-386, https://doi.org/10.1098/rsta.2010.0313, 2011, 2011.
Yli-Juuti, T., Nieminen, T., Hirsikko, A., Aalto, P. P., Asmi, E., Hõrrak, U., Manninen, H. E., Patokoski, J., Dal Maso, M., Petäjä, T., Rinne, J., Kulmala, M., and Riipinen, I.: Growth rates of nucleation mode particles in Hyytiälä during 20032009: variation with particle size, season, data analysis method and ambient conditions, Atmos. Chem. Phys., 11, 12865-12886, https://doi.org/10.5194/acp-11-12865-2011, 2011.

Zender, C. S., Bian H., and Newman, D: Mineral Dust Entrainment and Deposition (DEAD) model: Description and 1990s dust climatology, J. Geophys. Res., 108, 4416, https://doi.org/10.1029/2002JD002775, 2003.

Zhang, K., Wan, H., Liu, X., Ghan, S. J., Kooperman, G. J., Ma, P.-L., Rasch, P. J., Neubauer, D., and Lohmann, U.: Technical Note: On the use of nudging for aerosol-climate model intercomparison studies, Atmos. Chem. Phys., 14, 8631-8645, https://doi.org/10.5194/acp-14-8631-2014, 2014. 